\title{
MODULATION OF TIGHT JUNCTIONS BY PEPTIDES TO INCREASE DRUG PENETRATION ACROSS BIOLOGICAL BARRIERS
}

Ph.D. thesis

Alexandra Bocsik 
DEPARTMENT OF PHARMACEUTICAL TECHNOLOGY

UNIVERSITY OF SZEGED

AND

BIOLOGICAL RESEARCH CENTRE

HUNGARIAN ACADEMY OF SCIENCES

\title{
MODULATION OF TIGHT JUNCTIONS BY PEPTIDES TO INCREASE DRUG PENETRATION ACROSS BIOLOGICAL BARRIERS
}

\author{
Ph.D. thesis \\ Alexandra Bocsik \\ Biologist \\ Supervisors: \\ Dr. habil. Mária A. Deli, M.D., Ph.D., D.Sc. \\ Prof. Dr. habil. Piroska Szabó-Révész, Pharm.D., D.Sc.




\section{CONTENTS}

\section{PUBLICATONS RELATED TO THE SUBJECT OF THE THESIS \\ OTHER PUBLICATIONS}

\section{ABBREVIATIONS}

1. INTRODUCTION 1

1.1. Biological barriers - functions and characteristics $\quad 1$

1.2. Major mechanisms at biological barriers limiting the penetration of drugs $\mathbf{3}$

1.3. Strategies to enhance drug delivery across barriers $\quad 6$

1.4. Tight junction modulator peptides $\quad \mathbf{8}$

1.4.1. TJ modulator peptides acting on E-cadherin $\quad \mathbf{8}$

1.4.2. TJ modulator peptides derived from microbial toxins 9

1.4.3. TJ modulator peptides identified by phage display $\quad \mathbf{1 0}$

1.5. The use of culture barrier models for drug transport studies $\quad \mathbf{1 1}$

2. AIMS 12

3. MATERIALS AND METHODS

$\begin{array}{ll}\text { 3.1. Materials } & 13\end{array}$

$\begin{array}{ll}\text { 3.2. Peptide synthesis } & 13\end{array}$

3.3. Cell cultures $\quad \mathbf{1 4}$

3.3.1. Human Caco-2 intestinal epithelial cell line $\quad \mathbf{1 4}$

3.3.2. Culture model of the blood-brain barrier $\quad 14$

3.4. Peptide treatment concentrations and intervals $\quad \mathbf{1 5}$

3.5. Cell viability studies $\quad \mathbf{1 5}$

3.5.1. MTT dye conversion assay 16

3.5.2. Impedance measurement 16

$\begin{array}{ll}\text { 3.6. Measurement of the paracellular barrier integrity } & 17\end{array}$

$\begin{array}{ll}\text { 3.6.1. Electrical resistance of cell layers } & 17\end{array}$

$\begin{array}{ll}\text { 3.6.2. Permeability studies } & 17\end{array}$

3.7. Immunohistochemistry 19

3.8. Quantitative real-time PCR 19

3.9. Microscale thermophoresis $\quad \mathbf{2 0}$

3.10. Molecular modeling $\quad 20$

3.11. Circular dichroism spectroscopy

3.12. HPLC analytical procedures

3.13. Mass spectrometry $\quad 22$

3.14 Electron microscopy $\quad 23$ 
3.15. Holographic phase contrast microscopy

3.16. Statistical analysis

4. RESULTS 24

4.1. Opiorphin penetration across a BBB culture model 24

4.2. Effect of TJ modulator peptides on cell viability $\mathbf{2 5}$

4.3. Effect of TJ modulator peptides on barrier integrity 27

4.3.1. Effect of modulator peptides on electrical resistance $\quad 27$

4.3.2. Effect of modulator peptides on permeability of cell layers 27

4.4. Effect of TJ modulator peptides on the morphology of intercellular junctions 29

4.5. Gene expression of occludin and claudins $\quad 31$

4.6. Affinity measurements of peptides to claudin proteins 32

4.7. Dose dependent effect of PN159 peptide on viability, barrier integrity and morphology of epithelial cells $\quad 33$

4.7.1. Effect of PN159 peptide on Caco-2 cell viability - MTT test 33

4.7.2. Effect of PN159 peptide on Caco-2 cell viability - impedance $\mathbf{3 3}$

4.7.3. Effect of PN159 peptide on electrical resistance and permeability of Caco-2 cells $\quad 34$

4.7.4. Effect of PN159 peptide on junctional staining of Caco-2 cells 35

4.8. Reversible effect of PN159 peptide on electrical resistance and ultrastructure of Caco-2 cell junctions

4.9. Effects of $\mathrm{PN} 159$ on the penetration of dextran marker molecules and drugs $\quad \mathbf{3 7}$

4.10. Characterization of the secondary structure of PN159 37

4.11. Structure and interaction of claudin-1, $-4,-5$ and -7 with PN159 38

5. DISCUSSION

5.1. Transfer of opiorphin across a culture BBB model $\mathbf{4 1}$

5.2. Comparative study on TJ modulator peptides $\quad \mathbf{4 2}$

5.2.1. Peptides acting on E-cadherin $\quad 42$

5.2.2. Peptides mimicking microbial toxins

5.2.3. Peptides discovered by phage display $\quad \mathbf{4 3}$

5.3. Comparison of the efficacy and barrier selectivity of the peptides $\quad \mathbf{4 4}$

5.4. Further characterization of the structure, effects and interactions of PN159

6. SUMMARY 46

7. REFERENCES $\quad 47$

ACKNOWLEDGEMENTS

APPENDIX 


\section{PUBLICATIONS RELATED TO THE SUBJECT OF THE THESIS}

I. Bocsik A., Darula Z., Tóth G., Deli M.A., Wollemann M.

Transfer of opiorphin through a blood-brain barrier culture model Archives of Medical Research 46, 502-506 (2015)

IF: 2.645 (2014)

II. Bocsik A., Walter R. F., Gyebrovszki A., Fülöp L., Blasig I., Dabrowski S., Ötvös F., Rákhely G., Veszelka S., Deli M.A.

Reversible opening of intercellular junctions of intestinal epithelial and brain endothelial cells with tight junction modulator peptides

Journal of Pharmaceutical Sciences 105, 754-765 (2016)

IF: 2.59 (2014)

III. Bocsik A., Kiss L., Gróf I., Ötvös F., Zsíros O., Fülöp L., Vastag M., Kittel Á., Szabó-Révész P., Deli M.A.

Tight junction modulator PN159 peptide increases drug penetration across Caco-2 intestinal barrier model

(manuscript in preparation)

\section{OTHER PUBLICATIONS}

I. Kürti L., Veszelka S., Bocsik A., Dung N.T.K., Ózsvári B., Puskás L.G., Kittel Á., Szabó-Révész P., Deli M.A.

The effect of sucrose esters on a culture model of the nasal barrier

Toxicology in Vitro 26, 445-454 (2012)

IF: $2.546(2012)$

II. Kürti L., Veszelka S., Bocsik A., Dung N.T.K., Ózsvári B., Puskás L.G., Kittel Á., Szabó-Révész P., Deli M.A.

Retinoic acid and hydrocortisone strengthen the barrier function of human RPMI 2650 cells, a model for nasal epithelial permeability

Cytotechnology 65, 395-406 (2013)

IF: 1.449 (2013)

III. Kürti L., Gáspár R., Márki A., Bocsik A., Veszelka S., Bartos C., Ambrus R., Vastag M., Deli M.A., Szabó-Révész P.

In vitro and in vivo characterization of meloxicam nanoparticles designed for nasal administration

Europian Journal of Pharmaceutical Sciences 50, 86-92 (2013)

IF: $2.61(2013)$

IV. Kiss L, Walter F. R., Bocsik A., Ózsvari B., Puskás L. G., Szabó-Révész P., Deli M. A.

Kinetic analysis of the toxocoty of Cremophor EL and RH40 on endothelial and epithelial cells

Journal of Pharmaceutical Sciences 102, 1173-1181 (2013)

IF: 3.13 (2013) 
V. Tóth A.E., Walter F.R., Bocsik A., Sántha P., Veszelka S., Nagy L., Puskás L.G., Couraud P.O., Takata F., Dohgu S., Kataoka Y., Deli M.A.

Edaravone protects against methylglyoxal-induced barrier damage in human brain endothelial cells

PLOS ONE 9, e100152 (2014)

IF: 3.73 (2014)

VI. Schilling-Tóth B., Sándor N., Walter F.R., Bocsik A., Sáfrány G., Hegyesi H.

Role of GDF15 in radiosensitivity of breast cancer cells

VERSITA 9, 982-992 (2014)

IF: 0.28 (2014)

VII. Sándor N., Walter F.R., Bocsik A., Sántha P., Schilling-Tóth B., Léner V., Varga Z., Kahán Z., Deli M.A., Sáfrány G., Hegyesi H.

Low dose cranial irradiation-induced cerebrovascular damage is reversible in mice PLOS ONE 9, e112397 (2014)

IF: 3.73 (2014)

VIII. Lénárt N., Walter F.R., Bocsik A., Sántha P., Tóth M.E., Harazin A., Tóth A.E., Vizler C., Török Z., Pilbat A.M., Vígh L., Puskás L.G., Sántha M., Deli M.A.

Cultured cells of the blood-brain barrier from apolipoprotein B-100 transgenic mice: effects of oxidized low-density lipoprotein treatment

Fluids Barriers CNS 12, 17, doi: 10.1186/s12987-015-0013-y (2014)

IF:-

IX. Manczinger M., Bocsik A., Kocsis G.F., Vörös A., Hegedüs Z., Ördögh L., Kondorosi É., Marton A., Vízler C., Tubak V., Deli A.M., Kemény L., Nagy I., Lakatos L.

The absence of N-Acetyl-D-glucosamine causes attenuation of virulence of Candida albicans upon interaction with vaginal epithelial cells in vitro Biomed Research Internationale 2015:398045. doi: 10.1155/2015/398045 (2015) IF: 1.579 (2014)

X. Róka E., Ujhelyi Z., Deli A.M., Bocsik A., Fenyvesi É., Szente L., Fenyvesi F., Vecsernyés M., Váradi J., Fehér P., Gesztelyi R., Félix C., Perret F., Bácskay I.K.

Evaluation of the cytotoxicity of $\alpha$-Cyclodextrin derivatives on the Caco- 2 cell line and human erythrocytes

Molecules 20, 20269-20285, doi:10.3390/molecules201119694, (2015)

IF: $2.791(2014)$ 


\section{ABBREVIATIONS}

$\mathrm{ABC}$

ATP-binding cassette

ATCC

American Type Culture Collection

$\mathrm{BBB}$

blood-brain barrier

$\mathrm{CNS}$

central nervous system

DCC

N,N'-diisopropylcarbodiimide

DMEM

Dulbecco's Modified Eagle Medium

DMF

dimethylformamide

DMSO

dimethyl sulfoxide

FBS

featal bovine serum

FD

FITC labeled marker

FITC

fluorescein isothiocyanate labeled

Fmoc

fluorenylmethyloxycarbonyl

GI

gastrointestinal tract

$\mathrm{HOBt}$

1-hydroxybenzotriazole

HPLC

LC-MS

High Performance Liquid Chromatography

MTT

liquid chromatography mass spectrometry

3-(4,5-dimethyltiazol-2-yl)-2,5-diphenyltetrazolium bromide

$\mathrm{P}_{\text {app }}$

PBS

apparent permeability coefficient

phosphate buffer

$\mathrm{SD}$

standard deviation

SLC

solute carrier

TEER

transepithelial/transedothelial electric resistance

TFA

trifluoroacetic acid

TIS

triisopropyl silane

TJs

tight junctions

ZO-1

zonula occludens- 1 protein

$\mathrm{ZO}-2$

Zonula occludens-2 


\section{INTRODUCTION}

\subsection{Biological barriers - functions and characteristics}

Biological barriers separate our bodies from the external environment and certain protected organs, like the brain, from the systemic circulation. Epithelial and endothelial cells form the anatomical basis of these barriers which provide protection from harmful agents and pathogens and establish and maintain the homeostasis of body compartments (Deli, 2009). Cells of the barriers are connected by tight junctions (TJs) which close the intercellular gap and determine the tightness of barriers. These TJs restrict the paracellular passage of cells, molecules or ions across epithelial and endothelial barriers and limit the penetration of drugs. Therefore, the paracellular permeability is one of the most important determinant of drug delivery across biological barriers and enhancing the permeability of certain drugs, especially large biopharmaceuticals is a great challenge in pharmaceutical research (Ward et al., 2000; Abbott, 2013).

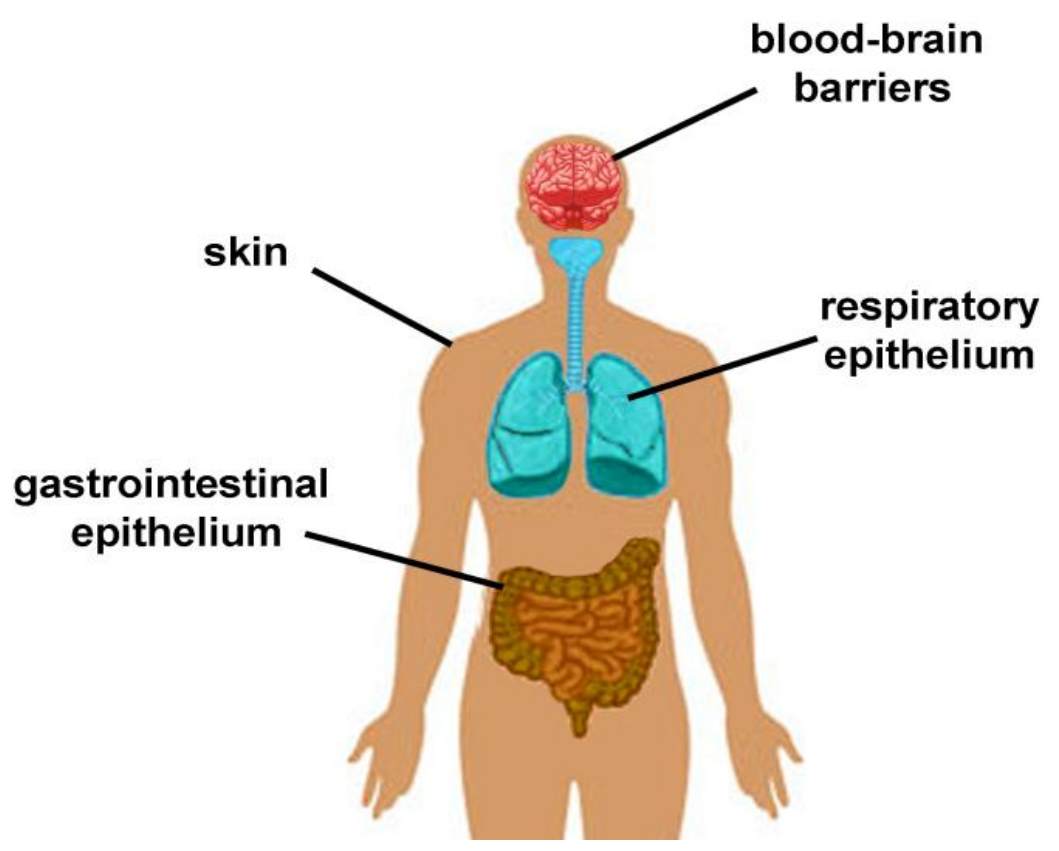

Figure 1. Major biological barriers of the human body.

The main epithelial barriers are the skin, the respiratory surface and the gastrointestinal tract (Fig. 1). Dermal epithelium is the least permeable barrier due to its anatomical structure, and shows a high, about $5000 \Omega \times \mathrm{cm}^{2}$ electrical resistance reflecting very low ionic permeability. In comparison, the resistance of small intestinal or proximal renal epithelium is typically below $100 \Omega \times \mathrm{cm}^{2}$ indicating a more permeable barrier for ions (Yu and Turner, 2008). Despite the tightness of the skin as a barrier, transdermal drug delivery is a promising field of pharmaceutical research and therapy (Naik et al., 2000; 
Karande and Mitragotri, 2009). Airway epithelium is another non-invasive administration route for drugs to treat systemic disorders. Due to the large surface area (about $160 \mathrm{~m}^{2}$ alveolar surface) and high vascularization of respiratory epithelium, the pulmonary or nasal drug administration has a great potential to target the systemic circulation besides local effects (Scheuch et al; 2006). The most popular method for drug therapy is the oral administration. This route is efficient and safe with good patient compliance. However drug absorption in the gastrointestinal tract (GI) is limited by intercellular junctions, and the paracellular route is one of the factors determining drug penetration (Deli, 2009). The total surface area of the GI tract is approximately $200 \mathrm{~m}^{2}$, but the extent of absorption is different between its regions (Deli, 2009). The jejunum and ileum show higher drug absorption rate compared to buccal and rectal mucosa where the penetration is restricted but these are important site for drug administration due to rapid effect in crisis therapy (Ward et al., 2000; Deli, 2009). The absorption level and rate depends on the composition of cellular membranes, the anatomical structures, the expression pattern of TJ proteins and transporters in the cell membrane (Chiba et al., 2008).

The blood-brain barrier (BBB), a special dynamic interface between the blood and the central nervous system (CNS) is formed by endothelial cells. The BBB is composed of brain microvascular endothelial cells surrounded by pericytes and astrocytic endfeet. The interactions of these cells with microglia and neurons constitute a functional unit, the neurovascular unit (Abbott et al., 2010). The BBB maintains the ionic homeostasis for neuronal functions, regulates the nutrient transport to the CNS and the level of toxic metabolites, provides protection from xenobiotics and represents a communication interface between the periphery and the brain (Campos-Bedolla et al., 2014). The estimated length of human brain capillaries is $650 \mathrm{~km}$ and the surface area is 10 to $20 \mathrm{~m}^{2}$. This surface is the major entry route for therapeutic compounds to the CNS. Compared to other vascular endothelium, the passive penetration of hydrophilic molecules and ions across the para- and transcellular pathways of brain endothelial cells is very low. TJ proteins block the paracellular route, while the low level of non-specific transendothelial vesicular trafficking and the presence of efflux transporters at the luminal membranes of brain endothelial cells limit the penetration across cell membrane (Deli, 2011). The electrical resistance of brain microvessels is also high, more than $2000 \Omega \times \mathrm{cm}^{2}$ indicating the limited ionic penetration through the BBB. Because the BBB restricts drug permeation, the treatment of many CNS diseases is still a challenge (Deli, 2011; Abbott, 2013). 


\subsection{Major mechanisms at biological barriers limiting the penetration of drugs}

Active agents can penetrate across epithelial and endothelial barriers by several pathways, including lipid-mediated diffusion, carrier or receptor mediated transport and paracellular passive diffusion (Laksitorini et al., 2014). The same mechanisms of biological barriers which provide protection also limit drug delivery.

Efflux transporters limit the absorption and CNS delivery of lipophilic compounds, xenobiotics and a large number of drugs. Efflux pumps localize to the apical and/or basolateral side of polarized cell membranes of both the intestinal mucosa and the BBB (Fricker and Miller, 2004; Terasaki and Ohtsuki, 2005). Most efflux pumps belong to the ABC (ATP binding cassette) transporter family, like P-glycoprotein or multidrug resistance associated proteins, or to the SLC (solute carrier) family, like the organic aniontransporting polypeptides.

Barriers, including the endothelial cells of the BBB provide a metabolic barrier by expressing enzymes that modify endogenous and exogenous molecules (Cecchelli et al., 2007; Deli, 2011). Peptide or neurotransmitter transport to the brain is restricted not only by this mechanism but also by the restricted paracellular route (Deli, 2011). Opioid peptides are potent analgesics with therapeutic potential in the treatment of acute and chronic pain but their efficacy is limited because of the short half-life time and low metabolic stability (Tömböly et al., 2002; Janecka et al., 2008). Opiorphin pentapeptide (QRFSR) is a human endogenous inhibitor of enkephalinases, which prevents the metabolism of opioid peptides (Rougeot et al., 2010; Javelot et al., 2010). Opiorphin is the only natural enkephalinase inhibitor which was characterized in human and has similar pain suppressive potency to morphine without adverse effects (Wisner et al., 2006). This peptide is able to increase the binding and affinity of endogenous opiates to $\mu$-opioid receptors, thus the mechanism of opiorphin may provide a new therapeutic approach in pain management. The analgesic effect of opiorphin was verified in several in vitro and in vivo models (Wisner et al., 2006), but previously there were no data about their transfer through a BBB model.

Lipophilic drugs possess high affinity for the lipid bilayer of the cell membrane, and their transcellular passive diffusion is considered as the major route of delivery, while the transcellular penetration of hydrophilic molecules is blocked. The permeability of drugs across paracellular pathway is modulated by TJs which seal the gaps between cells (Fig. 2; Johnson and Quay, 2005). TJs of barrier cells are complex structures (Fig. 3) composed of integral membrane proteins, linker proteins connecting membrane proteins to the actin cytoskeleton and signaling molecules regulating paracellular tightness and transport (Johnson and Quay, 2005; Van Itallie and Anderson, 2014). 


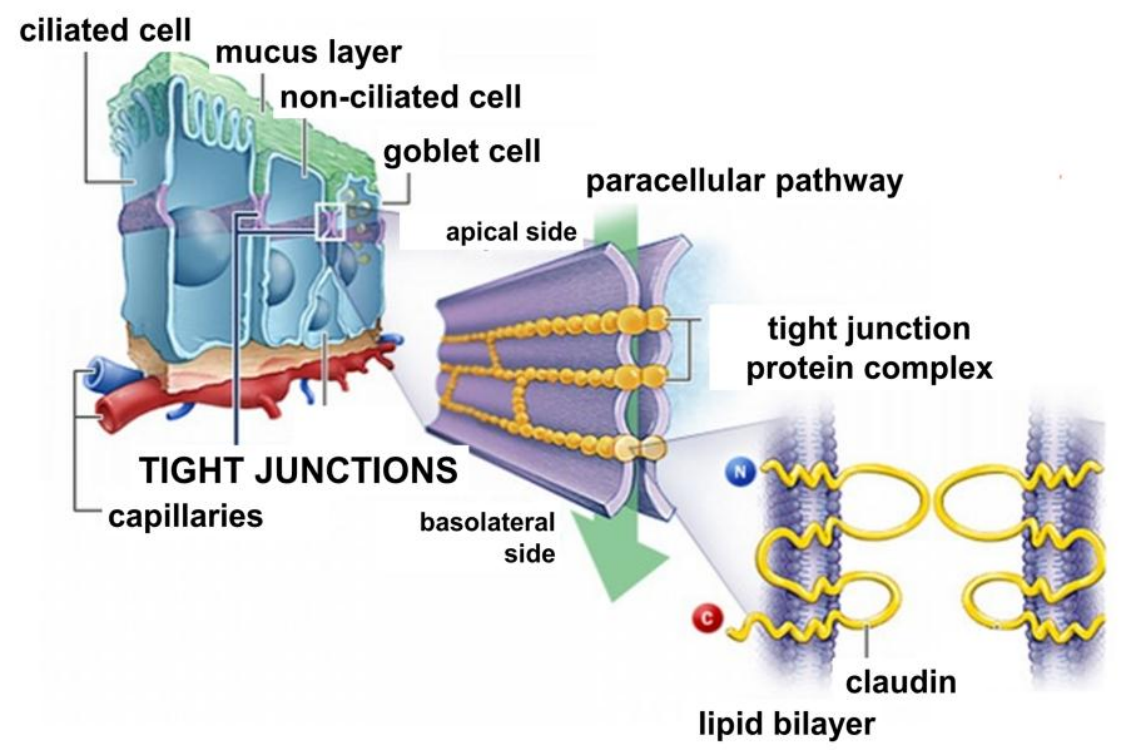

Figure 2. Structure of tight junctions between epithelial cells (Johnson and Quay, 2005).

Among the transmembrane TJ proteins occludin, tricellulin and the members of the claudin family have a prominent role in forming paracellular barriers (Krause et al., 2008). These TJ proteins share a tetraspan transmembrane topology (Fig. 2 and 3). Occludin which plays an important role in transport regulation is expressed at similar levels in different barrier-forming tissues, such as BBB forming brain endothelial cells or intestinal epithelial cells of GI (Haseloff et al., 2015). More than 20 members of the claudin family are expressed on epithelial and endothelial cells. The unique expression pattern of claudins determines the tissue-, charge- and size selectivity of the paracellular cleft.

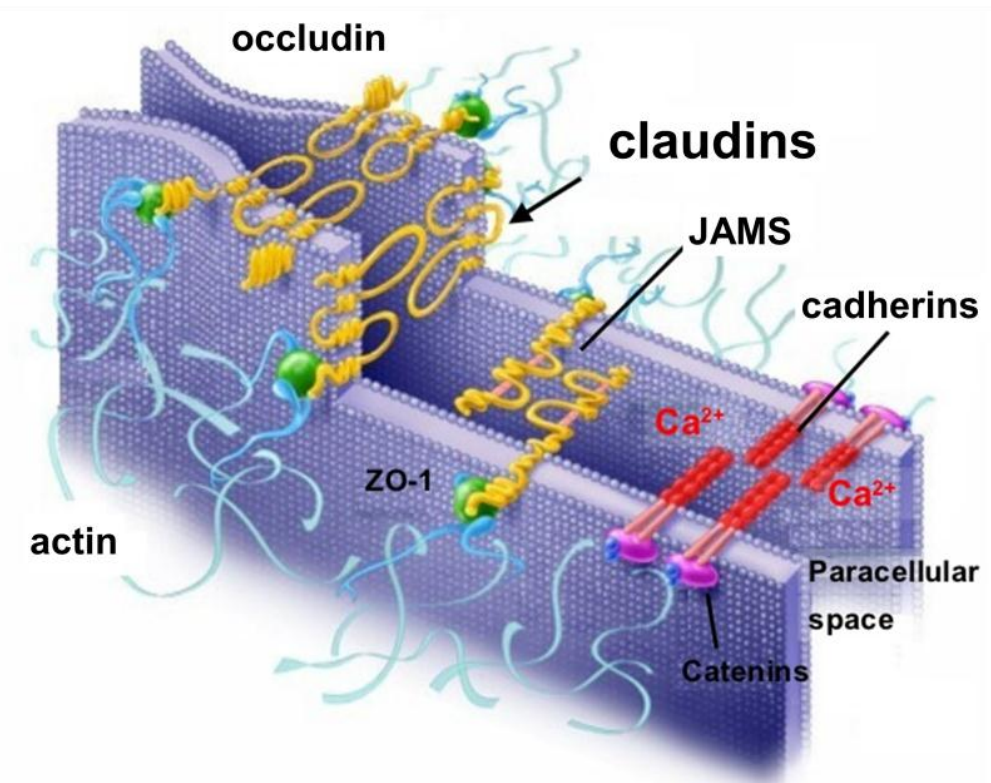

Figure 3. Tight and adherens junctional proteins between barrier forming cells (Johnson and Quay, 2005). 
Claudin-1, -3, -4, -5, -8, -11, -14 and -19 contribute to the tightness of paracellular barriers, while claudin-7 is permeable for ions (Krause et al., 2008). Intestinal epithelial cells express claudin-1, $-2,-3,-4,-7,-8,-12$ and -15 , but the level of their expression in various intestinal segments and their subcellular localization are different (Chiba et al., 2008). The presence of claudin-1, $-3,-5,-12$ and -18 were described in brain endothelial cells. Claudin-5 is the dominant claudin at the BBB which regulates the paracellular permeation of small molecules (Deli, 2009; Haseloff et al., 2015). Claudins can interact in a homo- and heterophilic manner in the plasma membrane of the same cell (cis-interaction) and between plasma membranes of opposing cells (trans-interaction) (Krause et al., 2009).

Zonula occludens proteins (ZO-1, ZO-2) connect occludin and claudins to the actin cytoskeleton (Fig. 3) and dynamically modulate several signaling pathways and junctional permeability (Paris et al., 2008). Another important adaptor protein is "dual-function" $\beta$ catenin, which stabilizes adherens junctions in the cell membrane, and acts as a key regulator of gene expression via binding to transcription factors (Reis and Liebner, 2013).

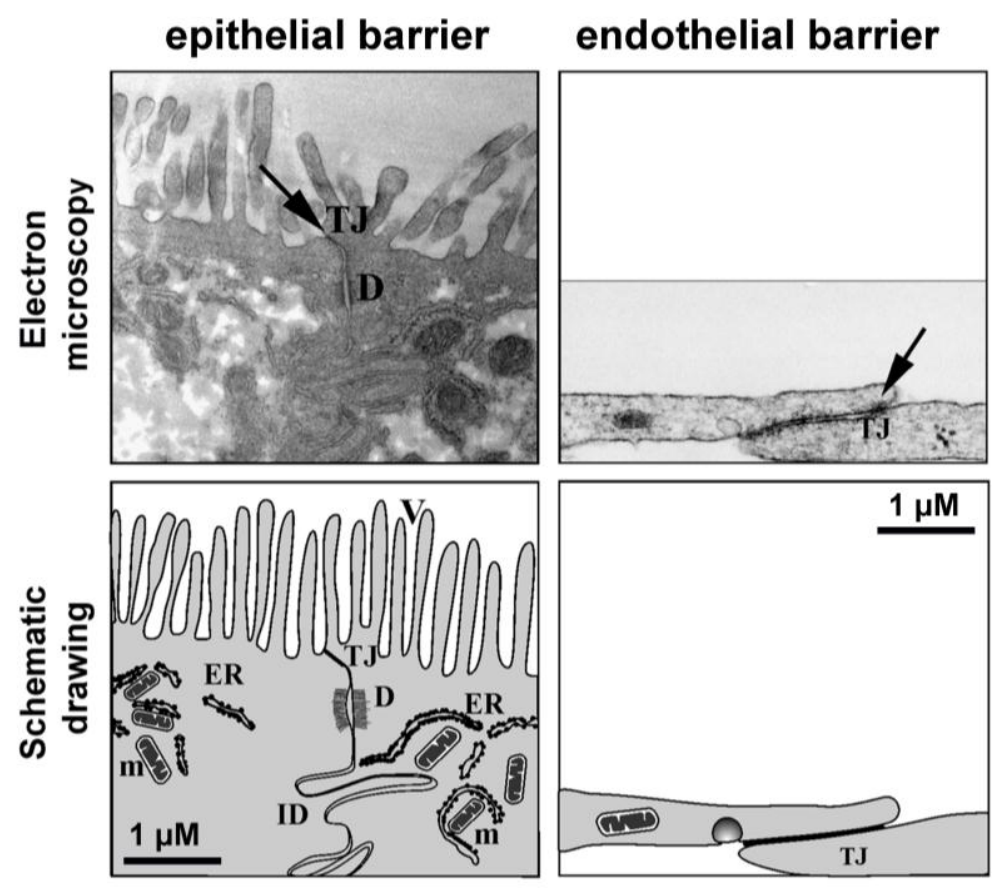

Figure 4. Morphology of intercellular junctions between cultured intestinal epithelial and brain endothelial cells. D, desmosome; ER, endoplasmatic reticulum; ID, interdigitations; m, mitochondria; TJ, tight junctions; V, microvilli (Hellinger et al., 2012).

Adherens junction proteins are also expressed in both epithelial and endothelial barriers, however, there are morphological and functional differences. In brain endothelial cells tight and adherens junctions are not separated morphologically (Fig. 4) and tight and adherens junctional proteins are intermingled (Vorbrodt et al., 2004). In epithelial barriers adherens junctions are situated in the apical junctional complex in basolateral direction from the TJs (Fig. 2-4) and play an important role in the localization of TJs (Johnson and 
Quay, 2005). Adherens junction proteins, like E-cadherin in epithelial cells and VEcadherin in endothelial cells also participate in the regulation of paracellular permeability (Fig. 3; Deli, 2009).

\subsection{Strategies to enhance drug delivery across barriers}

There are three basic strategies to enhance the permeability of biological barriers and improve drug delivery: (i) using an alternative route of drug administration; (ii) modification of the pharmacon; (iii) modificaton of the function of the barrier including targeted opening of tight junctions (Deli, 2009).

Alternative routes of drug administration such as the nasal pathway circumvent the $\mathrm{BBB}$ and allow pharmacons a direct transport route to the CNS (Illum, 2003). Previous results of our research group identified incomplete junctions between olfactory ensheating cells, which allowed the penetration of a marker molecule along the olfactory nerves to the CNS, as the anatomical basis of this alternative pathway (Wolburg et al., 2008). By exploiting this alternative route of delivery, our group described the brain penetration of a large marker molecule and a bioactive peptide after nasal administration in rats (Horvát et al., 2009; Sipos et al., 2011). Intranasal drug delivery can be an effective way to increase drug levels in the systemic circulation. We demonstrated that nasal administration of a meloxicam formulation which contained drug nanoparticles significantly increased plasma drug level compared to the oral administration route (Kürti et al., 2013).

Pharmacons can be modified chemically to increase their cationic or lipophilic properties which are known to promote their crossing across barriers (Deli, 2011). Cyclodextrins, especially hydrophilic derivatives, not only solubilize lipophilic pharmacons, but also improve drug absorption by complex formation (Strickley, 2004; Loftsson et al., 2007). Experimental and clinical data suggest that cyclodextrins can be used to increase drug delivery to the brain (Vecsernyés et al., 2014). Prodrug design for brain delivery of small- and medium-sized neuropeptides is achieved by the chemical modification of the bioactive molecule, which is attached to a lipid vector, like a fatty acid, a glyceride or phospholipid (Prókai-Tátrai and Prókai, 2009). The pharmacologically inactive molecule, which penetrates through the barrier, will be released enzymatically only at the site of action (Table 1). This method was successful in the case of a lipophilic analog of valproate (DP-VPA) in a clinical trial for the treatment of epilepsy and depression (Deli, 2011).

Ways to modify the two most important barrier properties, efflux transporters and TJs blocking drug penetration are actively investigated in pharmaceutical research. Inhibiting efflux pumps without systemic or CNS side-effects would be optimal for clinical 
use to increase delivery of a wide variety of drugs, including antibiotics, antineoplastic agents and drugs to treat epilepsy and AIDS. While P-glycoprotein blockers, like cyclosporine A and verapamil are effective to enhance the penetration of drugs across barriers in experiments, the first- and second-generation P-glycoprotein modulators have failed in clinical trials due to toxic side effects (Szakács et al., 2009).

Table 1. Restricted transport of different compounds through biological barriers and strategies to overcome.

\begin{tabular}{|l|l|l|l|}
\hline Barrier feature & Blocked pathway & Restricted transport & Strategies to overcome \\
\hline \hline Efflux transporters & $\begin{array}{l}\text { lipid-mediated transcellular } \\
\text { diffusion }\end{array}$ & lipophilic compounds & $\begin{array}{l}\text { efflux transporter } \\
\text { inhibitors }\end{array}$ \\
\hline Enzymes & $\begin{array}{l}\text { carrier or receptor mediated } \\
\text { transcellular transport }\end{array}$ & $\begin{array}{l}\text { bioactive pharmacons, } \\
\text { peptide, proteins }\end{array}$ & Prodrugs \\
\hline $\begin{array}{l}\text { Lipid plasma } \\
\text { membrane }\end{array}$ & $\begin{array}{l}\text { transcellular passive } \\
\text { diffusion }\end{array}$ & hydrophilic compounds & absorption enhancers \\
\hline Tight junctions & $\begin{array}{l}\text { paracellular passive } \\
\text { diffusion }\end{array}$ & $\begin{array}{l}\text { hydrophilic compounds, } \\
\text { biopharmaceuticals }\end{array}$ & opening the junctions \\
\hline
\end{tabular}

Several approaches are used to open the paracellular route of barrier to increase the flux of hydrophilic molecules, especially larger biopharmaceuticals, including proteins, peptides or lipophilic efflux pump ligands (Deli, 2009; Deli, 2011). There are many well characterized and effective pharmaceutical excipients, like anionic and non-ionic surfactants and fatty acids which are widely used as solubilizing agents in oral, injectable and nasal formulations (Strickley, 2004). These excipients increase transcellular permeation and several studies described their absorption enhancer properties (Aungst, 2012). In our previous work non-ionic surfactant sucrose esters were investigated on culture models of the intestinal and blood-brain barriers (Kiss et al., 2014). We demonstrated that sucrose esters can act on TJs and increase the paracellular permeability for ions, drugs and marker molecules (Kiss et al., 2014).

Opening the TJs at the $\mathrm{BBB}$ to increase drug delivery for the treatment of neurological diseases, like brain tumors is especially challenging (Deli, 2011). Osmotic stress induced by intraarterial mannitol improves the delivery of cytostatic drugs to brain tumors and prolongs the survival of patients, but this technique is invasive and used only in few clinical centers (Doolittle et al., 2000). Short-chain alkylglycerols were also described to enhance the penetration of drugs across the BBB by opening TJs in rats (Erdlenbruch et al., 2003), and our group confirmed the direct, reversible action of these small lipid molecules on the paracellular pathway in cultured brain endothelial cells (Hülper et al., 2013). We also demonstrated that tesmilifene, a tamoxifen analog increased the blood- 
tumor barrier permeability in rats and opened TJs in brain endothelial cells (Walter et al., 2015).

\subsection{Tight junction modulator peptides}

Occludin was the first identified and cloned integral membrane TJ protein in the early 90s (Furuse et al., 1993), soon followed by different claudins (Krause et al., 2008). Knowledge of the amino acid sequence of these proteins and their (putative) secondary structure made it possible to design peptides as novel type of TJ modulators to open the paracellular barrier for drug delivery. A wide variety of modulator peptides were synthesized based on different junctional proteins and tested on barrier models in vivo and in vitro (Deli, 2009). Based on literature data we have selected for our study six different modulator peptides which act at different targets (Table 2).

Table 2. Characteristics of the selected TJ modulator peptides.

\begin{tabular}{|l|l|l|l|l|}
\hline Peptide & Target & Mechanism & Derived from & Refrence \\
\hline \hline ADT-6 & E-cadherin & EC1 domain analog & designed to target EC1 & Sinaga et al., 2002 \\
\hline HAV-6 & E-cadherin & EC1 domain analog & designed to target EC1 & Kiptoo et al., 2010 \\
\hline C-CPE & Claudin-3,-4 & interact with ECLs & microbial toxin fragment & Sonoda et al., 1999 \\
\hline AT-1002 & ZO-1 & Zot receptor & microbial toxin fragment & Song et al., 2008 \\
\hline $\begin{array}{l}\text { 7-mer } \\
\text { (PN78) }\end{array}$ & unknown & unknown & phage display & Herman et al., 2007 \\
\hline PN159 & unknown & unknown & phage display & Johnson and Quay, 2005 \\
\hline
\end{tabular}

Abbreviation: ZO-1, zonula occludens protein-1; EC1, first extracellular domain; ECL, extracellular loop.

\subsubsection{TJ modulator peptides acting on E-cadherin}

The first extracellular domain (EC-1) of E-cadherin mediates cell-cell adhesion (Fig. 5A). The bulge and groove regions of EC-1 are responsible for the trans interaction between two E-cadherins (Fig. 5B). Two hexameric peptides, ADT-6 and HAV-6 were designed based on these bulge and groove regions of EC-1 (Sinaga et al., 2002). These peptides interfere with the homophilic binding of E-cadherin, and time- and dosedependently increase the paracellular permeability in different epithelial cells (Kiptoo et al., 2011). Modulation of integrity of intercellular junctions by cadherin peptides depends on the epithelial cell type: Madin-Darby canine kidney (MDCK) cell monolayers were more sensitive for the effect of HAV-6 than Caco-2 cell monolayers (Makagiansar et al., 2001). 
A B

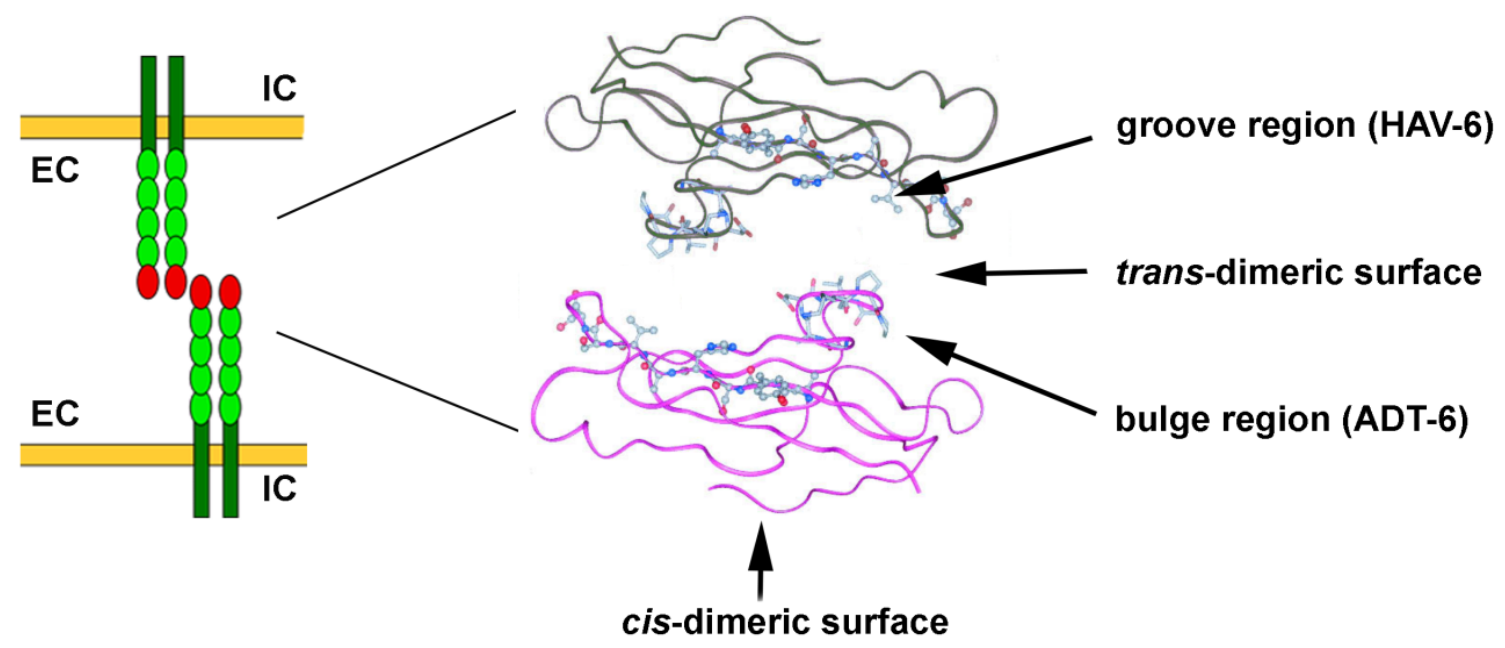

Figure 5. (A) Simplified structure of E-cadherin, EC1 is shown in red. (B) The groove (SHAVSS, HAV-6 peptide) and bulge (ADTPP, ADT-6 peptide) regions in the EC1-domain of E-cadherin (Sinaga et al., 2002).

\subsubsection{TJ modulator peptides derived from microbial toxins}

Several pathogenic bacteria and viruses increase barrier permeability because integral membrane TJ proteins can be receptors for their toxins. Microbial toxins or toxin fragments were therefore tested as modulators to enhance drug penetration through barriers. One example is the enterotoxin of the gut bacterium Clostridium perfringens (CPE), which binds to epithelial claudins (Sonoda et al., 2002) via its C-terminal 16residue long fragment (C-CPE) (Fig. 6). The non-toxic C-CPE fragment binds specifically to the second extracellular loop (ECL2) of claudin-3 and -4 and increases intestinal permeability in vivo and in vitro (Kondoh et al., 2006; Li et al., 2014).

The enterotoxin of the intestinal pathogen Vibrio cholerae enhances the permeability of small intestinal mucosa acting on intercellular TJs through ZO linker proteins (Fasano in 1991). The active domain of cholera enterotoxin was named zonula occludens toxin (ZOT), and containes a hexamer peptide AT-1002. This active hexapeptide causes the redistribution of ZO-1 (Gopalakrishnan et al., 2009) and increases the permeability of epithelial, especially intestinal barriers in vitro and in vivo (Song et al., 2008). 


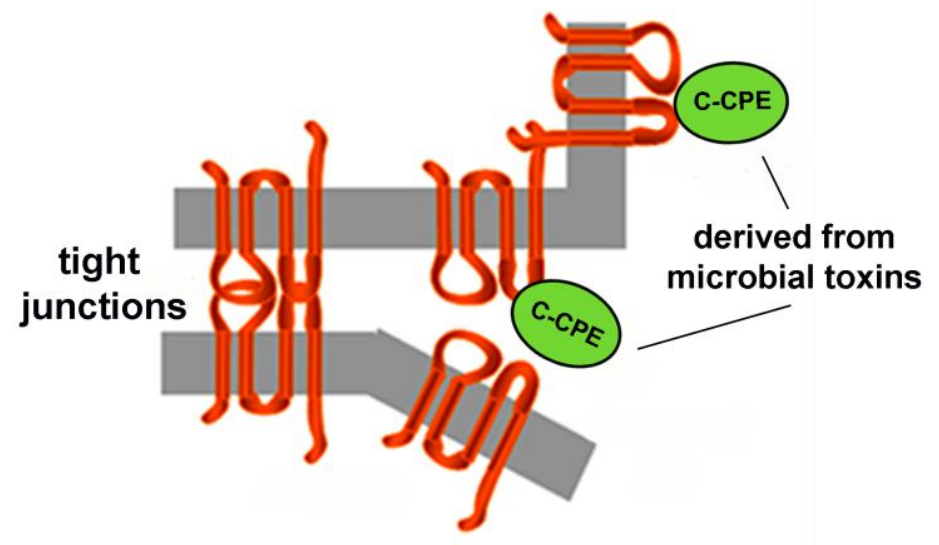

Figure 6. Modulation of TJs by peptides derived from microbial toxins C-CPE: C-terminal 16-residue long fragment of Clostridium perfringens enterotoxin.

\subsubsection{TJ modulator peptides identified by phage display}

Another approach to find novel TJ modulator peptides is to use phage display, a powerful method to select specific peptides for a given target. First a peptide library is prepared by cloning randomised oligonucleotides into the phage, than several rounds of specific binding-washing steps (panning) are followed by the elution of the phages bound to the target, amplification of the phages and DNA sequencing. Enriched peptides are synthesised and tested on models for biological activity (McCafferty and Schofield, 2015). The 7-mer (PN78) and PN159 peptides were identified by phage display on EGTA-treated cultured human bronchial epithelial cell layers (Johnson and Quay, 2005; Herman et al., 2007). PN159 effectively increases the permeability of respiratory epithelium, in culture and animal experiments (Chen et al., 2006).

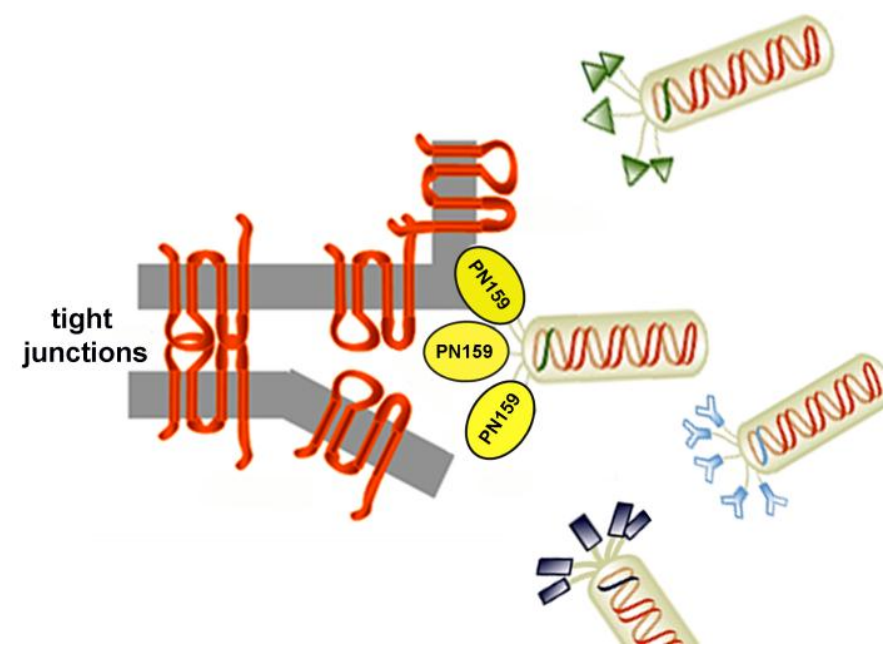

Figure 7. Specific interaction between juntional proteins and peptides expressed by phages. PN159: tight junction modulator peptide. 
Because these peptides were selected by phage display, their specific target proteins are unknown. They probably interact with the ECLs of integral membrane TJ protein(s) similarly to other modulator peptides. Based on the available data PN159 could be a potential permeability enhancer for drug therapy, but there are no published information about its targets, structure or long term safety.

\subsection{The use of culture barrier models for drug transport studies}

The prediction of permeability properties of new active agents or drug candidates across biological barriers is crucial in the early phase of drug development, especially for neuropharmacons (Vastag et al., 2009). There are many available methods, from in silico screening through non-cell-based and cell-based in vitro methods to animal studies and human clinical trials with different predictive values, speed and throughput (Veszelka et al., 2011). Cell culture-based barrier models have proved to be one of the most versatile tools in both basic research and permeability testing (Deli et al., 2005). There are several important characteristics that a culture barrier model for drug transport studies should fulfill including physiological barrier properties, easy use, reproducibility, costs and test capacity. In our studies we used two well characterized and widely used culture models of the intestinal and blood-brain barriers.

Oral drug formulations are the most widespread in human therapy, therefore intestinal drug absorption is the most studied in pharmaceutical research. The human Caco2 cell line, which resembles the epithelium of small intestine both from structural and functional aspects (Hubatsch et al., 2007) is a routinely used culture model of intestinal drug penetration (Hellinger et al., 2010). The cells are polarized, grow in monolayer, possess microvilli, and form TJs between cells (Fig. 4). Caco-2 cells also express nutrient and efflux transporters, such as P-gp (Artursson et al., 2001; Hellinger et al., 2010).

The treatment of neuronal diseases such as epilepsy, stroke, Alzheimer's disease or brain tumors is still very difficult due to the low brain penetration of most novel drug candidates (Avdeef et al., 2015). Therefore, screening for BBB permeability has great importance in CNS drug discovery (Vastag et al., 2009; Veszelka et al., 2011). The primary cell based rat BBB triple co-culture model of our group has high complexity and good predictive value for drug penetration to brain (Nakagawa et al., 2009), and was favorably compared to surrogate models of the BBB (Hellinger et al., 2012). 


\section{AIMS}

While the triple co-culture BBB model was already tested for several types of marker molecules and drugs, it was previously not examined for the penetration of bioactive peptides. Therefore the first aim of this work was to study the transfer of an unlabeled neuropeptide, the analgesic opiorphin on our BBB culture model.

Several types of TJ modulator peptides are described in the literature as discussed above, but detailed comparative studies were missing at the start of our work. For example, there are many observations on C-CPE or E-cadherin peptides but their efficacy was investigated on one type of barrier model only. No data were available on their barrier specificity or their efficacy compared to other types of TJ modulator peptides either. Thus we wanted to compare the six TJ modulator peptides shown in Table 2 that we selected based on their diversity of targets, mode of action and different sequence on two different barrier models.

Our specific aims were the following:

(i) Testing the effects of TJ modulator peptides on intestinal epithelial and blood-brain endothelial models for:

cell viability

barrier integrity

cell morphology

(ii) Comparing the efficacy, safety, reversibility and barrier specifity of $\mathrm{TJ}$ modulator peptides.

(iii) Investigation of PN159 peptide for:

dose dependence of efficacy

long-term effect on cell viability

reversibility of kinetic and morphological changes

penetration enhancement for marker molecules and drugs

(iv) Identification of the potential targets of PN159 TJ modulator peptide. 


\section{MATERIALS AND METHODS}

\subsection{Materials}

All reagents were purchased from Sigma (Sigma-Aldrich, Ltd., Budapest, Hungary), unless otherwise indicated.

\subsection{Peptide synthesis}

Opiorphin (QRFSR), TJ modulator peptides and peptides with scrambled sequences (Table 3) were synthesized manually by our cooperation partners by using Fmoc as described in detail in Publications I and II in Appendix. In the case of opiorphin the side chain protecting groups used to building the peptide sequences were the following: trityl (Trt) for Gln, tert-butyl (t-Bu) for Ser and 2,2,5,7,8-pentamethylchroman (Pmc) for Arg. The couplings were performed by $\mathrm{HOBt}$ and DIC. The coupling efficiencies were monitored by the Kaiser test. The Fmoc groups were removed by a solution of $20 \%$ piperidine in dimethylformamide. The peptides were cleaved from the resin by incubating it with the mixture of TFA/TIS/ $\mathrm{H}_{2} \mathrm{O}$ (48:1:1volume ratio) at room temperature for 3 hours, precipitated and washed with diethyl-ether and then lyophilized. The crude peptides were purified using a semi-preparative RP-HPLC column (opiorphin: Altima HP C18; tight junction peptides: Phenomenex Jupiter C18). Analysis and purity control was carried out on an analytical HPLC instrument.

Table 3. Characteristics of the selected modulator peptides.

\begin{tabular}{|l|l|l|}
\hline Peptide & Mw (Da) & Amino acid sequence \\
\hline \hline $\begin{array}{l}\text { ADT-6 } \\
\text { sc ADT-6 }\end{array}$ & 640 & $\begin{array}{l}\text { Ac-ADTPPV-NH2 } \\
\text { Ac-PTDVAP-NH2 }\end{array}$ \\
\hline $\begin{array}{l}\text { HAV-6 } \\
\text { sc HAV-6 }\end{array}$ & 628 & $\begin{array}{l}\text { Ac-SHAVSS-NH2 } \\
\text { Ac-VSSSHA-NH2 }\end{array}$ \\
\hline $\begin{array}{l}\text { C-CPE } \\
\text { sc C-CPE }\end{array}$ & 2056 & $\begin{array}{l}\text { SSYSGNYPYS ILFQKF-OH } \\
\text { FYSQYYGDNLSKSFIP-OH }\end{array}$ \\
\hline $\begin{array}{l}\text { AT-1002 } \\
\text { sc AT-1002 }\end{array}$ & 797 & $\begin{array}{l}\text { FCIGRL } \\
\text { GLRIFC }\end{array}$ \\
\hline $\begin{array}{l}7-m e r(P N 78) \\
\text { sc 7-mer }\end{array}$ & 1031 & $\begin{array}{l}\text { FDFWITP } \\
\text { PWTFDIF }\end{array}$ \\
\hline $\begin{array}{l}\text { PN159 } \\
\text { sc PN159 }\end{array}$ & 2871 & $\begin{array}{l}\text { KLALKLALKALKAALKLA-amide } \\
\text { AALKLAKALLKLLKALAK-amide }\end{array}$ \\
\hline
\end{tabular}

Abbreviation: sc, scrambled sequence of peptides; Mw, molecular weight. 


\subsection{Cell cultures}

\subsubsection{Human Caco-2 intestinal epithelial cell line}

Human Caco-2 intestinal epithelial cell line (Fig. 8) was purchased from ATCC (cat.no. HTB-37) and used until passage 60 for the experiments. Caco-2 cells were grown in DMEM/HAM's F-12 culture medium with stable glutamine (Biochrom GmbH, Berlin, Germany) supplemented with $10 \%$ fetal bovine serum (FBS; Pan-Biotech $\mathrm{GmbH}$, Aidenbach, Germany) and $50 \mu \mathrm{g} / \mathrm{ml}$ gentamycin in a humidified incubator with $5 \% \mathrm{CO}_{2}$ at $37^{\circ} \mathrm{C}$. All plastic surfaces were coated with $0.05 \%$ rat tail collagen in sterile distilled water before cell seeding.

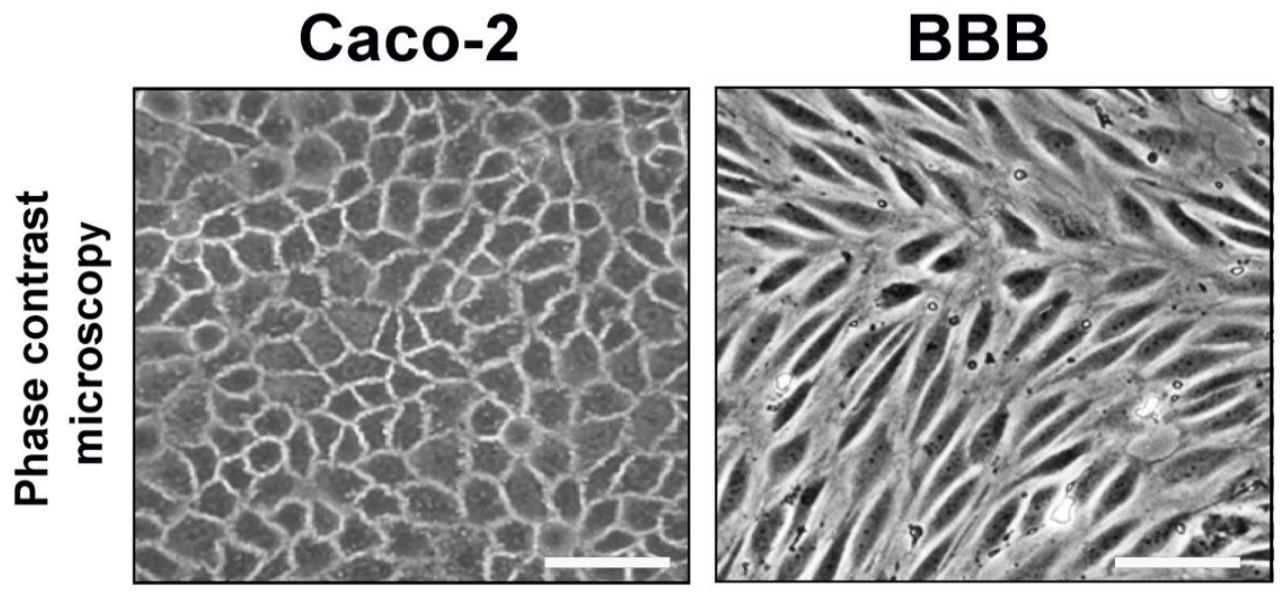

Figure 8. Phase contrast images of confluent cultures of Caco-2 and rat brain endothelial cells (BBB). Bar $=50 \mu \mathrm{m}$.

\subsubsection{Culture model of the blood-brain barrier}

Primary cultures of brain endothelial cells, glial cells, and pericytes, and the in vitro BBB model were prepared according to the method described in our previous study (Nakagawa et al., 2009). Brain endothelial cells (Fig. 8) were cultured in DMEM/F-12 (Gibco, Life Technologies, Carlsbad, CA, USA), $15 \%$ plasma-derived bovine serum (First Link, Wolverhampton, UK), $100 \mu \mathrm{g} / \mathrm{ml}$ heparin, $5 \mu \mathrm{g} / \mathrm{ml}$ insulin, $5 \mu \mathrm{g} / \mathrm{ml}$ transferrin, $5 \mathrm{ng} / \mathrm{ml}$ sodium selenite, $1 \mathrm{ng} / \mathrm{ml}$ basic fibroblast growth factor (Roche, Basel, Switzerland) and $50 \mu \mathrm{g} / \mathrm{ml}$ gentamycin. During the first three days of culture the medium of brain endothelial cells contained $3 \mu \mathrm{g} / \mathrm{ml}$ puromycin to eliminate P-glycoprotein negative, contaminating cell types (Perrière et al., 2005). During the experiments brain endothelial cells were always seeded on surfaces coated with $100 \mu \mathrm{g} / \mathrm{ml}$ collagen type IV and $100 \mu \mathrm{g} / \mathrm{ml}$ fibronectin in sterile distilled water. Primary rat brain pericytes were isolated by the same method, except pericytes were plated onto uncoated Petri dishes 
(Orange Scientific, Braine-l'Alleud, Belgium). Primary cultures of rat glial cells were prepared from one-day-old Wistar rats (Perrière et al., 2005) and passaged to 12-well dishes (Corning, Costar, New York, NY, USA) coated with $100 \mu \mathrm{g} / \mathrm{ml}$ collagen type IV in sterile distilled water and cultured for two weeks before using for the triple co-culture model. Pericytes and glial cells were cultured in DMEM/HAM's F-12 supplemented with $10 \%$ FBS (Pan-Biotech $\mathrm{GmbH}$ ) and $50 \mu \mathrm{g} / \mathrm{ml}$ gentamycin. For the triple co-culture model pericytes (P3) were passaged to the bottom side of 12-well tissue culture inserts (Transwell 3460 , polyester membrane, $0.4 \mu \mathrm{m}$ pore size, Corning Costar) at a density of $1.5 \times 10^{4}$ cells $/ \mathrm{cm}^{2}$. Endothelial cells were seeded to the upper side of the membranes $\left(8 \times 10^{4}\right.$ cells $/ \mathrm{cm}^{2}$ ) and placed to 12-well plates containing glial cells. Both compartments received endothelial culture medium and the three types of cells were cultured together for four or five days (Nakagawa et al., 2009; Walter et al., 2015) When brain endothelial cell layers became confluent $550 \mathrm{nM}$ hydrocortisone was added to tighten the junctions (Deli et al., 2005). For experiments with Caco- 2 cells passage numbers were close to each other. For the BBB model primary cultures were obtained from several isolations, but the barrier parameters were very similar in the assays.

\subsection{Peptide treatment concentrations and intervals}

The stock solutions (10 mM) were prepared freshly, ADT-6, HAV-6, C-CPE and AT-1002 peptides were dissolved in sterile distilled water, while 7-mer (PN78) and PN159 peptides were dissolved in sterile DMSO. Treatment solutions were further diluted in Ringer-Hepes $(150 \mathrm{mM} \mathrm{NaCl}, 6 \mathrm{mM} \mathrm{NaHCO} 3,5.2 \mathrm{mM} \mathrm{KCl}, 2.2 \mathrm{mM} \mathrm{CaCl}, 0.2 \mathrm{mM}$ $\mathrm{MgCl}_{2}, 2.8 \mathrm{mM}$ D-glucose, $5 \mathrm{mM}$ Hepes; $\mathrm{pH}$ 7.4) or cell culture medium. For the comparative studies final concentrations of the peptides in treatment solutions were as follows: $2 \mathrm{mM}$ for ADT-6, HAV-6 and AT-1002 peptides, $1 \mathrm{mM}$ for C-CPE peptide, $100 \mu \mathrm{M}$ for 7-mer peptide and $10 \mu \mathrm{M}$ for PN159 peptide. For additional experiments with PN159 peptide final concentrations in treatment solutions were as follows: 1, 3, 10, 30 and $100 \mu \mathrm{M}$ for cell viability assays; 1, 3, 10 and $30 \mu \mathrm{M}$ for the barrier integrity assays and $10 \mu \mathrm{M}$ for the recovery measurements. Peptide concentrations were selected based on literature data (Deli, 2009) and cell viability experiments.

\subsection{Cell viability studies}

Two methods were applied to determine the effects of TJ modulator peptides on cell viability: MTT dye conversion assay, and cell impedance measurement. 


\subsubsection{MTT dye conversion assay}

For the cell viability assays Caco-2 epithelial cells and rat brain endothelial cells were seeded to 96-well plates at the density of $6 \times 10^{3}$ cells/well (Orange Scientific) and cultured for 3-5 days. Confluent cultures were treated with peptides in phenol red free DMEM (Life Technologies, Gibco, Carlsbad, CA, USA) for 1 hour. In the case of PN159 peptide the treatments were also 1-hour long at concentrations of $1,3,10,30$ and $100 \mu \mathrm{M}$. MTT tests were performed at three different time points: (i) immediately after the 1-hour long treatment and at one-day recovery for all six peptides, (ii) at one-week recovery for PN159. To determine $100 \%$ toxicity cells were incubated with $1 \mathrm{mg} / \mathrm{ml}$ Triton X-100 detergent. After treatment the medium was changed and $0.5 \mathrm{mg} / \mathrm{ml}$ MTT solution was added to the cells for $3 \mathrm{~h}$ in a $\mathrm{CO}_{2}$ incubator. The metabolic activity of cells is reflected by the conversion of the yellow 3-(4,5-dimethyltiazol-2-yl)-2,5-diphenyltetrazolium bromide (MTT) dye to purple formazan. Formazan crystals were dissolved in DMSO and the amount of converted dye was determined by measuring absorbance at $595 \mathrm{~nm}$ wavelength with a microplate reader (Fluostar Optima, BMG Labtechnologies, Ortenberg, Germany). Cell viability/metabolic activity was calculated as percentage of dye conversion by nontreated cells.

\subsubsection{Impedance measurement}

Kinetics of epithelial and endothelial cell reaction to peptide treatment was monitored by impedance measurement at $10 \mathrm{kHz}$ (RTCA-SP instrument, ACEA Biosciences, San Diego, CA, USA). Impedance measurement is label-free, real time, noninvasive and correlates linearly with adherence, growth, number and viability of cells (Kiss et al., 2013; Kürti et al., 2012). For background measurements $50 \mu 1$ cell culture medium was added to the wells, then cells were seeded at a density of $6 \times 10^{3}$ cells/well to coated 96-well plates with integrated gold electrodes (E-plate 96, ACEA Biosciences). Cells were cultured for 5-7 days in $\mathrm{CO}_{2}$ incubator at $37^{\circ} \mathrm{C}$ and monitored every 10 minutes until the end of experiments. At the beginning of plateau phase of growth cells were treated with peptide solutions and the effects were followed for 24 hours. In the case of PN159 cells were also treated with peptide solutions at 1, 3, 10, 30 and $100 \mu \mathrm{M}$ concentrations at the beginning of the plateau phase of growth and the effects were followed for 24 hours. To measure cell recovery PN159 solutions were changed to culture medium and the impedance was monitored for one week. Culture medium was changed every 2 days. Triton X-100 detergent ( $1 \mathrm{mg} / \mathrm{ml})$ was used as reference compound inducing cell toxicity. 
Cell index was defined as $R_{n}-R_{b}$ at each time point of measurement, where $R_{n}$ is the cellelectrode impedance of the well when it contains cells and $R_{b}$ is the background impedance of the well with the medium alone.

\subsection{Measurement of the paracellular barrier integrity}

\subsubsection{Electrical resistance of cell layers}

Transepithelial or transendothelial electrical resistance (TEER) reflects the tightness of the intercellular junctions (Benson et al., 2013). TEER was measured by an EVOM volt-ohmmeter (World Precision Instruments, Sarasota, FL, USA) combined with STX-2 electrodes, and was expressed relative to the surface area of the monolayers as $\Omega \times \mathrm{cm}^{2}$. Resistance of cell-free inserts $\left(130 \Omega \times \mathrm{cm}^{2}\right)$ was subtracted from the measured values. For the measurement of barrier integrity Caco-2 cells were seeded onto Transwell inserts (Fig. 9A) and cultured for three weeks (Hellinger et al., 2012; Kiss et al., 2014). The BBB model was used after 4-5 days of co-culture (Fig. 9B). For both models culture medium was changed and resistance was checked every second day. Barrier models were used for permeability experiments when high TEER values reflecting tight intercellular junctions were measured.

\subsubsection{Permeability studies}

For permeability experiment inserts were transferred to 12-well plates (Figs. 9C and 9D) containing $1.5 \mathrm{ml}$ Ringer-Hepes buffer in the lower (basal/abluminal) compartments. In the upper (apical/luminal) compartments culture medium was replaced by $0.5 \mathrm{ml}$ buffer containing peptide solutions for 1 hour. Permeability marker molecules albumin (10 mg/ml; Mw: $65 \mathrm{kDa})$ labeled with Evans blue $(167.5 \mu \mathrm{g} / \mathrm{ml})$ and fluorescein $(10 \mu \mathrm{g} / \mathrm{ml}$; Mw: $376 \mathrm{Da})$ were added 30 minutes later. The incubation with permeability markers in the presence of peptides lasted for 30 minutes. Treatment solutions from both compartments were collected and after a gentle wash were changed for culture medium. Cells were kept in $\mathrm{CO}_{2}$ incubator at $37^{\circ} \mathrm{C}$ for 24 hours then after the measurement of TEER the permeability experiments were repeated.

To measure the transfer of opiorphin across the BBB model cell culture inserts were also transferred to 12 -well plates containing $1.5 \mathrm{ml}$ Ringer-Hepes solution in the lower or acceptor compartments. The peptide was dissolved in distilled water to yield a $10 \mathrm{mM}$ solution, which was further diluted in Ringer-Hepes buffer. In the upper or donor chambers culture medium was replaced by $0.5 \mathrm{ml}$ Ringer-Hepes buffer containing 
opiorphin at $10 \mu \mathrm{M}$ concentration. To measure peptide flux from the upper to lower compartment (blood to brain direction) the inserts were transferred at 30 and 60 minutes to new wells containing Ringer-Hepes solution. Samples were collected after the experiments and the opiorphin levels were detected by mass spectrometry.

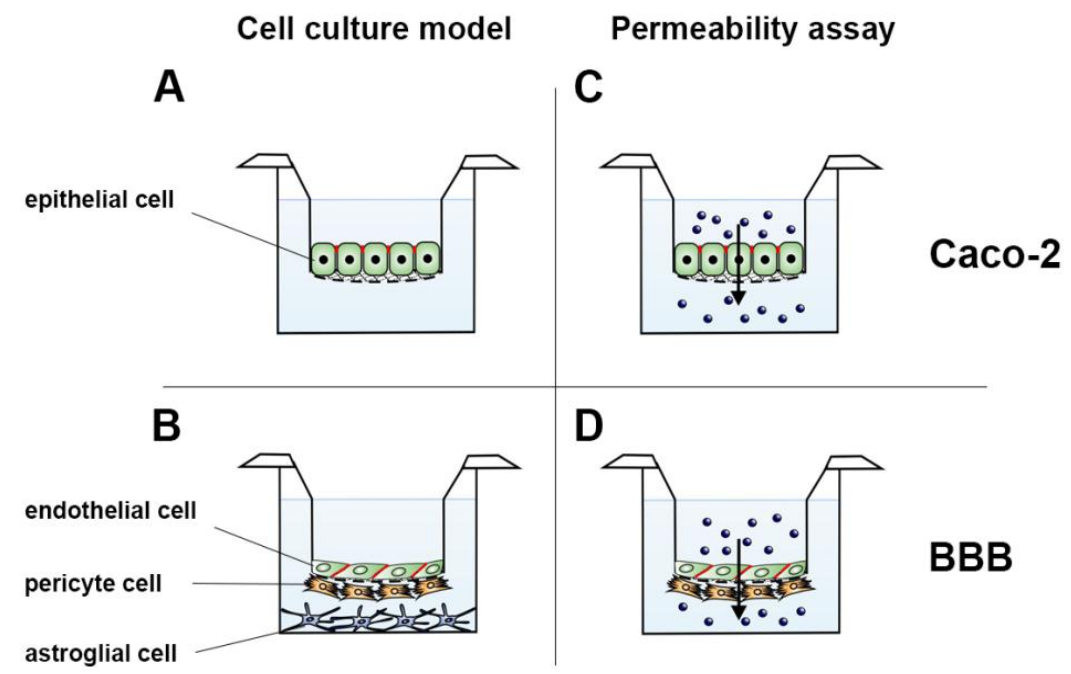

Figure 9. (A) Human Caco-2 cell line and (B) primary rat brain cells were cultured on Transwell inserts for (C-D) permeability assays.

The concentrations of the marker molecules of collected samples were determined by a fluorescence multi-well plate reader (Fluostar Optima; for fluorescein: excitation wavelength: $485 \mathrm{~nm}$, emission wavelength: $535 \mathrm{~nm}$; for Evans-blue labeled albumin excitation wavelength: $584 \mathrm{~nm}$, emission wavelength: $680 \mathrm{~nm}$ ). To test the reversibility of the peptide effect inserts with the cells were placed back to the culture plates containing medium after the permeability tests. Treatment solutions from the upper compartments were removed and after a gentle wash were changed for culture medium. Cells were kept in $\mathrm{CO}_{2}$ incubator at $37^{\circ} \mathrm{C}$ for 24 hours then after the measurement of TEER the permeability experiments were repeated.

In permeability experiments with PN159 $(10 \mu \mathrm{M})$ on Caco-2 cells fluorescein isothiocyanate (FITC)-labeled dextran marker molecules (Table 4) were used at $1 \mathrm{mM}$ concentrations, and fluorescence intensities of collected samples were measured using a Fluorolog FL3-22 spectrofluorometer (Horiba Jobin Yvon, Paris, France) using 492 nm excitation wavelength, $515 \mathrm{~nm}$ emission wavelength, and $0.5 \mathrm{~s}$ integration time. Drugs were used at $10 \mu \mathrm{M}$ concentrations and samples were measured by HPLC (Methods 3.12.). 
Table 4. Molecular weight of the tested FITC-labeled dextrans and drugs.

\begin{tabular}{|l|l|l|l|l|l|}
\hline Markers & Mw (Da) & Property & Drugs & MW (Da) & Property \\
\hline \hline FD-4 & 4.4 & hydrophilic & atenolol & 0.266 & lipophilic \\
\hline FD-10 & 9.4 & hydrophilic & cimetidine & 0.252 & lipophilic \\
\hline FD-20 & 17.2 & hydrophilic & quinidine & 0.324 & hydrophilic \\
\hline FD-40 & 35.6 & hydrophilic & verapamil & 0.4554 & hydrophilic \\
\hline
\end{tabular}

Abbreviation: FD, FITC-labeled dextran molecule; Mw, molecular weight.

The apparent permeability coefficients $\left(\mathrm{P}_{\text {app }}\right)$ were calculated as described previously (Kiss et al., 2014; Kürti et al., 2012). Briefly, cleared volume was calculated from the concentration difference of the tracer in the lower/basal compartment $\left(\Delta[\mathrm{C}]_{\mathrm{B}}\right)$ after 30 minutes and upper/apical compartments at 0 hour $\left([\mathrm{C}]_{\mathrm{A}}\right)$, the volume of the lower/basal compartment $\left(\mathrm{V}_{\mathrm{B}} ; 1.5 \mathrm{~mL}\right)$ and the surface area available for permeability $(\mathrm{A}$; $1.1 \mathrm{~cm}^{2}$ ) using this equation:

$$
\mathrm{P}_{\mathrm{app}}(\mathrm{cm} / \mathrm{s})=\frac{\Delta[C]_{A} \times V_{A}}{A \times[C]_{L} \times \Delta t}
$$

\subsection{Immunohistochemistry}

Morphological changes in epithelial and endothelial barrier integrity were followed by immunostaining for TJ proteins occludin, claudin-1 and -5, adherens junction protein Ecadherin and linker proteins $\beta$-catenin and ZO-1 after peptide treatments and one-day recovery. After treatments cells were washed with phosphate buffer (PBS), and fixed with 1:1 mixture of ice cold acetone and methanol for 10 minutes at room temperature. After blocking with $3 \%$ bovine serum albumin in PBS cells were incubated with primary antibodies rabbit anti-occludin, mouse anti-claudin-5 and anti-claudin-1, mouse anti-Ecadherin, rabbit anti-ZO-1, and rabbit anti- $\beta$-catenin (Life Technologies, Carlsbad, CA, USA) overnight. Incubation with secondary antibodies Alexa Fluor-488-labeled antimouse (Life Technologies, Invitrogen, USA) and Cy3-labeled anti-rabbit lasted for 1 hour. Hoechst 33342 was used to stain cell nuclei. After mounting the samples (Fluoromount-G; Southern Biotech, Birmingham, USA) staining was visualized by a Leica TCS SP5 confocal laser scanning microscope (Leica Microsystems GmbH, Wetzlar, Germany).

\subsection{Quantitative real-time PCR}

Gene expression analysis was performed as described recently by our group (Tóth et al., 2014). Confluent cultures were washed, scraped, collected and cell pellets were used 
for total RNA isolation using RNAqueous-4PCR Kit (Life Technologies, Ambion, Austin, TX, USA). cDNA synthesis was performed by High Capacity cDNA Reverse Transcription Kit (Life Technologies). The expression of occludin and the selected claudin genes were analyzed by quantitative PCR using TaqMan Low Density Array 384-well microfluidic cards preloaded with inventoried TaqMan Gene Expression Assays (Appendix, Publication II, Supplementary material; Life Technologies, Applied Biosystems, Austin, TX, USA). Expression of all genes was normalized to the 18S rRNA as endogenous control, highly expressed in eukaryotic cells. Expression values of studied genes were determined by the correlation of normalized expression of genes calculated by $2^{-\Delta \mathrm{Ct}}$ formula to the lowest expression level which can be safely detected by this method.

\subsection{Microscale thermophoresis}

Association between PN159 peptide and claudins was measured with microscale thermophoresis (Jarabek-Willemsen et al., 2011). The claudins carried yellow fluorescence protein (Piontek et al., 2011) and the peptide was added in defined amounts as titration series (in PBS, 15 dilutions). After incubation (1 hour, $22^{\circ} \mathrm{C}$ ), samples were loaded into standard treated capillaries, and fluorescence was measured with Monolith ${ }^{\mathrm{TM}}$ NT.115 (light-emitting diode power $50 \%$, infrared laser power $80 \%$, laser-on time $35 \mathrm{~s}$ ). Evaluation was performed with NT Analysis software 1.2.229 (NanoTemper, Munich, Germany). Binding was characterized by dissociation constant $\left(\mathrm{K}_{\mathrm{d}}\right)$. Determination was achieved using saturation-binding curves obtained at equilibrium (Dabrowski et al., 2015).

\subsection{Molecular modeling}

Protein structures were obtained by homology modeling using the MODELLER program package (Sali and Blundell, 1993). First, the structure of mouse claudin-15 was completed by homology modelling because its $\mathrm{x}$-ray structure file is lacking the fragment of residues from 34 to 41 (Suzuki et al., 2014). Human claudins 1, 3, 4, 5 and 7 were homology modeled using the completed mouse claudin-15 as a template. The protein homology models were further relaxed by a short (400 ns) molecular dynamics simulation in which the proteins were embedded in a 95 by $95 \AA$ POPC bilayer-water system containing $150 \mathrm{mM} \mathrm{NaCl}$. Molecular dynamics simulations were performed by the program NAMD using the CHARMM27 molecular force field with CMAP correction (Phillips et al., 2005). The results were visualized by VMD v1.9.1 (Humphrey et al., 1996). 
The docking studies were performed by the CABS docking server and the resulted C-alpha traces were reconstructed by MODELLER using the python script supplied by the server homepage (Kurcinski et al., 2015).

\subsection{Circular dichroism spectroscopy}

Far-UV circular dichroism (CD) spectra of PN159 peptide were recorded at $25^{\circ} \mathrm{C}$ temperature on a J-810 spectropolarimeter (JASCO International Co. Ltd., Tokyo, Japan). The CD spectra were measured between $260 \mathrm{~nm}$ and $185 \mathrm{~nm}$ with an optical pathlength of $1 \mathrm{~mm}$, at a peptide concentration of $0.1 \mathrm{mg} / \mathrm{ml}$ in Milli-Q water diluted directly from powder. The bandwidth was $2 \mathrm{~nm}$ and data pitch $0.5 \mathrm{~nm}$, the scan speed was set to $100 \mathrm{~nm} / \mathrm{min}$ and the integration time was $1 \mathrm{~s}$. Ten spectra were accumulated and plotted. The data were analyzed by CDSSTR method on the Dichroweb server. To test the stability of the peptide structure the $\mathrm{CD}$ spectra were recorded between $25{ }^{\circ} \mathrm{C}$ and $95{ }^{\circ} \mathrm{C}$ temperature with a ramp rate of $5{ }^{\circ} \mathrm{C} / \mathrm{min}$ on a JASCO J-810 spectropolarimeter by using a Peltier sample holder. The CD spectra were measured immediately between 260 and $185 \mathrm{~nm}$ with an optical pathlength of $1 \mathrm{~mm}$, the peptide concentration was $0.1 \mathrm{mg} / \mathrm{ml}$ in Milli-Q water. The bandwidth was $2 \mathrm{~nm}$ and data pitch $1 \mathrm{~nm}$, the scan speed was set to $100 \mathrm{~nm} / \mathrm{min}$ and the integration time was $1 \mathrm{~s}$, five spectra were accumulated and plotted.

\subsection{HPLC analytical procedures}

Analytical measurements were performed on a Merck-Hitachi LaChrom HPLC system equipped with an UV and a fluorescence detector (Merck, Darmstadt, Germany). All reagents were used of analytical reagent grade. Atenolol and verapamil were determined by using a Gemini C18 column $(150 \times 3 \mathrm{~mm}, 5 \mu \mathrm{m}, 110 \AA$; Phenomenex Inc., Torrance, CA, USA) operated at $0.5 \mathrm{ml} /$ minute flow rate, maintained at $35^{\circ} \mathrm{C}$. For atenolol measurements isocratic elution was applied with a mixture of $300 \mathrm{ml}$ methanol, $400 \mathrm{ml}$ $100 \mathrm{mM}$ ammonium acetate, $20 \mathrm{ml} 10 \%$ ammonium-hydroxide and $2 \mathrm{ml} 0.1 \mathrm{M}$ ethylenediaminetetraacetic acid. Mobile phase for verapamil consisted of $350 \mathrm{ml}$ methanol with $250 \mathrm{ml} 20 \mathrm{mM}$ ammonium acetate and $2 \mathrm{ml} 10 \%$ trifluoroacetic acid with isocratic elution, at $0.5 \mathrm{ml} / \mathrm{minute}$ flow rate. UV detection for atenolol was performed at $270 \mathrm{~nm}$ while for verapamil $230 \mathrm{~nm}$ wavelength was adjusted. The calibration curve was linear $\left(\mathrm{r}^{2}=0.9999\right)$ over a range of $0.01-1.5 \mu \mathrm{M}$ for atenolol. The calibration curve for verapamil also showed a good linearity within the examined concentration range of $0.01-1 \mu \mathrm{M}$ $\left(r^{2}=0.9952\right)$. In both cases $10 \mu$ sample was injected into the chromatographic system. 
Samples at higher than $1 \mu \mathrm{M}$ atenolol and verapamil concentrations were $10 \times$ diluted with Ringer-Hepes solution.

HPLC measurement of quinidine was performed using a YMC Pack Pro C18 column (RS $150 \times 2.1 \mathrm{~mm}, 5 \mu \mathrm{m}, 80 \AA$; YMC America Inc., Allentown, PA, USA) equipped with a guard column operated at $0.2 \mathrm{ml} /$ minute flow rate. The chromatographic column was maintained at $40{ }^{\circ} \mathrm{C}$ and $5 \mu \mathrm{l}$ sample was injected onto the column. The elution of quinidine was performed with a buffer containing a mixture of $100 \mathrm{ml}$ methanol, $250 \mathrm{ml} 0.1 \%$ ammonium acetate, and $4 \mathrm{ml} 10 \%$ trifluoroacetic acid. Quinidine was quantified at 250/430 $\mathrm{nm}$ excitation/emission wavelengths. The calibration curve was linear over the quantitation range of $0.01-1 \mu \mathrm{M}\left(\mathrm{r}^{2}=0.9984\right)$.

HPLC measurement of cimetidine was performed using a Gemini NX column $(150 \times 4.6 \mathrm{~mm}, 3 \mu \mathrm{M})$ equipped with a guard column operated at $0.8 \mathrm{ml} /$ minute flow rate. The column temperature was maintained at $40{ }^{\circ} \mathrm{C}$ and $20 \mu \mathrm{l}$ sample was injected onto the chromatographic system. A buffer comprising of $15 \%$ acetonitrile and $85 \% 100 \mathrm{mM}$ ammonium acetate was utilized for the isocratic elution of cimetidine. UV detection was set at $228 \mathrm{~nm}$. The calibration curve was linear $\left(\mathrm{r}^{2}=0.9999\right)$ over the range of 0.01-10 $\mu \mathrm{M}$.

\subsection{Mass spectrometry}

LC-MS experiments were performed on a nanoAcquity UPLC (Waters) on-line coupled to an Orbitrap-Elite (Thermo Scientific) hybrid tandem mass spectrometer operated in the positive ion mode. Five $\mu l$ of the samples containing opiorphin peptide was injected onto a trapping column (Waters Symmetry C18; $180 \mu \mathrm{m} \times 20 \mathrm{~mm}, 5 \mu \mathrm{m}$ particle size) and after washing with $1 \%$ solvent $\mathrm{B}$ for 5 minutes was transferred onto the separating column (Dionex Acclaim PepMap;75 $\mu \mathrm{m} \times 25 \mathrm{~cm}, 2 \mu \mathrm{m}$ particle size, $100 \AA$ pore size) developing a linear gradient of 1-35\% solvent B in 10 minutes using a flow rate of $200 \mathrm{nl} /$ minute (solvent A: $0.1 \%$ formic acid/water; solvent $\mathrm{B}: 0.1 \%$ formic acid/acetonitrile). For MS experiments, mass range of m/z: 200-600 was monitored at resolution of 60000 using internal calibration to the background polysiloxane ion (m/z:445.120024). Relative quantity of opiorphin was estimated using the extracted ion chromatogram (XIC) of m/z: $347.1932( \pm 5 \mathrm{ppm})$ peak intensity corresponding to the doubly charged opiorphin peptide cation. 


\subsection{Electron microscopy}

Cells grown on culture inserts were treated with $10 \mu \mathrm{M}$ PN159 peptide for 30 minutes and fixed immediately after treatment or after a 1-day recovery. Cells were briefly washed with PBS and fixed with $3 \%$ paraformaldehyde containing $0.5 \%$ glutaraldehyde in cacodylate buffer ( $\mathrm{pH}$ 7.4) for 30 minutes at $4{ }^{\circ} \mathrm{C}$. After washing with the buffer several times, cells were postfixed in $1 \% \mathrm{OsO}_{4}$ for 30 minutes. Following a rinse with distilled water, the cells were block stained with $1 \%$ uranyl acetate in $50 \%$ ethanol for 30 minutes, dehydrated in graded ethanol and after the last step of dehydration inserts were placed in the 1:1 mixture of ethanol and Taab 812 (Taab; Aldermaston, Berks, UK) for 30 minutes at $30{ }^{\circ} \mathrm{C}$. Finally, the membranes of the culture inserts with the cells were removed from their support and embedded in Taab 812. Polymerization was performed overnight at $60{ }^{\circ} \mathrm{C}$. Ultrathin sections were cut perpendicularly for the membrane using a Leica EM UC6 ultramicrotome (Nussloch, Germany) and picked up on formvar-coated single-slot copper grids. The sections were examined using a Hitachi 7100 transmission electron microscope (Hitachi Ltd., Tokyo, Japan) and a side-mounted Veleta CCD camera (Olympus Soft Imaging Solutions). Altogether 105 non-overlapping images from the 3 groups at the same magnification were analyzed for the presence or absence of tight junctions (control group $n=28$; PN159 group $n=42$; recovery group $n=35$ ).

\subsection{Holographic phase contrast microscopy}

Caco-2 epithelial cells were treated with $10 \mu \mathrm{M}$ PN159 peptide or culture medium in glass-bottom cell-culture dishes (MatTek Corp., Ashland, MA, USA) for 30 minutes. Digital holographic images were taken by the HoloMonitor M3 instrument (Phase Holographic Imaging AB, Phiab, Sweden) of control cells, peptide treated cells, and cultures after peptide treatment followed by a 1-day recovery. Cell morphological changes were analyzed by the Holostudio 2.4 software (Phase Holographic Imaging AB, Phiab, Sweden).

\subsection{Statistical analysis}

For statistical analysis GraphPad Prism 5.0 software (GraphPad Software Inc., San Diego, USA) was used. All data presented are means \pm SD. Values were compared using analysis of variance followed by Dunnett's test and t-test. Changes were considered statistically significant at $p<0.05$. All measurements were repeated three times, the number of parallel samples was minimum three. 


\section{RESULTS}

\subsection{Opiorphin penetration across a BBB culture model}

MS/MS characterization of the synthetic opiorphin peptide was performed using both collision induced dissociation and higher energy collisional activation. The observed $\mathrm{m} / \mathrm{z}$ value of the protonated peptide ions and fragmentation pattern were in good agreement with those expected for the QRFSR sequence (Fig. 10A). Signal intensities in the receiver compartment samples were $1.5 \times 10^{8}$ as opposed to $1-2 \times 10^{6}$ in the donor compartment samples. The relative quantity of opiorphin which penetrated through the BBB model was calculated to be $2.91 \pm 1.13 \%$ based on the area under curve of the doubly charged opiorphin peptide ion $\mathrm{m} / \mathrm{z}$ 347.1932. As a comparison, $0.41 \pm 0.03 \%$ of fluorescein and $0.03 \pm 0.01 \%$ of albumin crossed the brain endothelial cell layers in parallel inserts from the same cell isolation under identical assay conditions.

The clearance of opiorphin is shown on Fig. 10B. $\mathrm{P}_{\text {app }}$ of opiorphin was $0.53 \pm 1.36 \times 10^{-6} \mathrm{~cm} / \mathrm{s} \quad(\mathrm{n}=4)$. In parallel inserts from the same cell isolation under identical assay conditions the $\mathrm{P}_{\text {app }}$ of fluorescein was $1.03 \pm 0.09 \times 10^{-6} \mathrm{~cm} / \mathrm{s}(\mathrm{n}=4)$ and that of albumin $0.07 \pm 0.04 \times 10^{-6} \mathrm{~cm} / \mathrm{s}(\mathrm{n}=4)$.

A

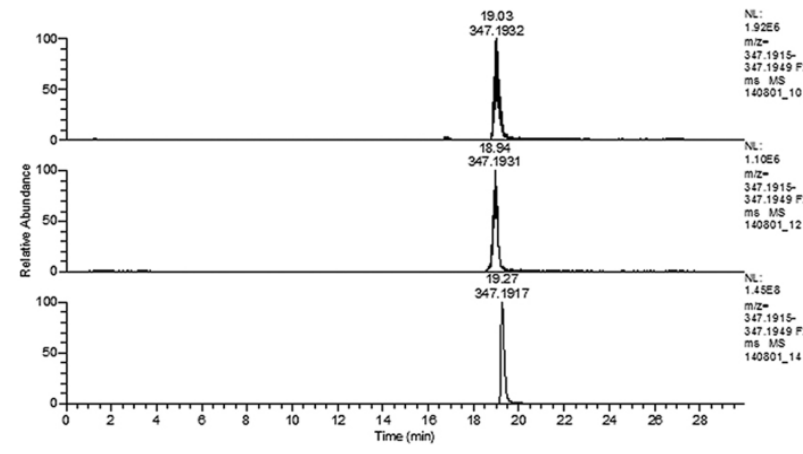

B

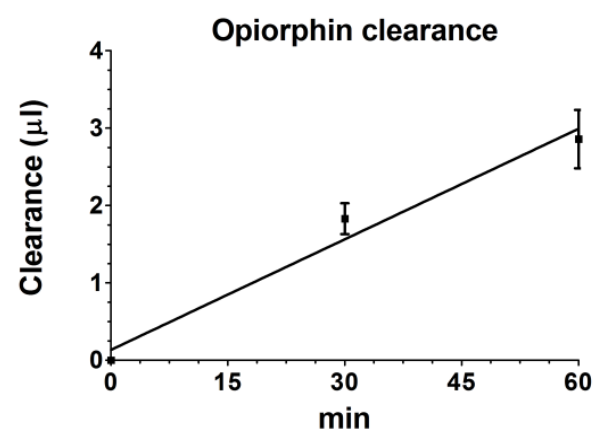

Figure 10. (A) Extracted ion chromatograms of m/z: $347.1932 \pm 5$ ppm corresponding to the doubly charged peptide ion of opiorphin. Upper panel: sample from the receiver compartment ("brain side") after 30 minutes incubation, middle panel: sample from the receiver compartment after 60 minutes incubation, bottom panel: sample from the donor compartment ("blood side") after 60 minutes incubation. Peak labels denote retention time and $\mathrm{m} / \mathrm{z}$ value. $(\mathrm{n}=4)$. (B) Clearance of opiorphin across the BBB model at 30 and 60 minutes (mean \pm $\mathrm{SD}, \mathrm{n}=4)$.

We have also observed rapid conversion of $\mathrm{N}$-terminal glutamine into pyroglutamic acid both in $0.1 \%$ formic acid and in Ringer-Hepes buffer used for BBB penetration experiments. We monitored the pyroglutamic acid containing peptide using its calculated molecular mass (monoisotopic Mw: 675.3453 yielding a doubly charged protonated peptide ion $\mathrm{m} / \mathrm{z}: 338.6799(\mathrm{z}=2))$. 


\subsection{Effect of TJ modulator peptides on cell viability}

Based on the colorimetric endpoint dye conversion MTT assay treatments with peptides for one hour did not cause significant change in the metabolic activity of Caco-2 epithelial (Fig. 11A) or brain endothelial cells (Fig. 11B). Impedance measurement, a sensitive method to detect cellular effects revealed no decrease for a 1-hour treatment in Caco-2 cells (Fig. 11C). Brain endothelial cells were more sensitive; ADT-6, HAV-6 and AT-1002 peptides caused 15-20\% decrease in cell layer impedance after 1-hour treatment. As a comparison Triton X-100 caused $100 \%$ toxicity in both assays (Fig. 11).
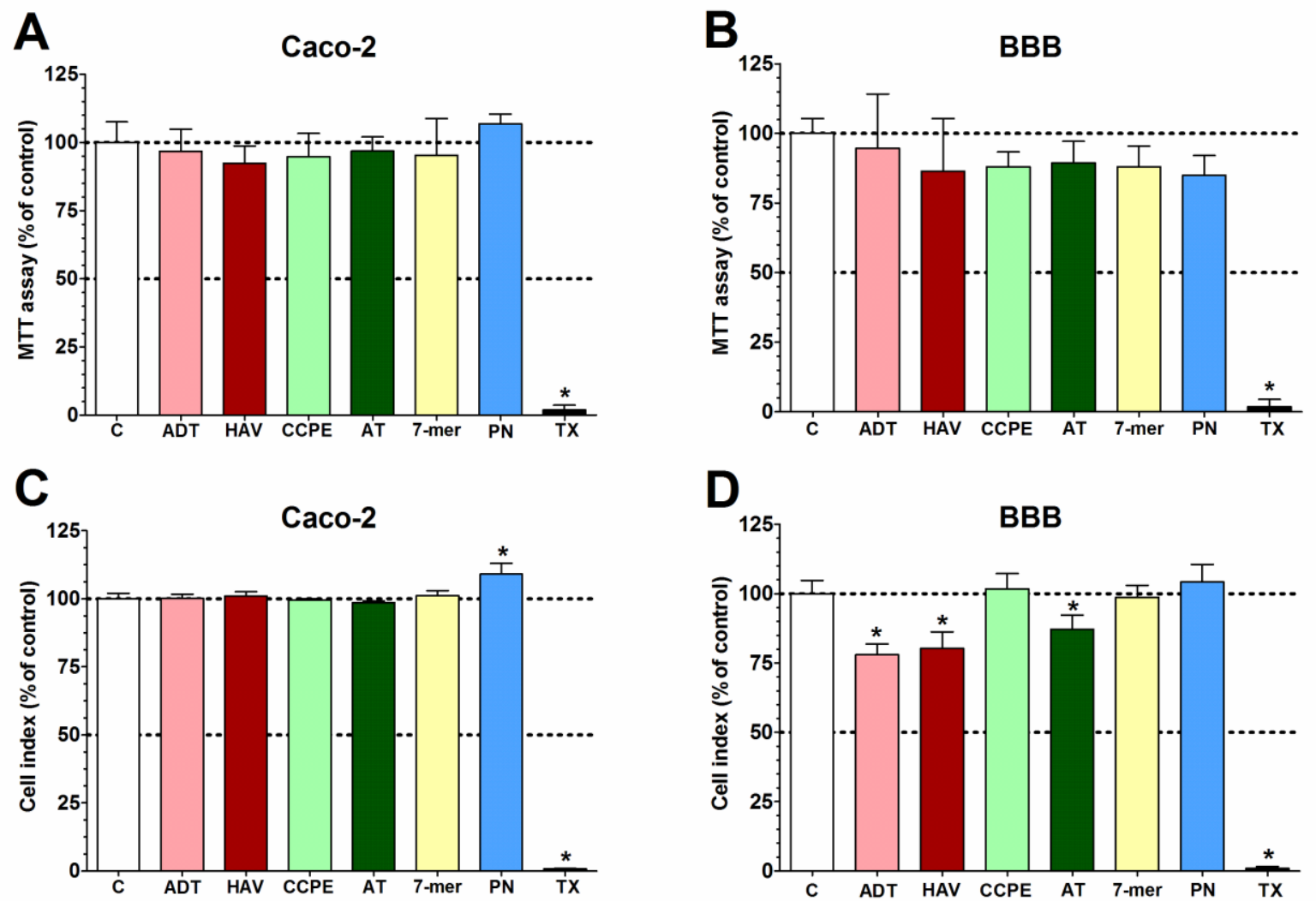

Figure 11. Cell viability assays after 1 hour treatment with TJ modulator peptides. Peptide concentrations were the following: $2 \mathrm{mM}$ for ADT-6, HAV-6 and AT-1002, $1 \mathrm{mM}$ for C-CPE, $100 \mu \mathrm{M}$ for 7 -mer, and $10 \mu \mathrm{M}$ for PN159. (A) The toxicity of peptides on Caco-2 intestinal epithelial cells and (B) brain endothelial cells were measured by MTT dye conversion assay. The effect of peptides on the impedance of (C) epithelial and (D) brain endothelial cell layers are shown as cell index. The MTT and cell index are given as percent of control (100\% viability). Values are presented as means $\pm \mathrm{SD}, \mathrm{n}=3-8$. Statistical analysis: ANOVA followed by Dunnett's test, $p<0.05$ as compared with the control groups. 
Long-term effect of peptides on epithelial and endothelial barriers was also determined (Fig. 12). In Caco-2 layers no change was seen in impedance except for a temporary increase after PN159 peptide treatment. In brain endothelial cells only AT-1002 and C-CPE peptides decreased significantly the cell index after 24 hours.
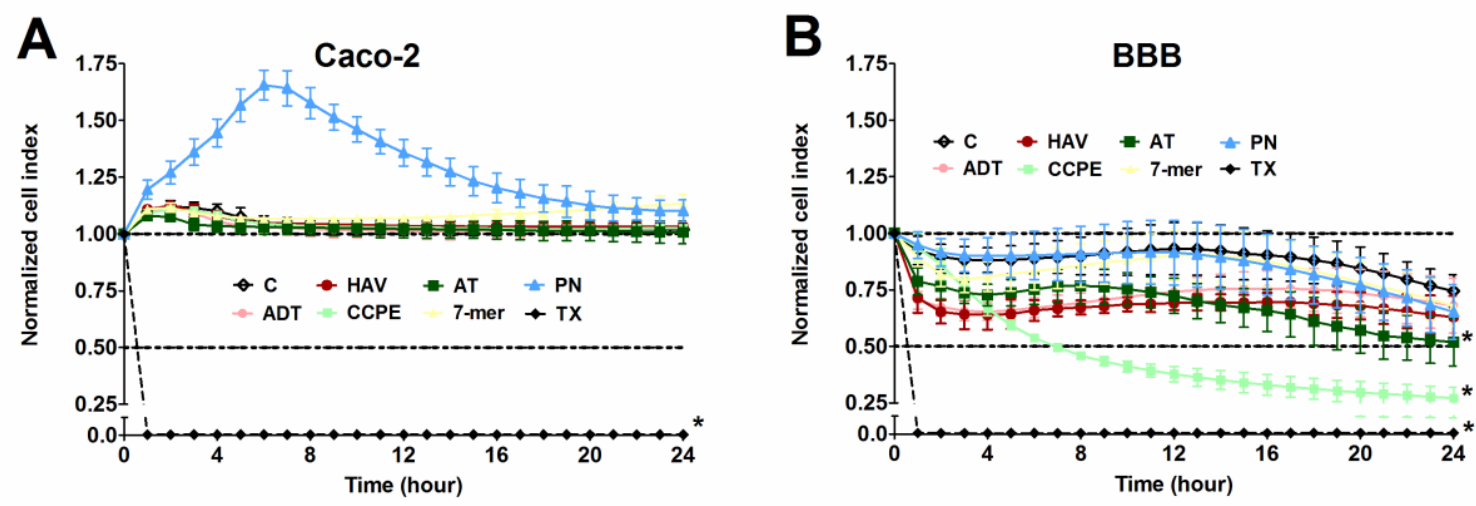

Figure 12. Kinetics of peptide effects on the impedance of (A) epithelial and (B) brain endothelial cell layers. Values are presented as means $\pm \mathrm{SD}, \mathrm{n}=3-8$. Statistical analysis: ANOVA followed by Dunnett's test; $p<0.05$, significant differences in peptide-treated groups at 24 hours as compared with control groups.

The effects of peptides with scrambled sequences (Table 3) were tested on epithelial cells at the same concentrations, as negative controls. Peptides did not cause significant decrease in the cell index until 24 hours (Fig. 13).

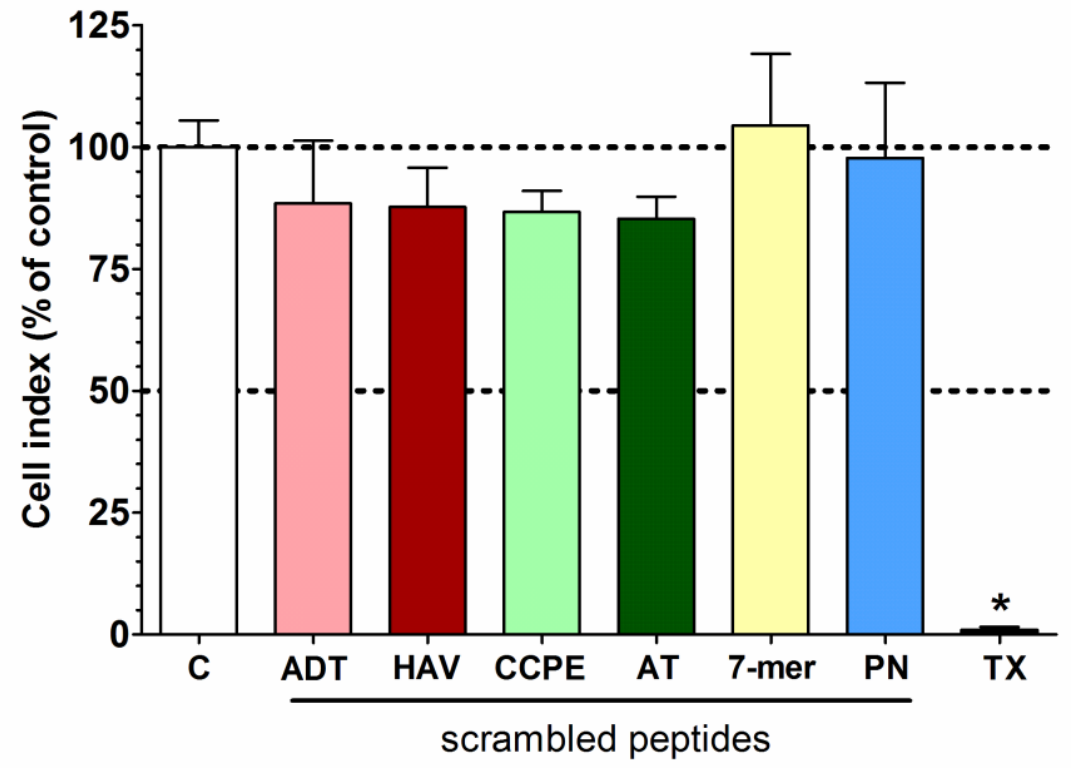

Figure 13. Effects of 24-hour treatment with scrambled peptides on Caco-2 epithelial cell viability. Data are shown as cell index in percentage of control group. Data are presented as means $\pm \mathrm{SD}, \mathrm{n}=3-6$. Statistical analysis: ANOVA followed by Dunett's test. Statistically significant differences are $p<0.05$, compared with control group. 


\subsection{Effect of $\mathbf{T J}$ modulator peptides on barrier integrity}

\subsubsection{Effect of modulator peptides on electrical resistance}

All six peptides significantly decreased the TEER of Caco-2 layers after 1-hour treatment (Fig. 14A). Treatments with ADT-6, C-CPE and PN159 reduced the resistance of cell layers by more than 50\%, while 7-mer, HAV-6 and AT-1002 caused a 30-45\% drop as compared to control $\left(1309 \pm 97 \Omega \times \mathrm{cm}^{2}\right)$. The resistance of brain endothelial monolayers was also decreased by the peptides, except C-CPE peptide, which had no significant effect (Fig. 14B). The TJ modulator peptides caused less than $50 \%$ reduction of TEER compared to control (314 $\left.\pm 48 \Omega \times \mathrm{cm}^{2}\right)$. PN159 peptide was the most effective on both models (Fig. 14). Barrier integrity was recovered in both models in all treatment groups after 24 hours.
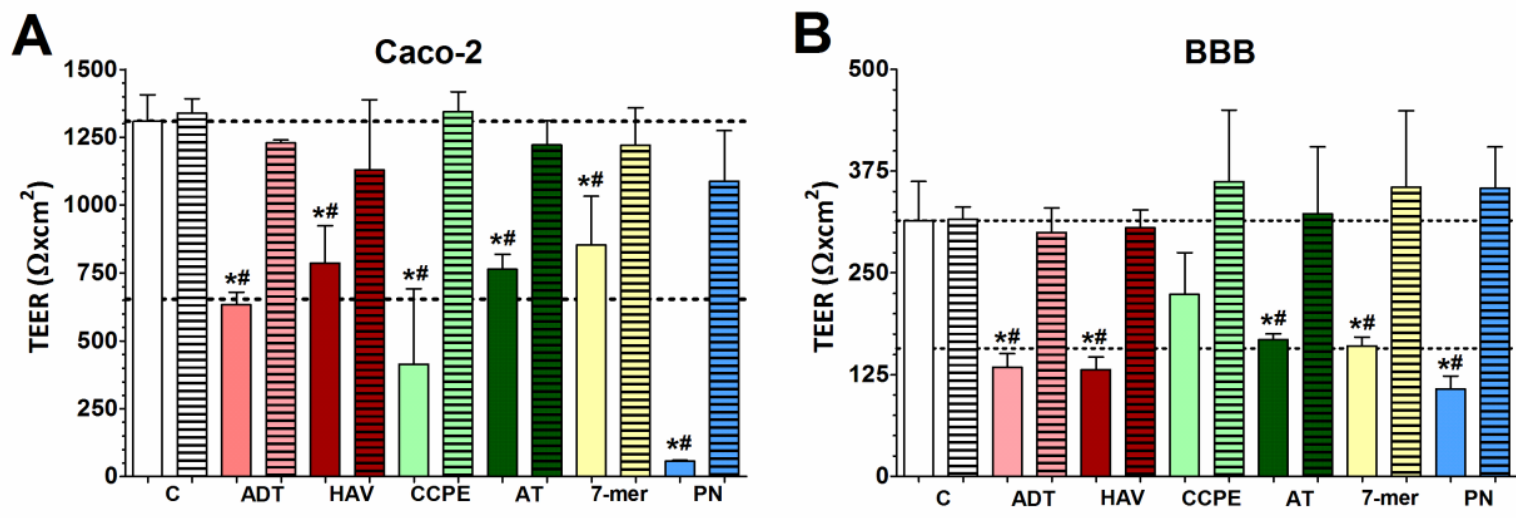

Figure 14. Effects of modulator peptides on the resistance of Caco-2 epithelial (A) and brain endothelial (B) cell layers. Empty columns represent the effect of 1-hour peptide treatment and striped columns show resistance after 24-hour recovery. Data are presented as means $\pm \mathrm{SD}, \mathrm{n}=3-6$. Statistical analysis: ANOVA followed by Dunett's test. Statistically significant differences are: $*, p<0.05$, compared to control group (Caco-2: $1309 \pm 97 \Omega \times \mathrm{cm}^{2}$; BBB: $314 \pm 48 \Omega \times \mathrm{cm}^{2}$ ); \#, $p<0.05$ compared to control group value 24 hours later (Caco-2: $1338 \pm 53 \Omega \times \mathrm{cm}^{2}$; BBB: $350 \pm 60 \Omega \times \mathrm{cm}^{2}$ ).

\subsubsection{Effect of modulator peptides on permeability of cell layers}

The modulator peptides increased the permeability of Caco-2 layers for fluorescein and albumin markers (Figs. 15A and 15B). ADT-6, HAV-6 and especially PN159 peptides were the most effective. PN159 peptide increased the epithelial permeability for fluorescein more than 200-fold and for albumin around 30-fold. The 7-mer peptide had no effect on fluorescein flux, but increased the permeability of albumin. On the BBB model AT-1002, 7-mer and PN159 peptides significantly enhanced the permeability of both markers (Figs. 15C and 15D). AT-1002 and 7-mer peptides increased the flux of markers 
3.5-6-fold, while PN159 peptide showed the highest effect with about 10-fold increase. In the BBB model E-cadherin peptides had a small effect on fluorescein, but not on albumin penetration, while C-CPE had no effect. Permeability assays were repeated after 24-hour recovery and the TJ modulating effect of the peptides were reversible on both Caco-2 and BBB models.
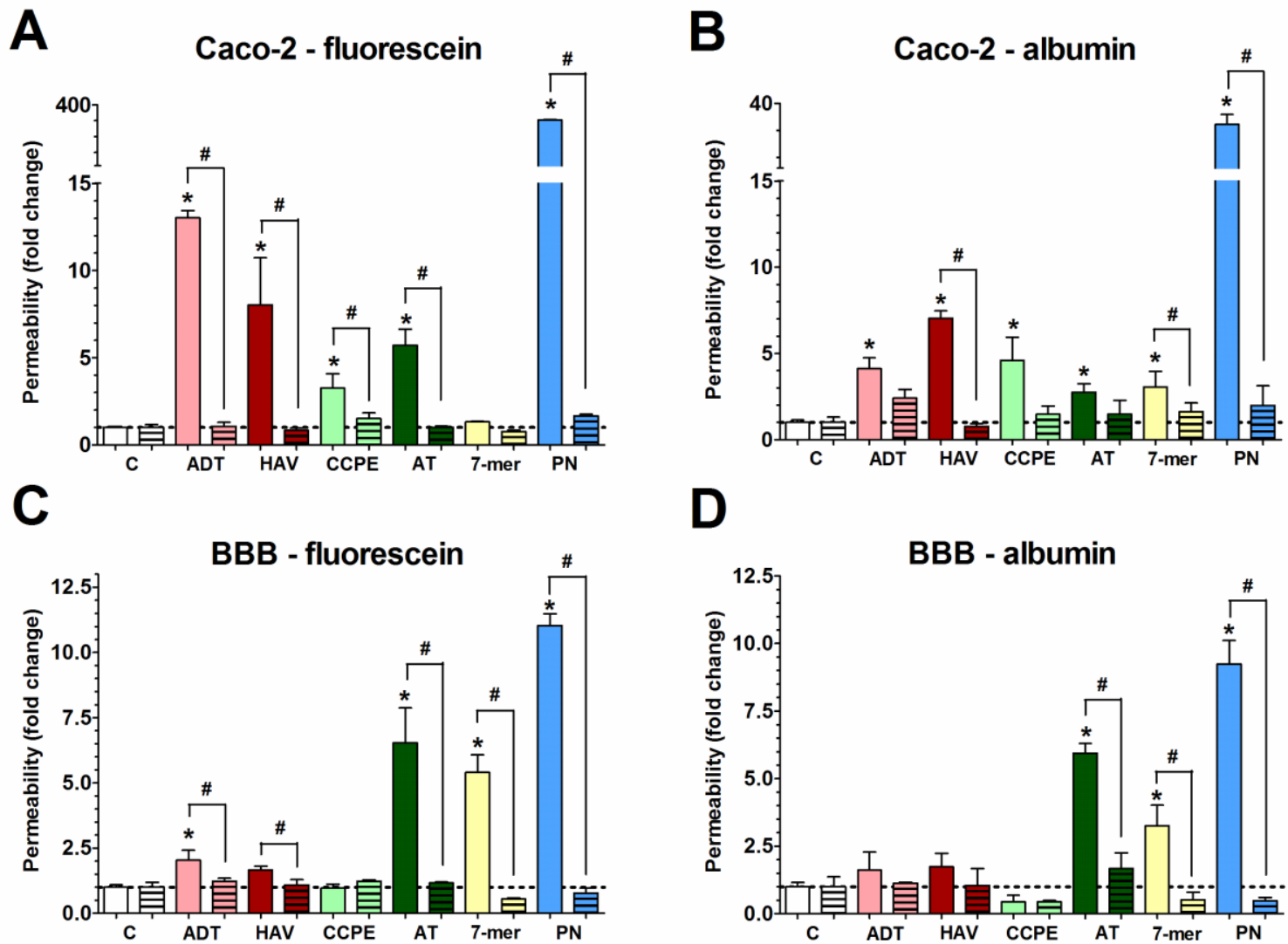

Figure 15. Evaluation of barrier integrity on Caco-2 epithelial (A and B) and brain endothelial cell layers (C and D). Permeability (A, C) for fluorescein and (B, D) for albumin after 1-hour treatment with modulator peptides and after 24-hour recovery. Empty columns represent the effect of 1-hour peptide treatment and striped columns show permeability after 24-hour recovery. Values of apparent permeability coefficients $\left(\mathrm{P}_{\text {app }}\right)$ in the respective control groups were: (A) fluorescein $\mathrm{P}_{\text {app }}$ in Caco-2: $0.20 \pm 0.02 \times 10^{-6} \mathrm{~cm} / \mathrm{s}$, and $0.30 \pm 0.02 \times 10^{-6} \mathrm{~cm} / \mathrm{s} ;(B)$ albumin $\mathrm{P}_{\text {app }}$ in Caco-2: $0.26 \pm 0.01 \times 10^{-6} \mathrm{~cm} / \mathrm{s}$ and $0.27 \pm 0.01 \times 10^{-6} \mathrm{~cm} / \mathrm{s} ;(\mathrm{C})$ fluorescein $\mathrm{P}_{\text {app }}$ in BBB model: $3.10 \pm 0.26 \times 10^{-6} \mathrm{~cm} / \mathrm{s}$ and $3.42 \pm 0.62 \times 10^{-6} \mathrm{~cm} / \mathrm{s}$; (D) albumin $\mathrm{P}_{\text {app }}$ in $\mathrm{BBB}$ model: $1.59 \pm 0.2 \times 10^{-6} \mathrm{~cm} / \mathrm{s}$ and $1.61 \pm 0.57 \times 10-6 \mathrm{~cm} / \mathrm{s}$. Data is expressed in the \% of control groups. Values are presented as means $\pm \mathrm{SD}, \mathrm{n}=3-6$. Statistical analysis: ANOVA followed by Dunett's test and ttest. Statistically significant differences were detected after treatment with peptides $(p<0.05)$ as compared with the control group $(*)$ and compared with each peptides (\#) after recovery. 
Scrambled peptides had no influence on intestinal barrier integrity. Neither fluorescein nor albumin permeability changed after 1-hour treatment (Fig. 16).
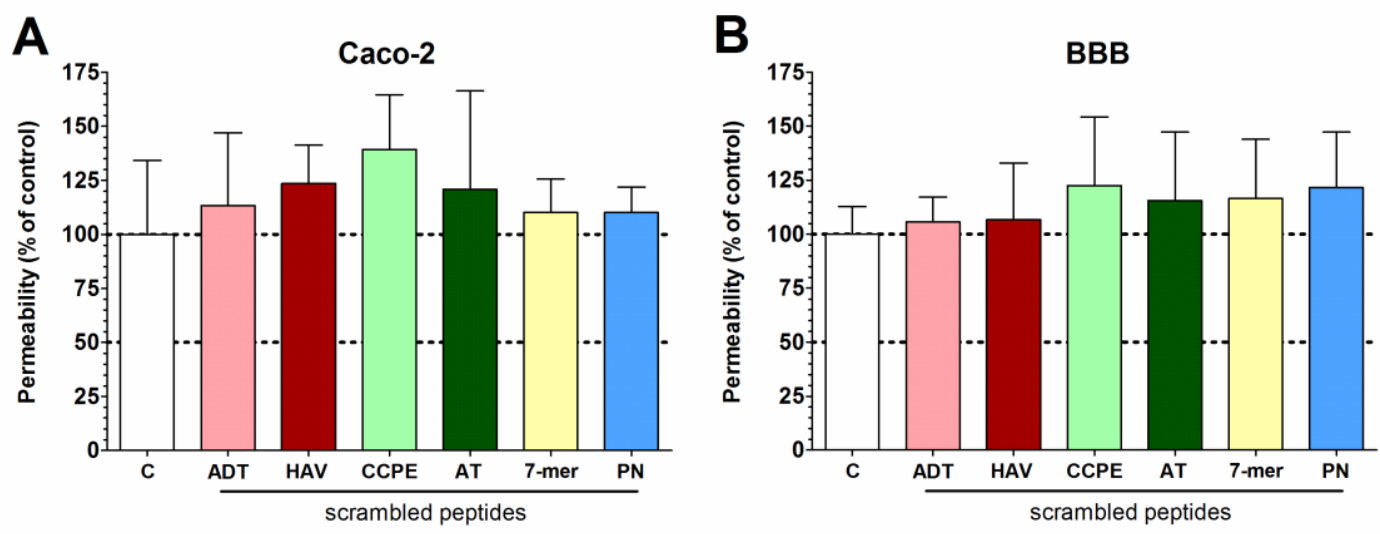

Figure 16. Permeability of Caco-2 cell layers for (A) fluorescein and (B) albumin after 1-hour treatment with scrambled peptides in the same concentration as Figure 15. Values of apparent permeability coefficients $\left(\mathrm{P}_{\text {app }}\right)$ in the control groups were for fluorescein: $0.2 \pm 0.06 \times 10^{-6} \mathrm{~cm} / \mathrm{s}$; for albumin: $0.17 \pm 0.02 \times 10^{-6} \mathrm{~cm} / \mathrm{s}$. Data are presented as means $\pm \mathrm{SD}, \mathrm{n}=3-6$. Statistical analysis: ANOVA followed by Dunett's test. Statistically significant differences are $p<0.05$, compared with control group.

\subsection{Effect of TJ modulator peptides on the morphology of intercellular junctions}

In both culture models the cells were tightly apposed and all junctional proteins were localized at the intercellular connections forming pericellular belts in control groups (Figs. 17-18). The E-cadherin peptides had robust effects on junctions of Caco-2 cells, fragmentation of $\beta$-catenin and E-cadherin stainings at the cell border and redistribution of the immunostaining to the cytoplasm was observed (Fig. 17). Microbial toxin C-CPE peptide caused visible changes in ZO-1, $\beta$-catenin and occludin immunostaining, labeling at the cell borders markedly decreased. AT-1002 and 7-mer peptides had slight effect on these junctional proteins. ZO-1 immunolabeling was less changed for peptide treatments except PN-159. Epithelial junctional morphology was drastically changed by PN159, ZO-1 and $\beta$-catenin proteins partially disappeared from cell borders. Occludin immunostaining in several cells became absent in cell contacts, enriched in the cytoplasm and showed spotty staining pattern. All peptides, except C-CPE, influenced junctional morphology at the BBB model (Fig. 18). E-cadherin peptides, AT-1002 and 7-mer peptides had similar effects on immunostaining of ZO-1, $\beta$-catenin and claudin-5 proteins, labeling was less sharp on cell borders, gaps and holes appeared between the cells. PN159 peptide caused the biggest change in immunostainings for all three proteins in brain endothelial cell junctions (Fig. 18). A strong decrease of the staining at the cell border was accompanied by an increase in staining over cell bodies. The morphological changes caused by the peptides were reversible after 24-hour recovery in both models (Figs. 17-18). 


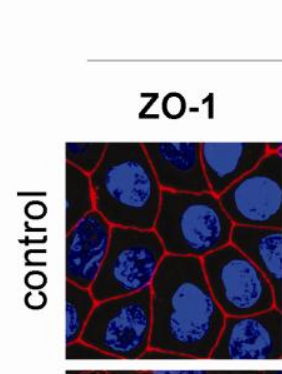

\section{Treatment}
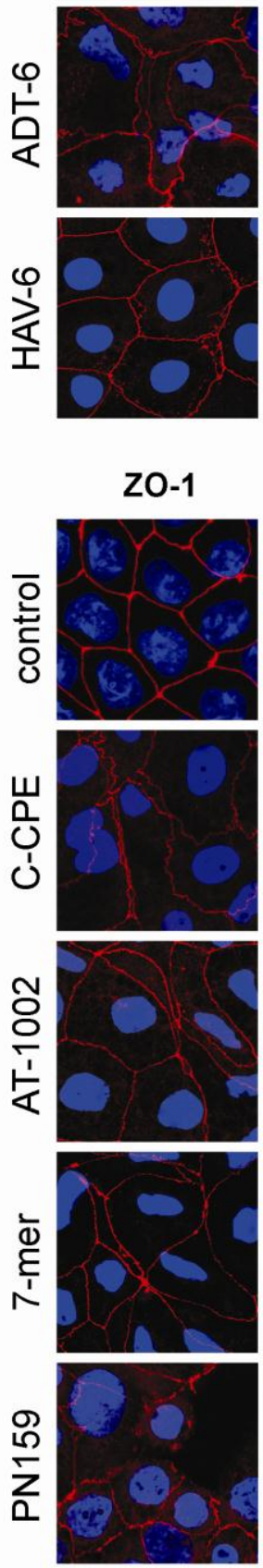
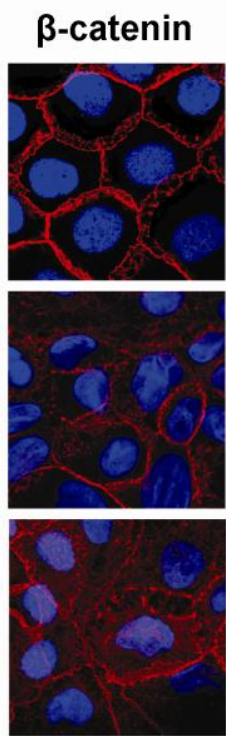

$\beta$-catenin
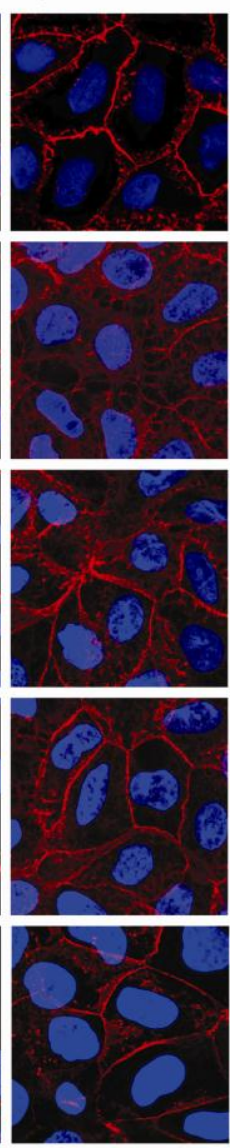
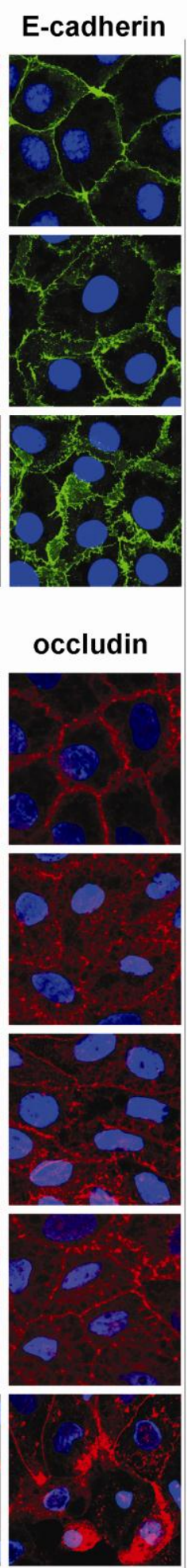

Recovery
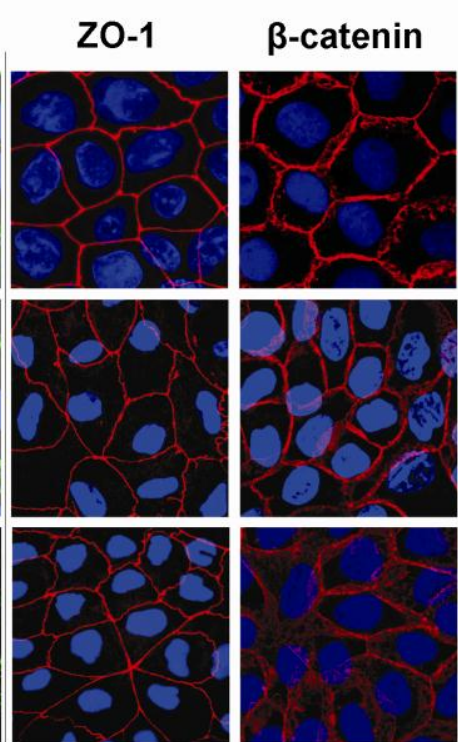

E-cadherin
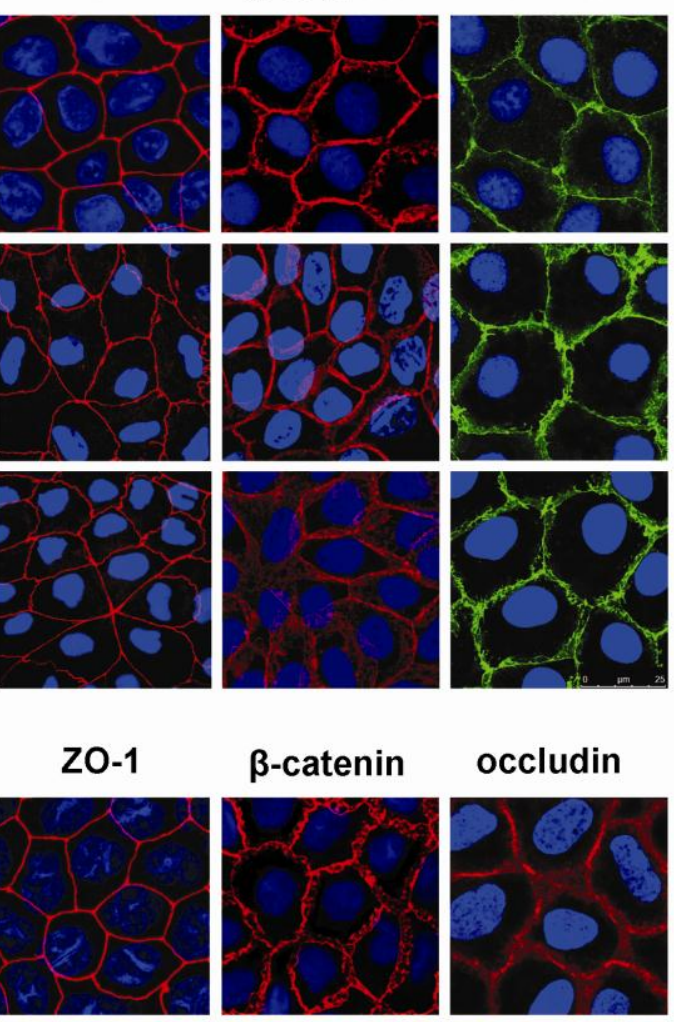

occludin
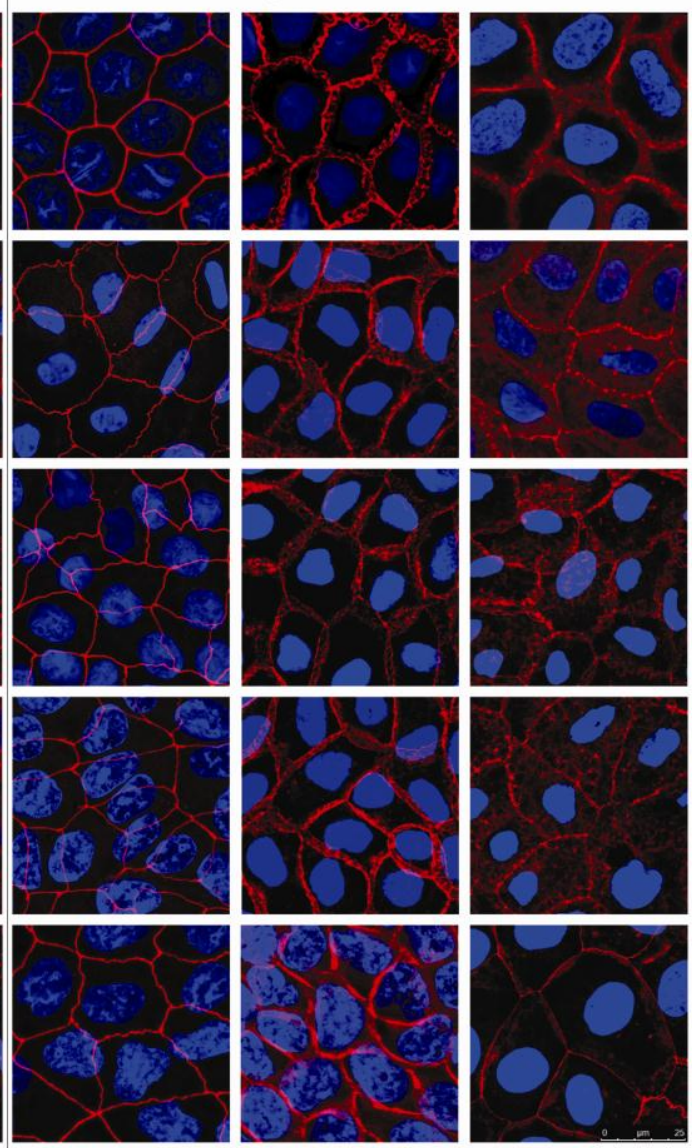

Figure 17. Effects of TJ modulator peptides on junctional morphology of Caco-2 cells. Immunostaining for occludin and zonula occludens-1 (ZO-1) tight junction proteins, and $\beta$-catenin and E-cadherin adherens junction proteins after 1-hour peptide treatment and 24-hour recovery. Red color: immunostaining for ZO-1, $\beta$-catenin and occludin. Green color: immunostaining for E-cadherin. Blue color: staining of cell nuclei. Bar $=25 \mu \mathrm{m}$. 


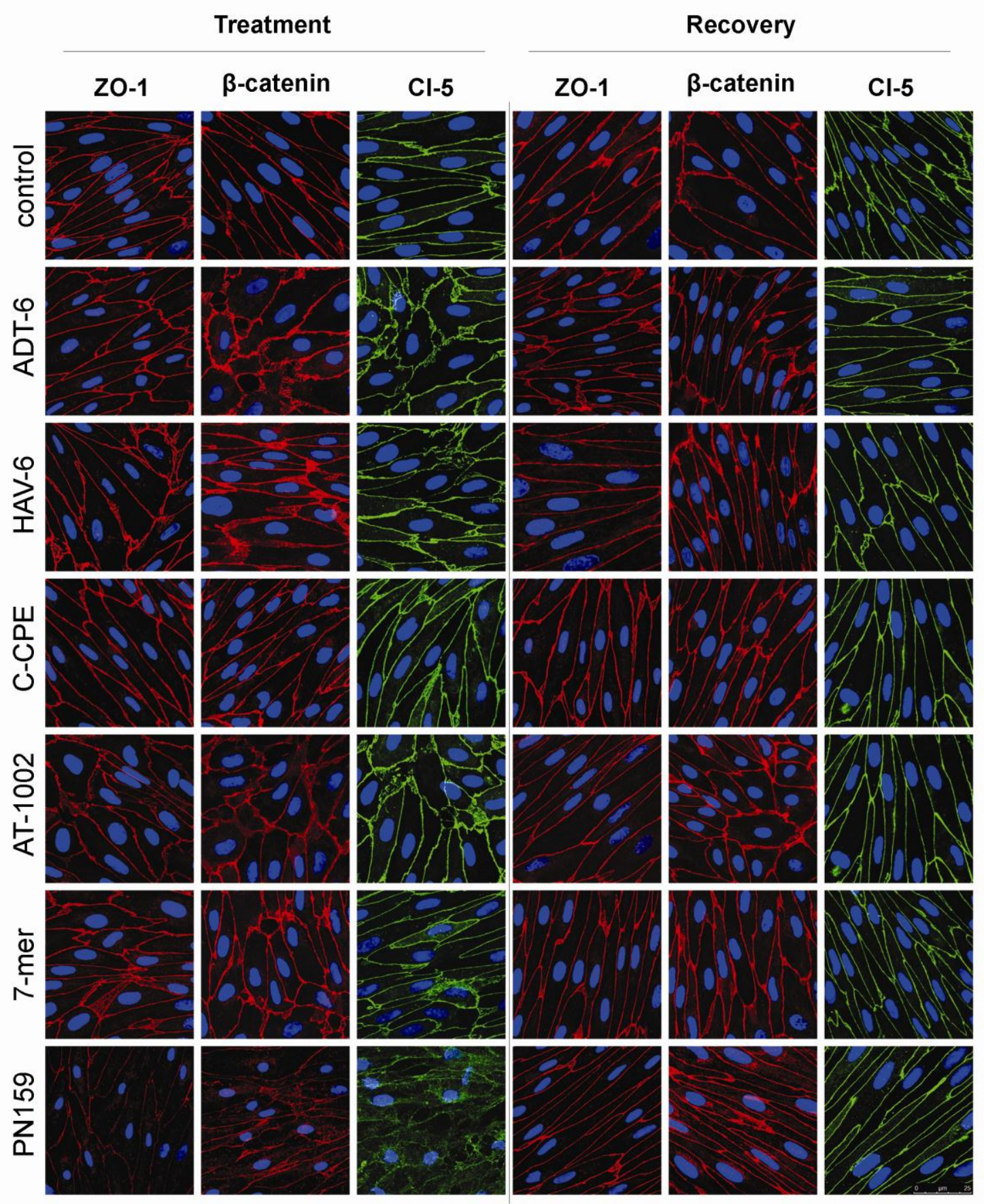

Figure 18. Effects of TJ modulator peptides on junctional morphology of brain endothelial cells. Immunostaining for claudin-5 and ZO-1 tight junction proteins, and $\beta$-catenin adherens junction protein after 1-hour peptide treatment and 24-hour recovery. Red color: immunostaining for ZO-1 and $\beta$-catenin. Green color: immunostaining for claudin-5. Blue color: staining of cell nuclei. Bar $=25 \mu \mathrm{m}$.

\subsection{Gene expression of occludin and claudins}

Occludin mRNA was highly expressed in both models (Fig. 19). In Caco-2 cells the expression of claudin-1, $-3,-4$ and -7 genes were the highest, while claudin $-5,-11$, and -19 were not expressed. In contrast, in brain endothelial cells claudin-5 mRNA was the most 
abundant, similarly to isolated brain capillary data. High levels of claudin-11 and -15 and lower levels of claudin-1 and -3 mRNA were measured in our culture BBB model. No expression of genes of claudin- $7,-8,-14,-16$ was measured in the BBB model. Claudin-18 was not found in the cultures.

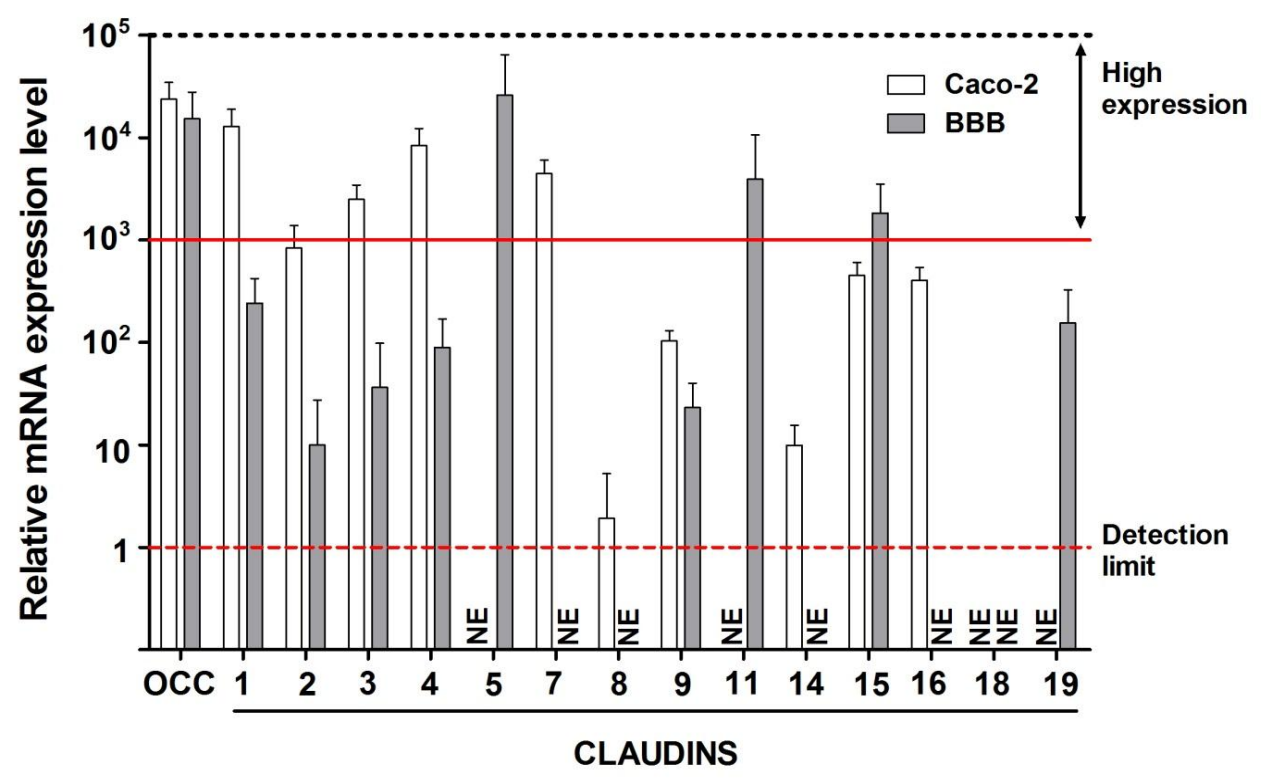

Figure 19. Gene expression level of occludin and selected claudins in Caco-2 epithelial and brain endothelial cells.

\subsection{Affinity measurements of peptides to claudin proteins}

High affinity binding of PN159 was detected by microscale thermophoresis to claudin-5-YFP $\left(\mathrm{K}_{\mathrm{d}}: 327 \mathrm{nM}\right)$ and claudin-1-YFP $\left(\mathrm{K}_{\mathrm{d}}: 820 \mathrm{nM}\right)$. Unspecific binding $\left(\mathrm{K}_{\mathrm{d}}>4000 \mathrm{nM}\right)$ was measured for claudin-3-YFP and YFP (negative control) (Figs. 20A and 20B).

A

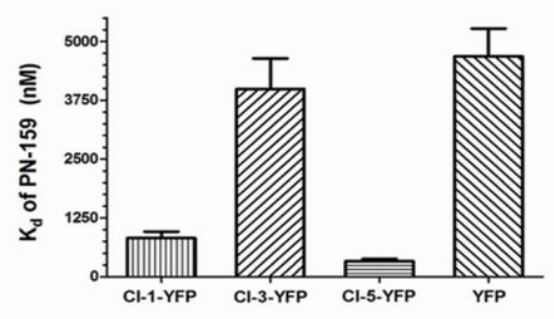

B

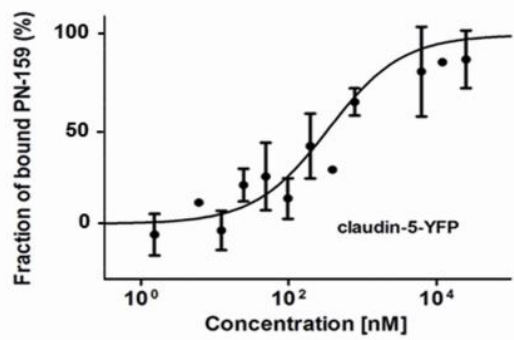

Figure 20. (A) Affinity measurements of the peptide PN159 to full-length claudins and (B) binding curve for claudin-5-YFP. The association was measured by microscale thermophoresis. YFP, yellow fluorescent protein; $\mathrm{K}_{\mathrm{d}}$, dissociation constant. 


\subsection{Dose dependent effect of PN159 peptide on viability, barrier integrity and morphology of epithelial cells}

\subsubsection{Effect of PN159 peptide on Caco-2 cell viability - MTT test}

As a follow-up work to the comparative study the most effective peptide, PN159 was further examined for safety and efficacy on Caco-2 epithelial cells. The colorimetric endpoint dye conversion MTT assay reflects the metabolic activity and viability of cells. MTT test was performed at three different time points after 1-hour treatment with different PN159 peptide concentrations: (i) immediately after the 1-hour treatment, (ii) at one-day recovery and (iii) at one-week recovery (Fig. 21). Low concentrations of the peptide (1$10 \mu \mathrm{M})$ did not decrease cell viability, while cell damage was found at higher 30 and $100 \mu \mathrm{M}$ concentrations. The cytotoxic effect of PN159 at $100 \mu \mathrm{M}$ concentration was not reversible after one day or one week.

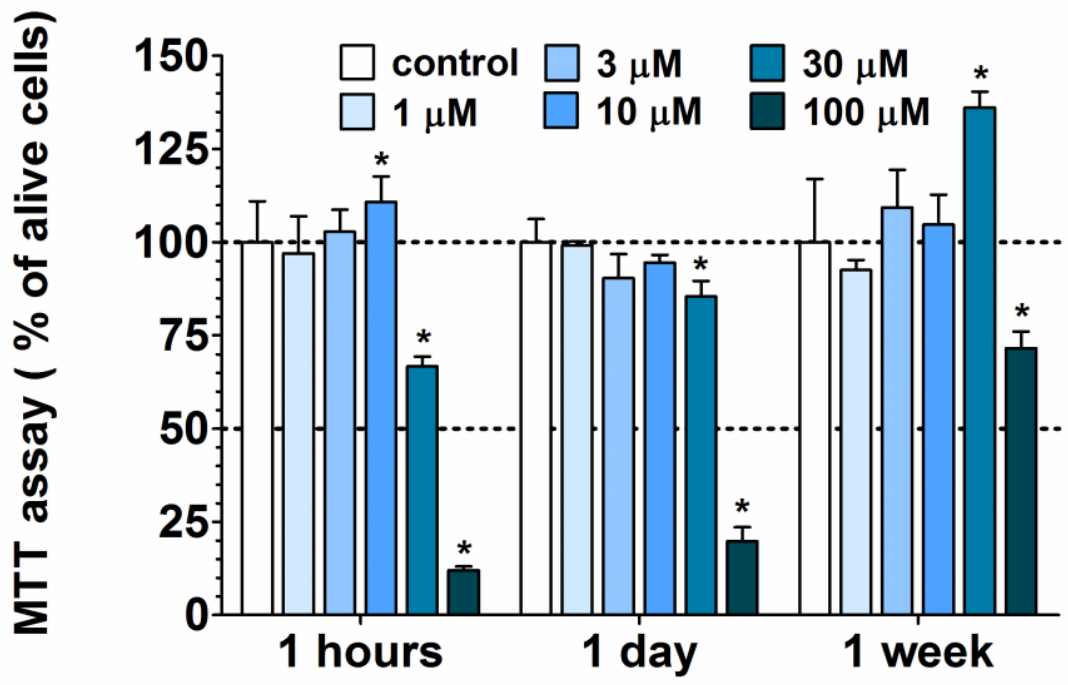

Figure 21. MTT assay after 1-hour treatment with PN159 peptide followed by 1 hour, 1 day or 1 week recovery. The MTT values are given as percent of control (100\% viability). Values are presented as means $\pm \mathrm{SD}, \mathrm{n}=3-8$. Statistical analysis: ANOVA followed by Dunnett's test, $p<0.05$ as compared with the control groups.

\subsubsection{Effect of PN159 peptide on Caco-2 cell viability - impedance}

Kinetics of PN159 effects on Caco-2 cells were followed by real-time impedance measurements (Fig. 22). Only the two highest peptide concentrations decreased the cell impedance after 1-hour treatment indicating cell damage (Fig. 22A), similarly to the results of the MTT assay. Based on both tests PN159 peptide treatment for 1 hour was non-toxic at $10 \mu \mathrm{M}$ and lower concentrations, reversible at $30 \mu \mathrm{M}$ and toxic at the highest $100 \mu \mathrm{M}$ concentration. 
Similar results were obtained by impedance measurement on Caco-2 cells treated with PN159 for 1 day, except for $100 \mu \mathrm{M}$ (Fig. 22B). Because of its toxicty, the $100 \mu \mathrm{M}$ concentration was not used in further experiments.
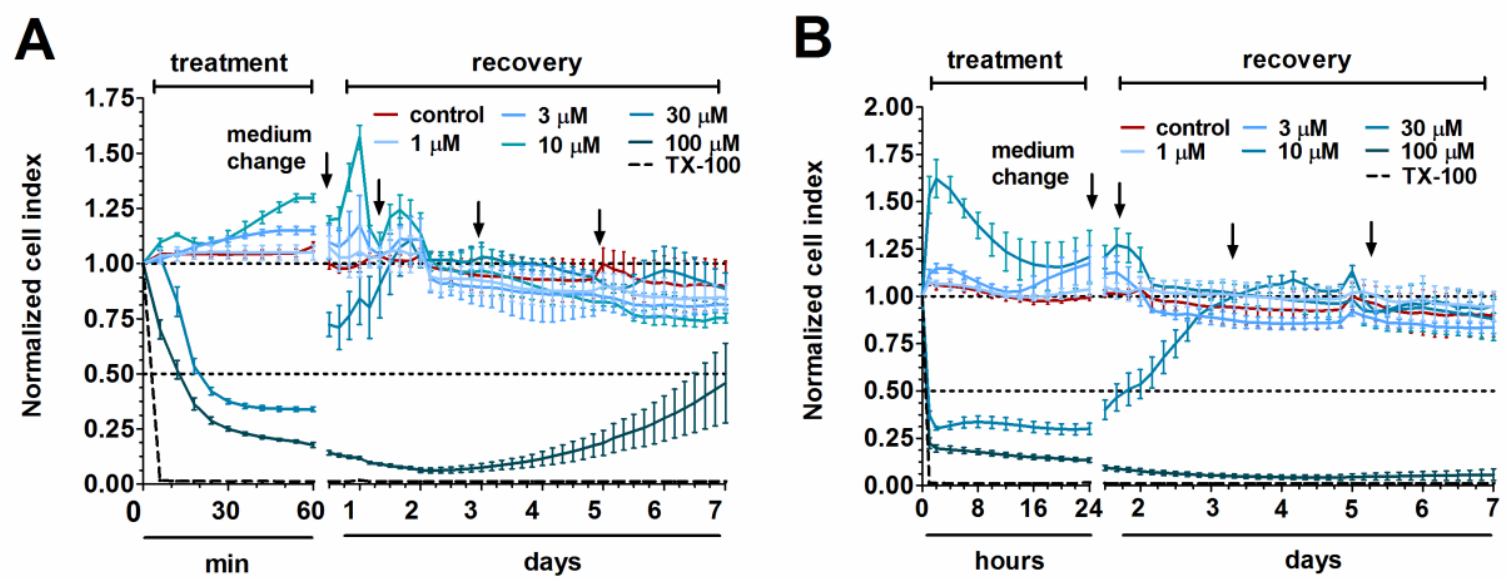

Figure 22. Impedance measurements after (A) 1-hour treatment and (B) one-day treatment followed by a recovery phase of 1 week. The effects of PN159 peptide on the impedance were shown as cell index. Values are presented as means $\pm \mathrm{SD}, \mathrm{n}=3-8$. Arrows indicate change of culture medium.

\subsubsection{Effect of PN159 peptide on electrical resistance and permeability of Caco-2 cells}

All tested concentrations of PN159 peptide significantly decreased the resistance of epithelial cell layers (Fig. 23A). The two highest 10 and $30 \mu \mathrm{M}$ concentrations opened the paracellular barrier the most causing 80-90\% decrease in TEER. In concordance, these two highest concentrations of PN159 showed the most effective permeability enhancer activity for both fluorescein and albumin (Fig. 23B).

A

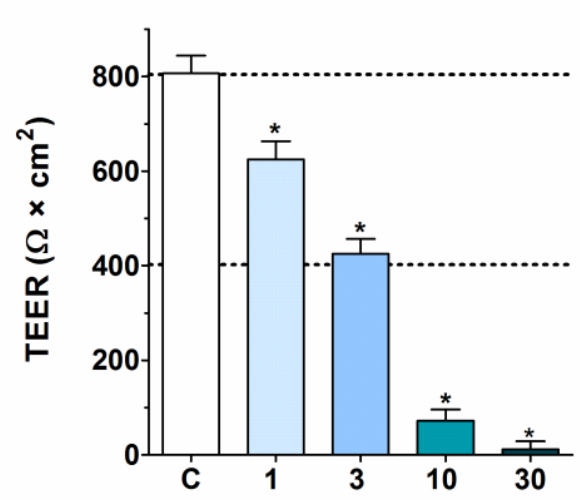

B

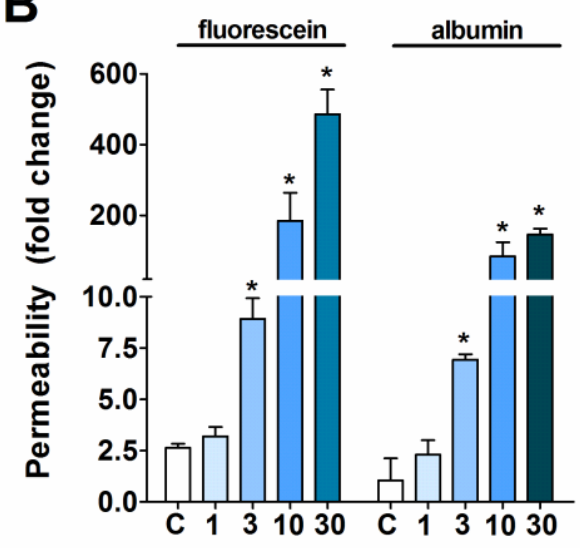

Figure 23. (A) Evaluation of barrier integrity on Caco-2 cell layers by measurement of transepithelial electrical resistance (TEER). (B) Caco-2 cell layer permeability for fluorescein and albumin marker molecules $\left(\mathrm{P}_{\text {app }} \mathrm{A}-\mathrm{B} 10^{-6} \mathrm{~cm} / \mathrm{s}\right)$. Values are presented as means $\pm \mathrm{SD}, \mathrm{n}=3-8$. Statistical analysis: ANOVA followed by Dunnett's test, $p<0.05$ as compared with the control groups. 


\subsubsection{Effect of PN159 peptide on junctional staining of Caco-2 cells}

The concentration-dependent effects of the peptide on epithelial viability and barrier integrity were confirmed by immunostaining of junctional proteins claudin-1, ZO-1 and $\beta$-catenin in Caco-2 cells (Fig. 24). Claudin-1 staining was the most sensitive to the peptide treatment, in concordance with the barrier integrity data. PN159 at concentrations of 10-100 $\mu \mathrm{M}$ caused a drastic change in epithelial junctional morphology.

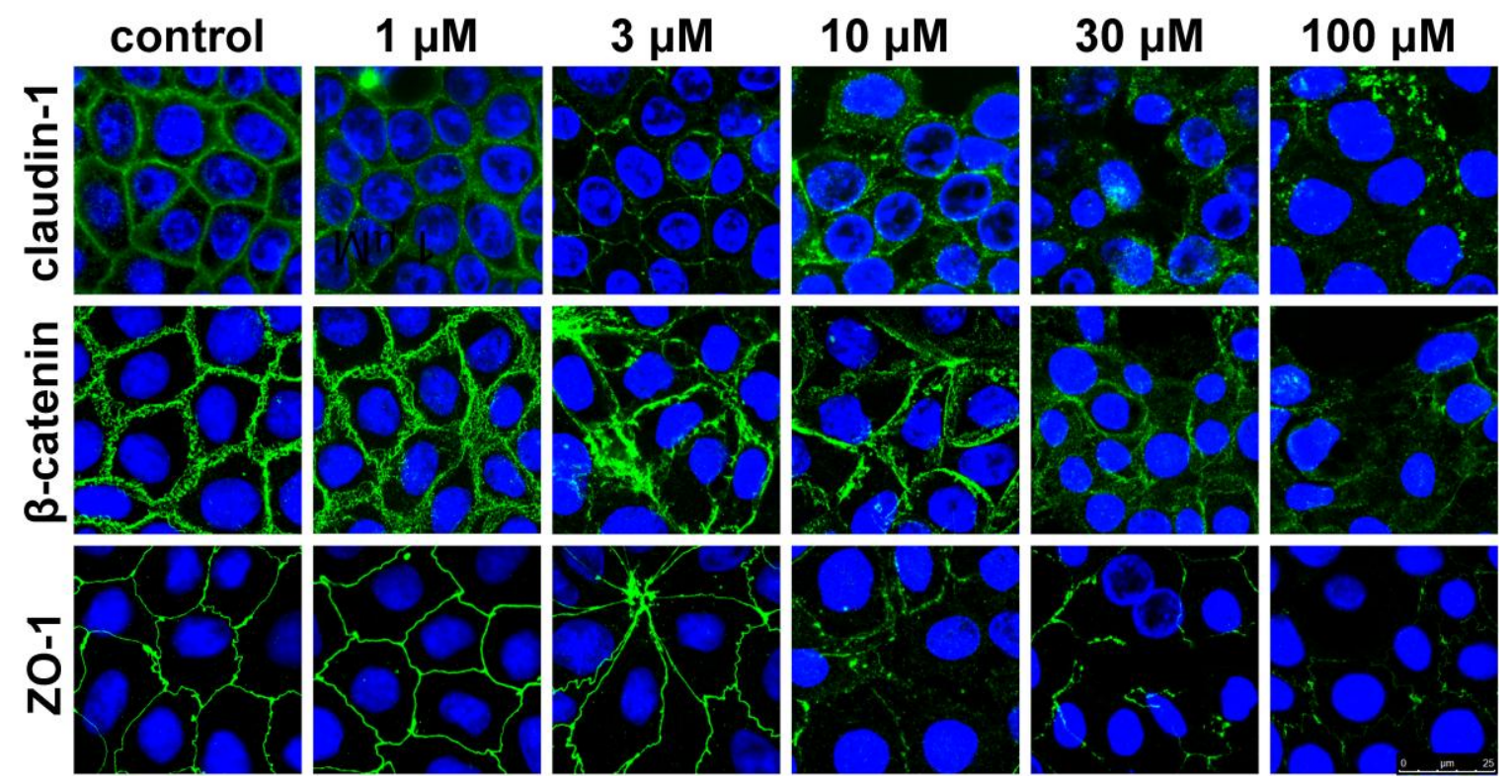

Figure 24. Effects of PN159 peptide on junctional morphology of Caco-2 cells. Immunostaining for claudin1 , zonula occludens-1 (ZO-1) and $\beta$-catenin junctional proteins are shown in control conditions or after 1hour peptide treatment. Green color: immunostaining for ZO-1, $\beta$-catenin and claudin-1. Blue color: staining of cell nuclei. Bar $=25 \mu \mathrm{m}$.

Because the peptide was safe for the cells but effectively opened the barrier at $10 \mu \mathrm{M}$, this concentration was selected to reveal the kinetics of the reversibility of barrier opening, and to investigate its effects on drug penetration.

\subsection{Reversible effect of PN159 peptide on electrical resistance and ultrastructure of Caco-2 cell junctions}

The effect PN159 peptide was very rapid, the electrical resistance dropped already to $42 \%$ of control value after 1 minute treatment (Fig. 25A), this decreasing tendency continued until the end of the 30-minute treatment (5 min: 16\%, 15 min: $2.7 \%$, 30 min: $1.4 \%$ of the control value). After the removal of the peptide the barrier function of Caco- 2 cells was restored about $44 \%$ of the control value at six hours and complete recovery could be observed at 20 hours. 
The area of Caco-2 cells was analysed on holographic phase contrast microscopy images. PN159 treatment decreased the average cell area, while the area of cells in the control and 1-day recovery groups was similar (Fig. 25B). This result may reflect opening of junctions and concomitant decrease of cell surface and increase of the paracellular space.
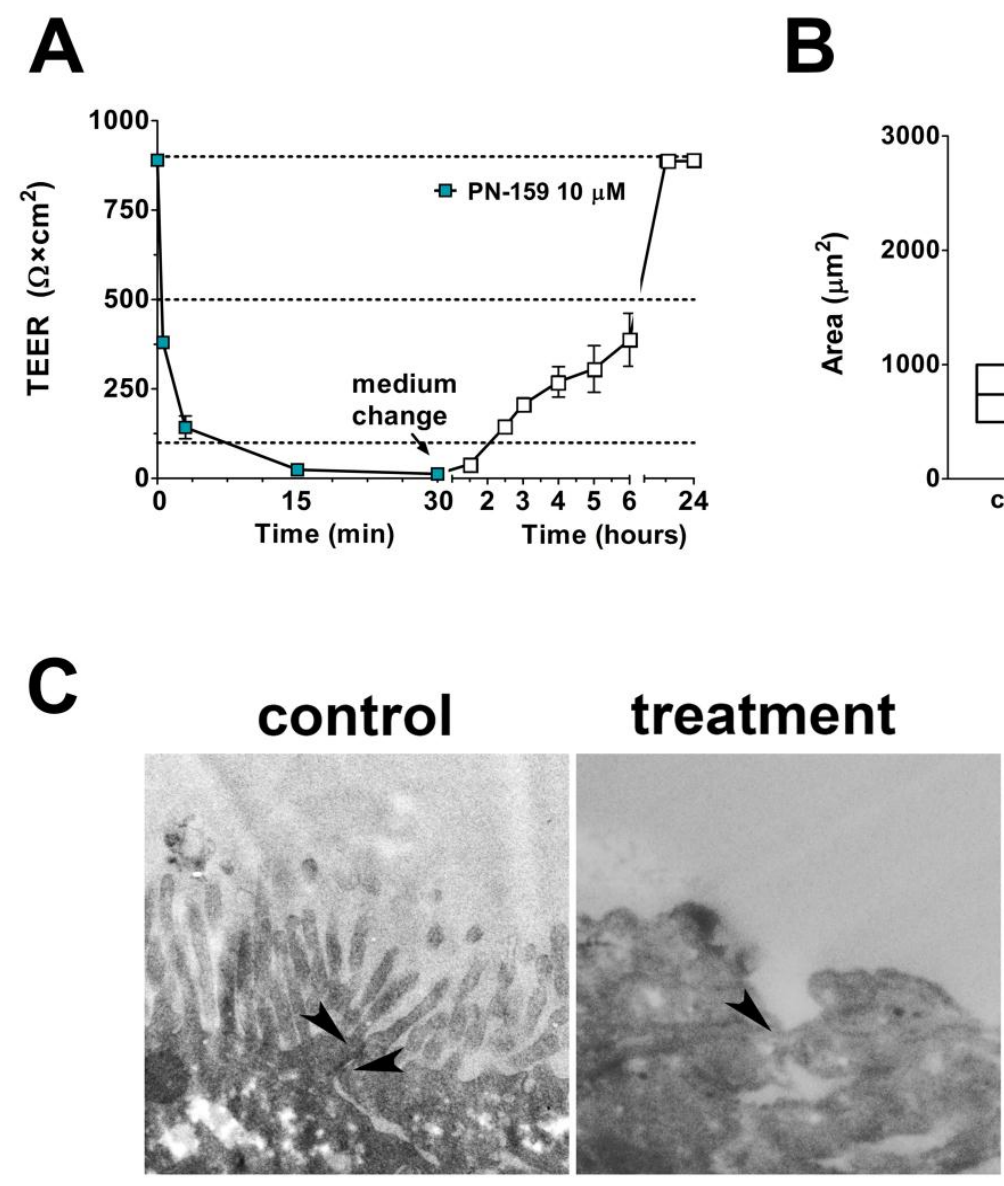

recovery

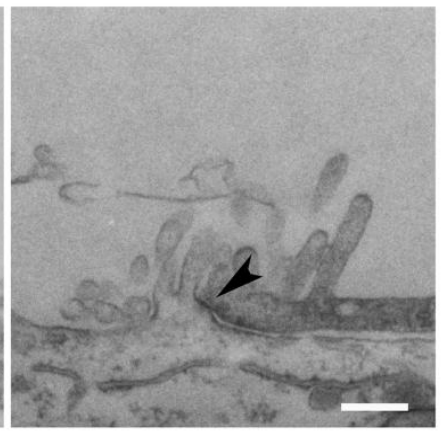

Figure 25. Reversible effect of PN159 peptide (10 $\mu \mathrm{M}, 30$-minutes treatment, 24-hour recovery) on Caco-2 cells. (A) Kinetic analysis of transepithelial electrical resistance (TEER) after PN159 peptide treatment. (B) Cell area analysis of holographic phase contrast images in control, treated and recovery groups. (C) Transmission electron micrographs of cell-cell connections (arrowheads); bar $=400 \mathrm{~nm}$.

Intact TJs providing the morphological basis of barrier functions were visualized between Caco-2 epithelial cells in the control group by transmission electron microscopy, but no junctions were observed following treatment with PN159 peptide (Fig. 25C). The disappearance of intercellular TJs was reversible, because after 1-day recovery the ultrastructure of epithelial junctions became similar to control cells. 


\subsection{Effects of PN159 on the penetration of dextran marker molecules and drugs}

All these previous functional and morphological results pointed to the TJ opening effect of PN159 in Caco-2 cells which potentially can be exploited to increase drug penetration across the intestinal barrier. The permeability of Caco-2 monolayers was measured in the apical to basal (intestine to blood) direction for four water soluble dextran marker molecules of different size (Table 4) and four drugs, the hydrophilic atenolol and cimetidine, and lipophilic quinidine and verapamil (Table 5). All four drugs are substrates of active efflux transporters (Hellinger et al., 2010).

Table 5. Apparent permeability coefficients of dextran marker molecules and drugs in the apicalbasal direction $\left(\mathrm{P}_{\text {app }} \mathrm{A}-\mathrm{B}, 10^{-6} \mathrm{~cm} / \mathrm{s}\right)$ in control and PN159 treated cultures. The differences between control and treated groups were expressed in fold changes.

\begin{tabular}{|c|c|c|c|c|}
\hline & \multicolumn{2}{|c|}{$P_{\text {app }} A-B\left(10^{-6} \mathrm{~cm} / \mathrm{s}\right) \pm S D$} & \multirow{2}{*}{$\begin{array}{c}\text { Fold } \\
\text { change }\end{array}$} \\
\hline & & control & PN159 & \\
\hline \multirow{4}{*}{ 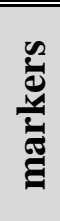 } & FD-4 & $0.021 \pm 0.001$ & $4.2 \pm 0.1$ & 42 \\
\hline & FD-10 & $0.025 \pm 0.01$ & $4.8 \pm 0.7$ & 48 \\
\hline & FD-20 & $0.022 \pm 0.002$ & $3.5 \pm 1.0$ & 35 \\
\hline & \begin{tabular}{|l|} 
FD-40 \\
\end{tabular} & $0.015 \pm 0.003$ & $6.0 \pm 0.3$ & 60 \\
\hline \multirow{4}{*}{${ }_{0}^{200}$} & atenolol & $1.2 \pm 0.3$ & $36.3 \pm 1.9$ & 30.3 \\
\hline & cimetidine & $0.9 \pm 0.2$ & $34.5 \pm 4.5$ & 38.3 \\
\hline & quinidine & $45.0 \pm 13.3$ & $72.6 \pm 2.4$ & 1.6 \\
\hline & verapamil & $46.2 \pm 3.9$ & $86.7 \pm 18.8$ & 1.9 \\
\hline
\end{tabular}

Abbreviation: FD, fluorescein isothiocyanate-labeled dextran.

Apparent permeability coefficients of the large FD macromolecules were very low in control conditions but they were elevated by 35-60 fold following PN159 treatment. The highest increase was measured in the case of FD-40. The permeability of atenolol and cimetidine was the lowest from the tested molecules, while the highest penetration was measured for quinidine and verapamil on Caco-2 cells. PN159 treatment caused more than 30 fold change for atenolol and cimetidine which penetrate slowly across the cells layers. In contrast, the peptide increased about 2 fold the permeability of the intestinal culture model for the lipophilic quinidine and verapamil.

\subsection{Characterization of the secondary structure of PN159}

According to the obtained CD spectra the secondary structure of PN159 peptide contains $11 \% \alpha$-helix, $31 \% \beta$-sheet, $24 \%$ turns and $34 \%$ unordered structure (Fig. 26A). This secondary structure of PN159 peptide was relatively stable between 25 and $95{ }^{\circ} \mathrm{C}$ 
(Fig. 26B). At $95{ }^{\circ} \mathrm{C}$ the $\beta$-sheet content decreased from $31 \%$ to $24 \%$, the amount of turns did not change, while a slight increase was measured in the content of $\alpha$-helix (from $11 \%$ to $14 \%$ ) and unordered structure (from $34 \%$ to $37 \%$ ).
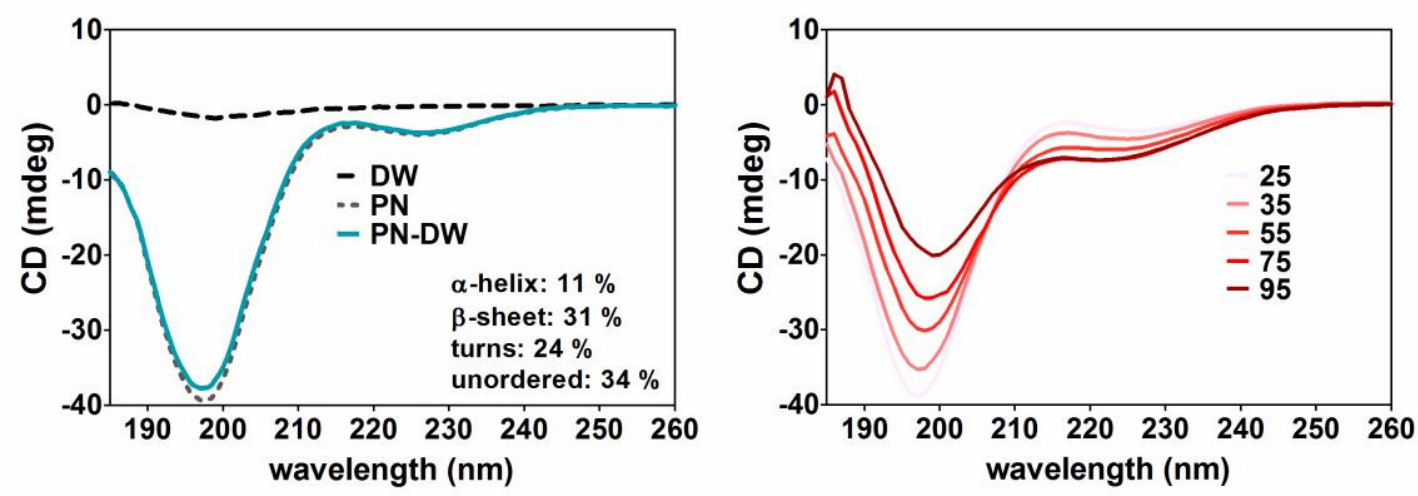

Figure 26. (A) Circular dichroism (CD) spectroscopy of PN159 peptide at $25^{\circ} \mathrm{C}$. (B) Heat stability measurement of the peptide structure.

\subsection{Structure and interaction of claudin- $1,-4,-5$ and -7 with PN159}

As shown on Fig. 19 the expression of claudin-5 is the highest in brain endothelial cells, while in Caco-2 intestinal epithelial cells claudin-1, -4 and -7 are the most abundant claudin subtypes which can be considered as potential targets of the barrier opening effects PN159. Claudin protein structures were obtained by homology modelling using the MODELLER program package (Fig. 27A; for the homology model of claudin-3 see the Supplementary information of Publication II in the Appendix).

Docking of PN159 peptide to full length homology modelled human claudin monomers $-1,-4,-5$ and -7 was performed on the CABS server. Favorable docking poses located around ECL1 and ECL2 were seeked by both energetic and geometric considerations and analysed in all docking trajectories. Docking energies ("total energy") were decomposed to "ligand energy", "interaction energy" and "receptor energy" parts (Table 6). Correct docking poses were expected to have low values not only for the total energies, but as low as possible for all energy components simultaneously. Thus, the "ligand energy", "interaction energy" and "total energy" values were investigated. Based on the modeling, energetically highly favorable interactions were found between PN159 and the ECLs of claudin-1, -4, -5 and -7 , but not that of claudin-3 (Table 6). Docked poses of PN159 with ECLs of claudin-1, $-4,-5$ and -7 are shown on Fig. 27B. 
A
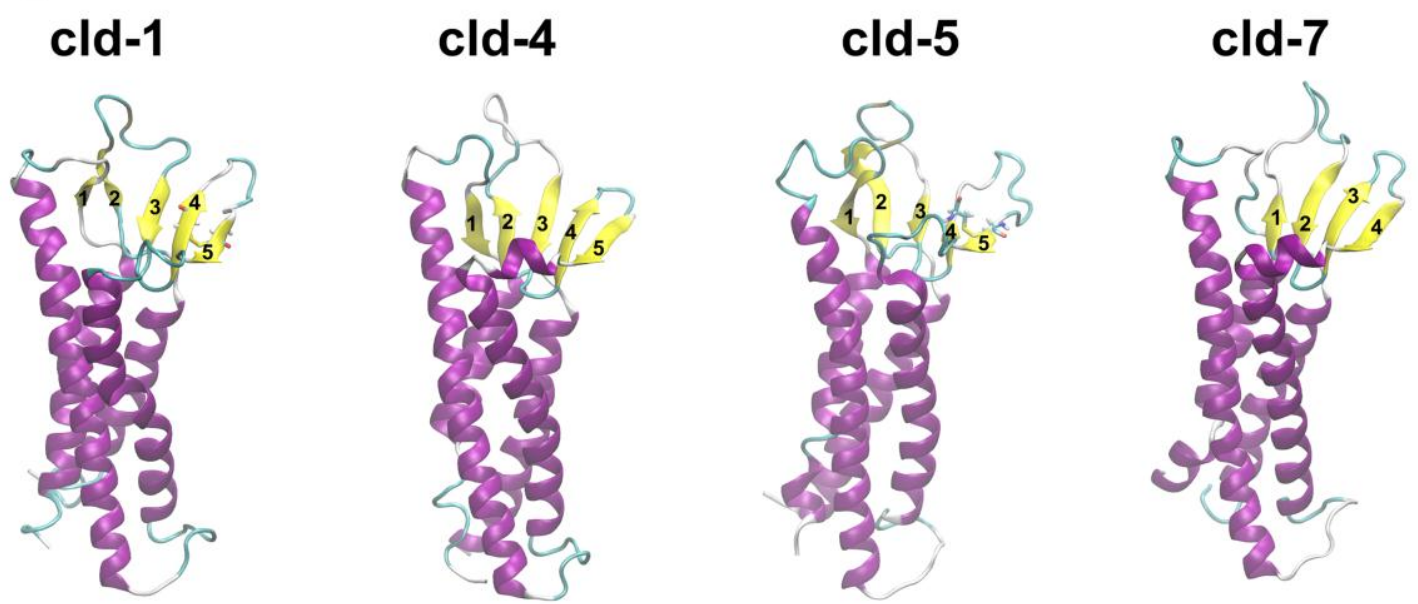

B
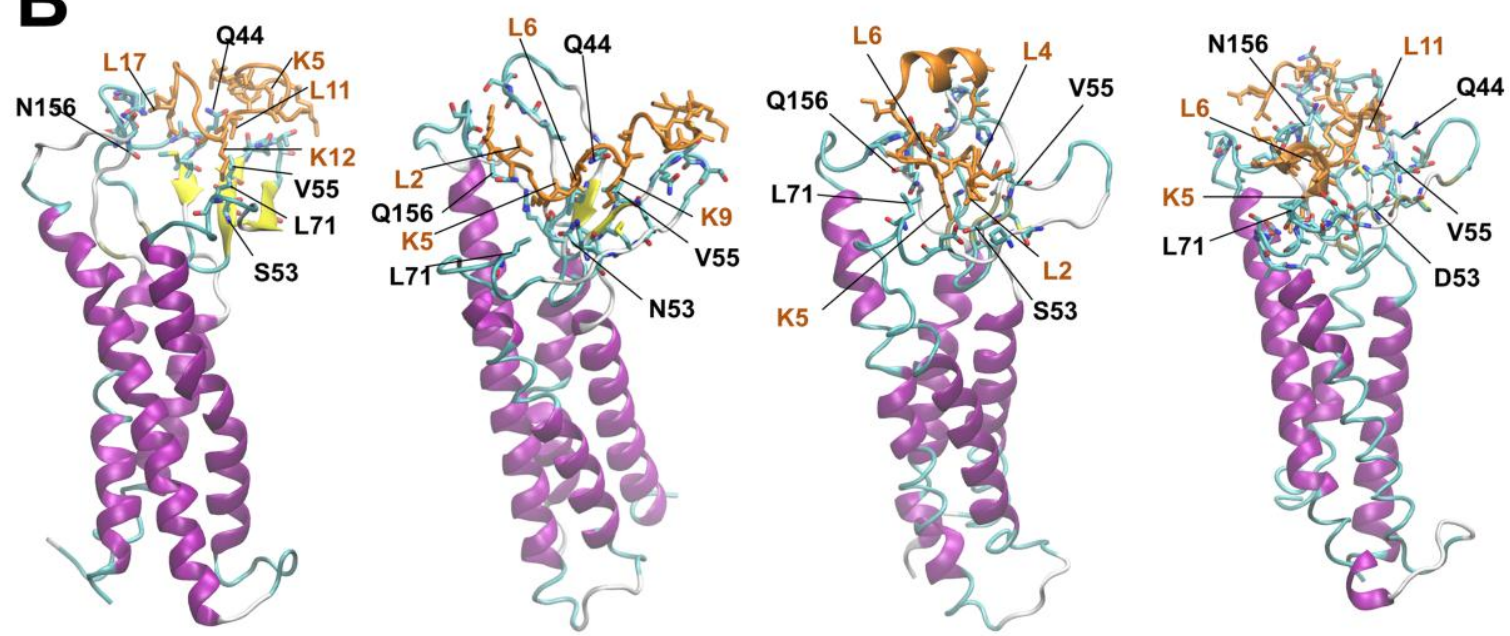

Figure 27. (A) Modelling human claudin proteins (claudin-1, -4, -5 -7). (B) Docking of PN159 peptide to claudin proteins. Interacting residues are shown as sticks. Orange color: PN159 peptide; Yellow color: $\beta$ strands; purple color: $\alpha$-helices of claudins.

Comparing the docking energy values of PN159 to claudins the following rank order in the strength of interaction can be established: claudin- $3<$ claudin- $1<$ claudin- $4<$ claudin-5 < claudin-7. The energy values from modeling (Table 6) correlate well with the rank order of the binding of PN159 to claudin-1, -3 and -5 (Fig. 20A).

Table 6. Docking energy components of PN159 to selected human claudin monomers

\begin{tabular}{|l|l|l|l|l|l|}
\hline & Claudin-1 & Claudin-3 & Claudin-4 & Claudin-5 & Claudin-7 \\
\hline \hline $\mathbf{E}_{\text {lig }}$ & -34 & -17 & -61 & -100 & -32 \\
\hline $\mathbf{E}_{\text {int }}$ & -63 & -59 & -79 & -76 & -186 \\
\hline $\mathbf{E}_{\text {tot }}$ & -1228 & -1163 & -1229 & -1439 & -1798 \\
\hline
\end{tabular}

Abbreviation: $\mathrm{E}_{\mathrm{tot}}$ : total energy; $\mathrm{E}_{\text {lig: }}$ ligand energy; $\mathrm{E}_{\text {int }}$ : interaction energy 
The amino acid sequence of ECL1 and ECL2 of the four claudins wich showed interaction with the $\mathrm{TJ}$ modulator peptide were compared and the most important amino acids which interact with PN159 were identified (Fig. 28). Four residues in ECL1, the polar Q44 and S/N/D53, the hydrophobic V55 and L71, and in ECL2 the polar N/Q156 participate in major interactions with the peptide.

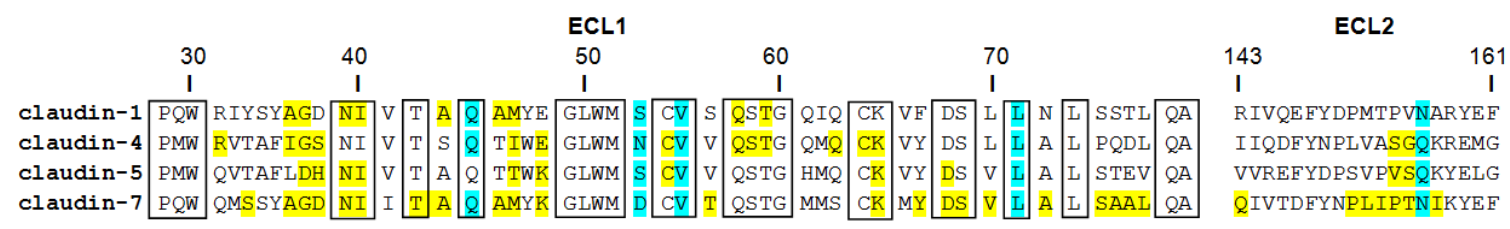

Figure 28. Amino acid sequence of ECL1 and ECL2 of human claudin monomers 1, 4, 5 and 7. Conserved amino acids are indicated in the boxes. The amino acids which interact with PN159 according to docking studies are marked by yellow and light blue. Blue color indicates interacting amino acids shown on Fig. 27. ECL: extracellular loop.

Q44 and V55 residues of claudin-1 and -7 form a binding pocket for L11 of the peptide, while the same two residues of claudin-4 bind L6 and K9 (Fig. 27-29). The polar S/N/D53 and L71 of claudin-4, -5 and -7 interact with K5, while the same amino acids of claudin-1 bind K12. The N/Q156 amino acid of ECL2 of all four claudins interacts with lysines: in the case of claudin-1 L17, claudin-4 L2, claudin-5 L4 and L6, claudin-7 L6, L8, L15, L17.

\begin{tabular}{|c|c|c|c|c|c|c|c|c|c|c|c|c|c|c|c|c|c|c|}
\hline PN159 & 1 & 2 & 3 & 4 & 5 & 6 & 7 & 8 & 9 & 10 & 11 & 12 & 13 & 14 & 15 & 16 & 17 & 18 \\
\hline claudin-1 & $\mathrm{K}$ & $\mathrm{L}$ & $A$ & $\mathrm{~L}$ & $\mathrm{~K}$ & $\mathrm{~L}$ & $\mathrm{~A}$ & $\mathrm{~L}$ & $\mathrm{~K}$ & $\mathrm{~A}$ & $\mathrm{~L}$ & $\mathrm{~K}$ & $\mathrm{~A}$ & A & $\mathrm{L}$ & $\mathrm{K}$ & $\mathrm{L}$ & $\mathrm{A}$ \\
\hline claudin-4 & $\mathrm{K}$ & $\mathrm{L}$ & $\mathrm{A}$ & $\mathrm{L}$ & K & $\mathrm{L}$ & A & $\mathrm{L}$ & $\mathrm{K}$ & A & $\mathrm{L}$ & $\mathrm{K}$ & A & A & $\mathrm{L}$ & K & $\mathrm{L}$ & A \\
\hline claudin-5 & K & $\mathrm{L}$ & A & L & K & $\mathrm{L}$ & A & L & K & A & L & K & A & A & L & K & $\mathrm{L}$ & A \\
\hline claudin-7 & $\mathrm{K}$ & $\mathrm{L}$ & A & $\mathrm{L}$ & $\mathrm{K}$ & $\mathrm{L}$ & A & $\mathrm{L}$ & K & A & $\mathrm{L}$ & K & A & A & $\mathrm{L}$ & K & $\mathrm{L}$ & A \\
\hline
\end{tabular}

Figure 29. Interaction between PN159 peptide and human claudin monomers 1, 4, 5 and 7. Amino acids of PN159 peptide which interact with the claudins according to docking studies are shown in yellow color.

Based on the docking results, lysines, especially K1 and K5 and leucins L6 and L17 of PN159 interact with all four claudins examined (Fig. 29).

After docking of the peptide disappearance of $\beta$-strands in ECLs of claudins was observed (Fig. 27), which seems to be correlated with the strength of interaction (Table 6). 


\section{DISCUSSION}

TJ proteins between epithelial and endothelial cells form a physical barrier and restrict the free passage of molecules, among them many active ingredients, through the paracellular cleft. The presence of several enzymes creates a metabolic barrier and intensifies the limited penetration of drugs, especially peptide or proteins. Due to these properties drug penetration across biological barriers is limited and new strategies for improving the permability are needed. Therefore investigation of biopharmacon transfer across barriers is an important field in the pharmaceutical research. One of the strategies to increase drug penetration is the targeted opening of $\mathrm{TJ}$ proteins. In the present $\mathrm{PhD}$ work we compared for the first time the effects of six selected modulator peptides acting on different targets on cultured intestinal and blood-brain barrier models.

\subsection{Transfer of opiorphin across a culture BBB model}

We measured for the first time the transfer of the biopharmacon opiorphin across a BBB culture model. Instead of radiolabeling we used the native form of the peptide and a sensitive method, LC-MS, to detect opiorphin. Our data indicate that opiorphin crosses the $\mathrm{BBB}$ in vitro in the absence of plasma factors at a slow rate, which is lower than that of the paracellular marker fluorescein but higher than that of the passive transcellular marker albumin. At the same time the extent of penetration was significant, $3 \%$ in contrast to the low amount of the paracellular markers. As a comparison, numerous endogenous peptides or regulatory proteins have $<0.1 \% / g$ uptake in brain and are still effective in the CNS after peripheral administration (Zlokovic et al., 1989; Banks et al., 1996).

Among the opiates, the centrally active morphine has an uptake of only $<0.02 \% / \mathrm{g}$ brain (Advokat et al., 1991). The amount of opiorphin transferred across the BBB culture model indicates that a specific transport mechanism, a peptide transport system or receptor-mediated transcytosis, may be involved in its transfer. Six transport systems (PTS1-6) have been identified for peptides at the BBB, which transport enkephalins, arginine vasopressin, or pituitary adenylate cyclase-activating polypeptides, among others (Banks, 2015). The peptide/histidine transporter 2 (PHT2, SLC15a3) was described at the BBB carrying di- and tripeptides, whereas larger peptides or proteins like insulin or transferrin cross the BBB by receptor-mediated transcytosis (Campos-Bedolla et al., 2014). To reveal if carriers or transporters participate in opiorphin transfer, further experiments are needed. The relative quantity of opiorphin penetration through the BBB culture model is obviously more elevated than values obtained with iv-administered labeled opioid 
peptides (Banks and Kastin, 1996). A possible explanation for this difference is that in our culture system no serum factors were present during the experiments, which is a limitation of the model. Peptidases are active in blood and rapidly cleave the native opiorphin peptide, which has a metabolic half-life of $6 \mathrm{~min}$ in human plasma; therefore, enzyme activity limits the transfer of opiorphin to the CNS in vivo (Wisner et al, 2006; Rougeot, 2009). In vivo data suggest that even in the presence of serum peptidases opiorphin can cross the $\mathrm{BBB}$ in sufficient amounts to raise the concentration of endogenous opioid ligands by inhibiting enkephalinases; thus, it can be appropriate for producing central effects. Our results indicate that opiorphin crosses cultured brain endothelial cells. These data are in agreement with observations that opiorphin potentiates enkephalin mediated antinociception and exerts antidepressant-like effects. We suggest that opiorphin may have a potential for further development as a centrally acting novel drug for the treatment of pain or depression.

\subsection{Comparative study on TJ modulator peptides}

\subsubsection{Peptides acting on E-cadherin}

Peptides HAV-6 designed for the bulge and ADT-6 designed for the groove regions of the EC1 domain of E-cadherin increased the permeability for marker molecules and decreased the TEER on Caco-2 intestinal cell layers. Our results are similar to those described on MDCK and Caco-2 epithelial cells (Sinaga et al., 2002; Kiptoo et al., 2011). We verified that the TJ modulator effect is reversible for both peptides. Full recovery of the barrier properties was also proved by immunostaining. Both peptides decreased TEER and induced reversible changes in immunostaining on the BBB model, but only ADT-6 induced an increase in paracellular permeability for the small marker. In contrast to epithelial cells, ADT-6 did not change the flux of albumin and HAV-6 had no effect on the permeability of markers in cultured endothelial cells (Table 9). A possible explanation for the different action of the peptides on the two culture models could be that E-cadherin, specific for epithelial cells contain the HAV motif, a classical cadherin binding motif in the EC1 domains of type I subfamily members, but vascular endothelial VE-cadherin expressed in brain endothelial cells (Bazzoni and Dejana, 2004), a member of the classical type II subfamily, lacks this motif (Vestweber, 2008). 


\subsubsection{Peptides mimicking microbial toxins}

AT-1002 peptide acting on ZO-1 cytoplasmic TJ linker protein decreased resistance on both models and increased permeability particularly in the case of BBB, which is a new observation. Our results are in agreement with previous studies showing that this peptide increases the permeability of epithelial barriers (Song et al., 2008). In the present work AT-1002 was examined in lower concentration and with shorter incubation time than in previous studies (Song et al., 2008) because brain endothelial cells seemed to be more sensitive to the peptide effect than epithelial cells based on the impedance measurements. AT-1002 peptide treatment caused visible changes in immunostaining for all the junctional proteins examined including ZO-1 in both models indicating a marked effect on paracellular junctions. Importantly, these changes were reversible on both cell types.

We observed that C-CPE peptide significantly decreased transepithelial resistance and increased the permeability of Caco- 2 cell layers for marker molecules in agreement with literature data. The effects on Caco-2 cells were reversible, similarly to data obtained on MDCK kidney epithelial cells (Sonoda et al., 1999). In contrast to Caco-2 cells C-CPE, which was tested on the BBB model for the first time, did not act on brain endothelial cells. This clostridium toxin peptide fragment increases intestinal permeability mainly through claudin-3 and -4 , but it cannot bind to claudin- 1 and -5 due to its structure (Protze et al., 2015). Expression level of claudin-3 and -4 is high in epithelial, but low in brain endothelial cells explaining our results.

\subsubsection{Peptides discovered by phage display}

The 7-mer peptide decreased the transepithelial resistance without changing fluorescein penetration on Caco-2 cell layers in concordance with data on four different epithelial cell lines including Caco-2 cells (Herman et al., 2007). Interestingly, albumin flux was increased after peptide treatment indicating a mechanism other than the paracellular transport route, which is also supported by the visibly intact intercellular junctions. This peptide was not studied on endothelial cells previously; therefore our study was the first to show that the 7-mer peptide increases the permeability for small and large marker molecules on a co-culture BBB model. We revealed that endothelial cell junctions are more responsive to 7-mer peptide than Caco-2 cell junctions (Table 9). The other peptide selected by phage display, PN159 was the most effective modulator of junctional permeability in both models. This peptide was characterized as an effective modulator of airway epithelial TJs in vitro and in vivo (Johnson and Quay, 2005). The effect of PN159 
was similar on bronchial epithelial cells than on Caco-2 cells (Johnson and Quay, 2005). However, until the present work there were no data on its effect on the BBB. This stable peptide with a low cytotoxicity profile and fully reversible action on different cell types has a potential for therapeutic application. Since PN159 peptide was originally discovered by phage technology on bronchial epithelial cell layers in which TJ proteins were made accessible by removal of calcium, its binding partner remained unknown so far. Our affinity measurements revealed that claudin-5 and claudin-1, but not claudin-3, can be among the potential targets of PN159.

\subsection{Comparison of the efficacy and barrier selectivity of the peptides}

All peptides induced reversible opening of junctions, but selectivity and differences in efficacy were observed. Comparing the efficacy of the peptides (Table 9) the following rank order can be established on Caco-2 cells: 7-mer < C-CPE < AT-1002 < HAV-6 < ADT-6 $<$ PN159. This order is different on the BBB model: C-CPE $<$ HAV-6 < ADT-6 $<7$-mer $<$ AT$1002<$ PN159.

Table 9. Comparison of the efficacy and barrier selectivity of the studied peptides.

\begin{tabular}{|c|c|c|c|c|c|c|c|}
\hline \multirow{2}{*}{\multicolumn{2}{|c|}{ Effective concentration }} & ADT-6 & HAV-6 & C-CPE & AT-1002 & 7-mer & PN159 \\
\hline & & $2 \mathrm{mM}$ & $2 \mathrm{mM}$ & $1 \mathrm{mM}$ & $2 \mathrm{mM}$ & $100 \mu \mathrm{M}$ & $10 \mu \mathrm{M}$ \\
\hline \multirow{2}{*}{$\begin{array}{l}\text { Presence of target } \\
\text { junctional protein }\end{array}$} & Caco-2 & + & + & + & + & $?$ & + \\
\hline & BBB & - & - & - & + & $?$ & + \\
\hline \multirow{2}{*}{$\begin{array}{l}\text { TEER reduction } \\
(\%)\end{array}$} & Caco-2 & 52 & 40 & 68 & 61 & 35 & 96 \\
\hline & BBB & 57 & 58 & 29 & 47 & 49 & 71 \\
\hline \multirow{2}{*}{$\begin{array}{l}P_{\text {app }} \text { increase (fold } \\
\text { change, SF/EBA) }\end{array}$} & Caco-2 & $12 / 2 \times$ & $7 / 6 \times$ & $2.2 / 3.6 \times$ & $0.3 / 2 \times$ & $4.7 / 1.7 \times$ & $303 / 21.2$ \\
\hline & BBB & $1 / 0.7 \times$ & $0.6 / 0.7 \times$ & $-/-$ & $4.4 / 2.6 \times$ & $5.5 / 5 \times$ & $10 / 8.2 \times$ \\
\hline \multirow{2}{*}{ Effect on barriers } & Caco-2 & ++ & ++ & + & $-1+$ & + & +++ \\
\hline & BBB & - & - & - & + & + & ++ \\
\hline
\end{tabular}

Abbreviation: $\mathrm{P}_{\mathrm{app}}$, apparent permeability coefficient; $\mathrm{SF}$, sodium fluorescein; EBA, Evans blue labeled albumin

AT-1002 and 7-mer peptide increased the drug penetration on both models but showed more effective permeability enhancing effects on the BBB model, while the effects of C-CPE, ADT-6 and HAV-6 were selective to epithelial cells. The reason for these differences may be due to the differences between epithelial and brain endothelial cells. In our previous study major differences were demonstrated between the co-culture BBB and the Caco-2 models in their cytoarchitecture, TJ structure and immunostaining (Hellinger et al., 2012). 


\subsection{Further characterization of the structure, effects and interactions of PN159 TJ modulator peptide}

The most effective PN159 peptide was further studied to reveal its safety and efficacy, its secondary structure and the potential binding target(s). PN159 peptide exerted a concentration dependent effect on viability and barrier integrity of Caco-2 epithelial cells. The results of morphological examinations and the kinetic analysis of PN159 during treatment showed safe and reversible penetration enhancer effect in the micromolar range and did not cause cellular damage. In agreement with a previous study the permeability of the large marker molecules was very low in control conditions, the permeability of the small hydrophilic atenolol and cimetidine was higher and that of the small lipophilic quinidine and verapamil was the highest on Caco-2 cell layers (Hellinger et al., 2010). PN159 treatment successfully increased the permeability for marker molecules and especially for hydrophilic drugs. All these functional and morphological results points to the TJ opening effect of PN159 in Caco-2 cells which can potentially be exploited to increase drug penetration across the intestinal barrier.

We present new data on the secondary structure of PN159, which contains predominantly random structure with $\beta$-sheet motives and shows thermostability. Our observation is in concordance with the high chemical stability of the peptide (Chen et al., 2006). Furthermore we identified four potential targets of PN159 namely claudin-1, 4, -5 and -7 by docking studies. These results suggest that PN159 peptide may open cell-cell junctions by acting on claudins, the most prominent family of integral membrane junctional proteins. $\mathrm{C}-\mathrm{CPE}$ and $\mathrm{C} 1 \mathrm{C} 2$ tight junction modulator peptides were described to target claudins. C-CPE is a fragment of Clostridium perfringens enterotoxin which directly binds claudin subtypes including claudin-4 and induces disintegration of tight junctions (Sonoda et al., 1999). The peptidomimetic C1C2 which contains the C-terminal half of ECL1 of claudin-1 predominantly binds to claudin-1, and -5 and opens the paracellular barrier in cultured cells (Staat et al., 2015). The secondary structure of C1C2 consists of $\beta$ sheet stabilized by $\alpha$-helix (Dabrowski et al., 2015), the claudin-binding domain of C-CPE is a nine-stranded $\beta$-sandwich (Veshnyakova et al., 2012), and PN159 also contains $\beta$-sheet beside the dominated random structure. This structural similarity between the three different but claudin-targeting peptides may be linked to the juntional modulator effect. Based on these results PN159 has a potential application of as a pharmaceutical excipient to improve drug delivery in oral formulations. 


\section{SUMMARY}

Epithelial and endothelial cells form the anatomical and functional basis of biological barriers. The penetration of drugs across these barriers is limited due to closed intercellular gaps by tight junction proteins, and metabolic enzymes expressed in cells. These important barrier properties which on one hand provide protection, on the other hand prevent the effective treatment of several diseases. The paracellular permeability is one of the most important determinants of drug delivery across biological barriers and enhancing the permeability of drugs, especially large biopharmaceuticals is a great challenge in pharmaceutical research. In the case of biopharmacon delivery beside tight junctions enzymes of the metabolic barrier represent the most limiting factor, particularly at the BBB. We demonstrated the transfer of opiorphin, a bioactive peptide across a well characterized and validated co-culture BBB model. Our data also support, that opiorphin may have a potential for further development as a centrally acting novel drug for the treatment of pain or depression.

One of the strategies to increase the penetration of large hydrophilic compounds is opening the paracellular gate by targeting TJ proteins. We studied six tight junction modulator peptides, ADT-6, HAV-6, C-CPE, AT-1002, 7-mer PN-78, PN159, which act on different targets, and compared their effects on intestinal epithelial and brain endothelial barriers. All peptides induced reversible opening of tight junctions as confirmed by different methods, but selectivity and differences in efficacy were observed. The targets of C-CPE, ADT-6 and HAV-6 peptides are expressed on epithelial cells which resulted in selective effects on epithelial cells. AT-1002 and 7-mer peptides caused enhanced permeability on both models but they were less effective on the intestinal barrier model. The selectivity of these peptides offers a great potential for innovative targeted drug delivery. PN159 peptide was the most effective permeability enhancer on both models: a rapid and reversible effect was found in low, non-toxic concentrations without permanent morphological changes. Potential targets of PN159 peptide were identified as claudin-1, -4 , -5 and -7 but not claudin-3 by affinity measurement and molecular modeling. The secondary structure and the high thermostability of PN159 were also revealed, which can be important for the development of new pharmaceutical formulations and drug delivery systems. The presented results indicate that these peptides can be effectively and selectively used as potential pharmaceutical excipients to improve drug delivery across biological barriers. 


\section{REFERENCES}

Abbott NJ, Patabendige AA, Dolman DE, Yusof SR, Begley DJ. Structure and function of the blood-brain barrier. Neurobiol Dis. 2010 Jan;37(1):13-25.

Abbott NJ. Blood-brain barrier structure and function and the challenges for CNS drug delivery. J Inherit Metab Dis. 2013 May;36(3):437-49.

Advokat C, Gulati A. Spinal transection reduces both spinal antinociception and CNS concentration of systemically administered morphine in rats. Brain Res. 1991 Aug 2;555(2):251-8.

Artursson P, Palm K, Luthman K. Caco-2 monolayers in experimental and theoretical predictions of drug transport. Adv Drug Deliv Rev. 2001 Mar 1;46(1-3):27-43.

Aungst BJ. Absorption enhancers: applications and advances. AAPS J. 2012 Mar;14(1):10-8.

Avdeef A, Deli MA, Neuhaus W. In Vitro Assays for Assessing BBB Permeability: Artificial membrane and cell culture models. In Di L, Kerns EH, editors. Blood-Brain Barrier in Drug Discovery: Optimizing Brain Exposure of CNS Drugs and Minimizing Brain Side Effects for Peripheral Drugs, Hoboken NJ: John Wiley and Sons, Inc. 2015, 188-237.

Banks WA, Kastin AJ. Passage of peptides across the blood-brain barrier: pathophysiological perspectives. Life Sci. 1996;59(23):1923-43.

Banks WA. Peptides and the blood-brain barrier. Peptides. 2015 Oct;72:16-9.

Bazzoni G, Dejana E. Endothelial cell-to-cell junctions: molecular organization and role in vascular homeostasis. Physiol Rev. 2004 Jul;84(3):869-901.

Benson K, Cramer S, Galla HJ. Impedance-based cell monitoring: barrier properties and beyond. Fluids Barriers CNS. 2013 Jan 10;10(1):5.

Campos-Bedolla P, Walter FR, Veszelka S, Deli MA. Role of the blood-brain barrier in the nutrition of the central nervous system. Arch Med Res. 2014 Nov;45(8):610-38.

Cecchelli R, Berezowski V, Lundquist S, Culot M, Renftel M, Dehouck MP, Fenart L. Modelling of the blood-brain barrier in drug discovery and development. Nat Rev Drug Discov. 2007 6(8):650-61.

Chen SC, Eiting K, Cui K, Leonard AK, Morris D, Li CY, Farber K, Sileno AP, Houston ME Jr, Johnson PH, Quay SC, Costantino HR. Therapeutic utility of a novel tight junction modulating peptide for enhancing intranasal drug delivery. J Pharm Sci. 2006 Jun;95(6):1364-71.

Chiba H, Osanai M, Murata M, Kojima T, Sawada N. Transmembrane proteins of tight junctions Biochim Biophys Acta. 2008 Mar;1778(3):588-600.

Dabrowski S, Staat C, Zwanziger D, Sauer RS, Bellmann C, Günther R, Krause E, Haseloff RF, Rittner H, Blasig IE. Redox-sensitive structure and function of the first extracellular loop of the cell-cell contact protein claudin-1: lessons from molecular structure to animals. Antioxid Redox Signal. 2015 Jan $1 ; 22(1): 1-14$.

Deli MA, Abrahám CS, Kataoka Y, Niwa M. Permeability studies on in vitro blood-brain barrier models: physiology, pathology, and pharmacology. Cell Mol Neurobiol. 2005 Feb;25(1):59-127.

Deli MA. Potential use of tight junction modulators to reversibly open membranous barriers and improve drug delivery. Biochim Biophys Acta. 2009 Apr;1788(4):892-910.

Deli MA. Drug Transport and the Blood-Brain Barrier. In: Solubility, Delivery and ADME Problems of Drugs and Drug Candidates, editors: Tihanyi K and Vastag M., Bentham E-books, 2011, 144-165.

Dichroweb, on-line analysis for protein Circular Dichroism spectra, dichroweb.cryst.bbk.ac.uk/html/home.shtml, (accessed December 2015).

Doolittle ND, Miner ME, Hall WA, Siegal T, Jerome E, Osztie E, McAllister LD, Bubalo JS, Kraemer DF, Fortin D, Nixon R, Muldoon LL, Neuwelt EA. Safety and efficacy of a multicenter study using intraarterial chemotherapy in conjunction with osmotic opening of the blood-brain barrier for the treatment of patients with malignant brain tumors. Cancer. 2000 Feb 1;88(3):637-47.

Erdlenbruch B, Alipour M, Fricker G, Miller DS, Kugler W, Eibl H, Lakomek M. Alkylglycerol opening of the blood-brain barrier to small and large fluorescence markers in normal and C6 glioma-bearing rats and isolated rat brain capillaries. Br J Pharmacol. 2003 Dec;140(7):1201-10.

Fasano A, Baudry B, Pumplin DW, Wasserman SS, Tall BD, Ketley JM, Kaper JB. Vibrio cholerae produces a second enterotoxin, which affects intestinal tight junctions. Proc Natl Acad Sci U S A. 1991 Jun 15;88(12):5242-6.

Fricker G, Miller DS. Modulation of drug transporters at the blood-brain barrier. Pharmacology. 2004 Apr;70(4):169-76.

Furuse M, Fujita K, Hiiragi T, Fujimoto K, Tsukita S. Claudin-1 and -2: novel integral membrane proteins localizing at tight junctions with no sequence similarity to occludin. J Cell Biol. 1998 Jun 29;141(7):1539-50. 
Gopalakrishnan S, Pandey N, Tamiz AP, Vere J, Carrasco R, Somerville R, Tripathi A, Ginski M, Paterson BM, Alkan SS. Mechanism of action of ZOT-derived peptide AT-1002, a tight junction regulator and absorption enhancer. Int J Pharm. 2009 Jan 5;365(1-2):121-30.

Haseloff RF, Dithmer S, Winkler L, Wolburg H, Blasig IE. Transmembrane proteins of the tight junctions at the blood-brain barrier: structural and functional aspects. Semin Cell Dev Biol. 2015 Feb;38:16-25.

Hellinger E, Bakk ML, Pócza P, Tihanyi K, Vastag M. Drug penetration model of vinblastine-treated Caco-2 cultures. Eur J Pharm Sci. 2010 Sep 11;41(1):96-106.

Hellinger E, Veszelka S, Tóth AE, Walter F, Kittel A, Bakk ML, Tihanyi K, Háda, V, Nakagawa S, Duy TD, Niwa M, Deli MA, Vastag M. Comparison of brain capillary endothelial cell-based and epithelial (MDCK-MDR1, Caco-2, and VB-Caco-2) cell-based surrogate blood-brain barrier penetration models. Eur J Pharm Biopharm. 2012 Oct;82(2):340-51.

Herman RE, Makienko EG, Prieve MG, Fuller M, Houston ME Jr, Johnson PH. Phage display screening of epithelial cell monolayers treated with EGTA: identification of peptide FDFWITP that modulates tight junction activity. J Biomol Screen. 2007 Dec;12(8):1092-101.

Horvát S, Fehér A, Wolburg H, Sipos P, Veszelka S, Tóth A, Kis L, Kurunczi A, Balogh G, Kürti L, Eros I, Szabó-Révész P, Deli MA. Sodium hyaluronate as a mucoadhesive component in nasal formulation enhances delivery of molecules to brain tissue. Eur J Pharm Biopharm. 2009 May;72(1):252-9.

Hubatsch I, Ragnarsson EG, Artursson P. Determination of drug permeability and prediction of drug absorption in Caco-2 monolayers. Nat Protoc. 2007;2(9):2111-9.

Hülper P, Veszelka S, Walter FR, Wolburg H, Fallier-Becker P, Piontek J, Blasig IE, Lakomek M, Kugler W, Deli MA. Acute effects of short-chain alkylglycerols on blood-brain barrier properties of cultured brain endothelial cells. Br J Pharmacol. 2013 Aug;169(7):1561-73.

Humphrey W, Dalke A, Schulten K. VMD: visual molecular dynamics. J Mol Graph. 1996 Feb;14(1):33-8, 27-8.

Illum L. Nasal drug delivery--possibilities, problems and solutions. J Control Release. 2003 Feb 21;87(13):187-98.

Janecka A, Staniszewska R, Gach K, Fichna J. Enzymatic degradation of endomorphins. Peptides. 2008 Nov;29(11):2066-73.

Javelot H, Messaoudi M, Garnier S, Rougeot C. Human opiorphin is a naturally occurring antidepressant acting selectively on enkephalin-dependent delta-opioid pathways. J Physiol Pharmacol. 2010 Jun;61(3):355-62.

Jerabek-Willemsen M, Wienken CJ, Braun D, Baaske P, Duhr S. Molecular interaction studies using microscale thermophoresis. Assay Drug Dev Technol. 2011 Aug;9(4):342-53.

Johnson PH, Quay SC. Advances in nasal drug delivery through tight junction technology. Expert Opin Drug Deliv. 2005 Mar;2(2):281-98.

Karande P, Mitragotri S. Enhancement of transdermal drug delivery via synergistic action of chemicals. Biochim Biophys Acta. 2009 Nov;1788(11):2362-73.

Kiptoo P, Sinaga E, Calcagno AM, Zhao H, Kobayashi N, Tambunan US, Siahaan TJ. Enhancement of drug absorption through the blood-brain barrier and inhibition of intercellular tight junction resealing by Ecadherin peptides. Mol Pharm. 2011 Feb 7;8(1):239-49.

Kiss L, Hellinger É, Pilbat AM, Kittel Á, Török Z, Füredi A, Szakács G, Veszelka S, Sipos P, Ózsvári B, Puskás LG, Vastag M, Szabó-Révész P, Deli MA. Sucrose esters increase drug penetration, but do not inhibit p-glycoprotein in caco-2 intestinal epithelial cells. J Pharm Sci. 2014 Oct;103(10):3107-19.

Kiss L, Walter FR, Bocsik A, Veszelka S, Ozsvári B, Puskás LG, Szabó-Révész P, Deli MA. Kinetic analysis of the toxicity of pharmaceutical excipients Cremophor EL and RH40 on endothelial and epithelial cells. J Pharm Sci. 2013 Apr;102(4):1173-81.

Kondoh M, Takahashi A, Fujii M, Yagi K, Watanabe Y. A novel strategy for a drug delivery system using a claudin modulator. Biol Pharm Bull. 2006 Sep;29(9):1783-9.

Krause G, Winkler L, Mueller SL, Haseloff RF, Piontek J, Blasig IE. Structure and function of claudins. Biochim Biophys Acta. 2008 Mar;1778(3):631-45.

Krause G, Winkler L, Piehl C, Blasig I, Piontek J, Müller SL. Structure and function of extracellular claudin domains. Ann N Y Acad Sci. 2009 May;1165:34-43.

Kurcinski M, Jamroz M, Blaszczyk M, Kolinski A, Kmiecik S. CABS-dock web server for the flexible docking of peptides to proteins without prior knowledge of the binding site. Nucleic Acids Res. 2015 Jul 1;43(W1):W419-24.

Kürti L, Gáspár R, Márki Á, Kápolna E, Bocsik A, Veszelka S, Bartos C, Ambrus R, Vastag M, Deli MA, Szabó-Révész $\mathrm{P}$. In vitro and in vivo characterization of meloxicam nanoparticles designed for nasal administration. Eur J Pharm Sci. 2013 Sep 27;50(1):86-92. 
Kürti L, Veszelka S, Bocsik A, Dung NT, Ozsvári B, Puskás LG, Kittel A, Szabó-Révész P, Deli MA. The effect of sucrose esters on a culture model of the nasal barrier. Toxicol In Vitro. 2012 Apr;26(3):445-54.

Laksitorini M, Prasasty VD, Kiptoo PK, Siahaan TJ. Pathways and progress in improving drug delivery through the intestinal mucosa and blood-brain barriers. Ther Deliv. 2014 Oct;5(10):1143-63.

Li X, Saeki R, Watari A, Yagi K, Kondoh M. Tissue distribution and safety evaluation of a claudin-targeting molecule, the C-terminal fragment of Clostridium perfringens enterotoxin. Eur J Pharm Sci. 2014 Feb $14 ; 52: 132-7$.

Loftsson T, Vogensen SB, Brewster ME, Konrádsdóttir F. Effects of cyclodextrins on drug delivery through biological membranes. J Pharm Sci. 2007 Oct;96(10):2532-46.

Makagiansar IT, Avery M, Hu Y, Audus KL, Siahaan TJ. Improving the selectivity of HAV-peptides in modulating E-cadherin-E-cadherin interactions in the intercellular junction of MDCK cell monolayers. Pharm Res. 2001 Apr;18(4):446-53.

McCafferty J, Schofield D. Identification of optimal protein binders through the use of large genetically encoded display libraries. Curr Opin Chem Biol. 2015 Jun;26:16-24.

Messer M. Enzymatic cyclization of L-glutamine and L-glutaminyl peptides. Nature. 1963 Mar 30;197:1299.

Naik A, Kalia YN, Guy RH. Transdermal drug delivery: overcoming the skin's barrier function. Pharm Sci Technolo Today. 2000 Sep 1;3(9):318-326.

Nakagawa S, Deli MA, Kawaguchi H, Shimizudani T, Shimono T, Kittel A, Tanaka K, Niwa M. A new blood-brain barrier model using primary rat brain endothelial cells, pericytes and astrocytes. Neurochem Int. 2009 Mar-Apr;54(3-4):253-63.

Paris L, Tonutti L, Vannini C, Bazzoni G. Structural organization of the tight junctions. Biochim Biophys Acta. 2008 Mar;1778(3):646-59.

Perrière N, Demeuse P, Garcia E, Regina A, Debray M, Andreux JP, Couvreur P, Scherrmann JM, Temsamani J, Couraud PO, Deli MA, Roux F. Puromycin-based purification of rat brain capillary endothelial cell cultures. Effect on the expression of blood-brain barrier-specific properties. J Neurochem. 2005 Apr;93(2):279-89.

Phillips JC, Braun R, Wang W, Gumbart J, Tajkhorshid E, Villa E, Chipot C, Skeel RD, Kalé L, Schulten K. Scalable molecular dynamics with NAMD. J Comput Chem. 2005, 26(16):1781-802.

Piontek J, Fritzsche S, Cording J, Richter S, Hartwig J, Walter M, Yu D, Turner JR, Gehring C, Rahn HP, Wolburg H, Blasig IE. Elucidating the principles of the molecular organization of heteropolymeric tight junction strands. Cell Mol Life Sci. 2011 Dec;68(23):3903-18.

Prokai-Tatrai K, Prokai L. Prodrugs of thyrotropin-releasing hormone and related peptides as central nervous system agents. Molecules. 2009 Feb 6;14(2):633-54.

Protze J, Eichner M, Piontek A, Dinter S, Rossa J, Blecharz KG, Vajkoczy P, Piontek J, Krause G. Directed structural modification of Clostridium perfringens enterotoxin to enhance binding to claudin-5. Cell Mol Life Sci. 2015 Apr;72(7):1417-32. doi: 10.1007/s00018-014-1761-6.

Reis M, Liebner S. Wnt signaling in the vasculature. Exp Cell Res. 2013 May 15;319(9):1317-23.

Rougeot C, inventor; Opiorphin peptide derivatives as potent inhibitors of enkephalin degrading ectopeptidases. World patent 124948. 2009.

Rougeot C, Robert F, Menz L, Bisson JF, Messaoudi M. Systemically active human opiorphin is a potent yet non-addictive analgesic without drug tolerance effects. J Physiol Pharmacol. 2010 Aug;61(4):483-90.

Sali A, Blundell TL. Comparative protein modelling by satisfaction of spatial restraints. J Mol Biol. 1993 Dec 5;234(3):779-815.

Scheuch G, Kohlhaeufl MJ, Brand P, Siekmeier R. Clinical perspectives on pulmonary systemic and macromolecular delivery. Adv Drug Deliv Rev. 2006 Oct 31;58(9-10):996-1008.

Sinaga E, Jois SD, Avery M, Makagiansar IT, Tambunan US, Audus KL, Siahaan TJ. Increasing paracellular porosity by E-cadherin peptides: discovery of bulge and groove regions in the EC1-domain of Ecadherin. Pharm Res. 2002 Aug;19(8):1170-9.

Sipos E, Kurunczi A, Fehér A, Penke Z, Fülöp L, Kasza A, Horváth J, Horvát S, Veszelka S, Balogh G, Kürti L, Eros I, Szabó-Révész P, Párducz A, Penke B, Deli MA. Intranasal delivery of human beta-amyloid peptide in rats: effective brain targeting. Cell Mol Neurobiol. 2010 Apr;30(3):405-13.

Song KH, Fasano A, Eddington ND. Effect of the six-mer synthetic peptide (AT1002) fragment of zonula occludens toxin on the intestinal absorption of cyclosporin A. Int J Pharm. 2008 Mar 3;351(1-2):8-14.

Sonoda N, Furuse M, Sasaki H, Yonemura S, Katahira J, Horiguchi Y, Tsukita S. Clostridium perfringens enterotoxin fragment removes specific claudins from tight junction strands: Evidence for direct involvement of claudins in tight junction barrier. J Cell Biol. 1999 Oct 4;147(1):195-204.

Staat C, Coisne C, Dabrowski S, Stamatovic SM, Andjelkovic AV, Wolburg H, Engelhardt B, Blasig IE. Mode of action of claudin peptidomimetics in the transient opening of cellular tight junction barriers. Biomaterials. 2015 Jun;54:9-20. doi: 10.1016/j.biomaterials.2015.03.007. 
Strickley RG. Solubilizing excipients in oral and injectable formulations. Pharm Res. 2004 Feb;21(2):201-30.

Suzuki H, Nishizawa T, Tani K, Yamazaki Y, Tamura A, Ishitani R, Dohmae N, Tsukita S, Nureki O, Fujiyoshi Y. Crystal structure of a claudin provides insight into the architecture of tight junctions. Science. 2014 Apr 18;344(6181):304-7.

Szakács G, Váradi A, Ozvegy-Laczka C, Sarkadi B. The role of ABC transporters in drug absorption, distribution, metabolism, excretion and toxicity (ADME-Tox). Drug Discov Today. 2008 May;13(910):379-93.

Terasaki T, Ohtsuki S. Brain-to-blood transporters for endogenous substrates and xenobiotics at the bloodbrain barrier: an overview of biology and methodology. NeuroRx. 2005 Jan;2(1):63-72.

Tóth AE, Tóth A, Walter FR, Kiss L, Veszelka S, Ózsvári B, Puskás LG, Heimesaat MM, Dohgu S, Kataoka Y, Rákhely G, Deli MA. Compounds blocking methylglyoxal-induced protein modification and brain endothelial injury. Arch Med Res. 2014 Nov;45(8):753-64.

Tömböly C, Péter A, Tóth G. In vitro quantitative study of the degradation of endomorphins. Peptides. 2002 Sep;23(9):1573-80.

Van Itallie CM, Anderson JM. Architecture of tight junctions and principles of molecular composition. Semin Cell Dev Biol. 2014 Dec;36:157-65.

Vastag M, Keseru GM. Current in vitro and in silico models of blood-brain barrier penetration: a practical view. Curr Opin Drug Discov Devel. 2009 Jan;12(1):115-24.

Vestweber D. VE-cadherin: the major endothelial adhesion molecule controlling cellular junctions and blood vessel formation. Arterioscler Thromb Vasc Biol. 2008 Feb;28(2):223-32.

Vecsernyés M, Fenyvesi F, Bácskay I, Deli MA, Szente L, Fenyvesi É. Cyclodextrins, blood-brain barrier, and treatment of neurological diseases. Arch Med Res. 2014 Nov;45(8):711-29.

Veshnyakova A, Piontek J, Protze J, Waziri N, Heise I, Krause G. Mechanism of Clostridium perfringens enterotoxin interaction with claudin-3/-4 protein suggests structural modifications of the toxin to target specific claudins. J Biol Chem. 2012 Jan 13;287(3):1698-708.

Veszelka S, Kittel Á, Deli MA. Tools for Modelling Blood-Brain Barrier Penetrability. In Tihanyi K, Vastag $\mathrm{M}$ editors. Solubility, Delivery and ADME Problems of Drugs and Drug Candidates, Washington: Bentham Science Publishers Ltd. 2011, 166-188.

Vorbrodt AW, Dobrogowska DH. Molecular anatomy of interendothelial junctions in human blood-brain barrier microvessels. Folia Histochem Cytobiol. 2004;42(2):67-75.

Walter FR, Veszelka S, Pásztói M, Péterfi ZA, Tóth A, Rákhely G, Cervenak L, Ábrahám CS, Deli MA. Tesmilifene modifies brain endothelial functions and opens the blood-brain/blood-glioma barrier. J Neurochem. 2015 Sep;134(6):1040-54.

Ward PD, Tippin TK, Thakker DR. Enhancing paracellular permeability by modulating epithelial tight junctions. Pharm Sci Technolo Today. 2000 Oct 1;3(10):346-358.

Wisner A, Dufour E, Messaoudi M, Nejdi A, Marcel A, Ungeheuer MN, Rougeot C. Human Opiorphin, a natural antinociceptive modulator of opioid-dependent pathways. Proc Natl Acad Sci U S A. 2006 Nov 21;103(47):17979-84.

Wolburg H, Wolburg-Buchholz K, Sam H, Horvát S, Deli MA, Mack AF. Epithelial and endothelial barriers in the olfactory region of the nasal cavity of the rat. Histochem Cell Biol. 2008 Jul;130(1):127-40.

Yu D, Turner JR. Stimulus-induced reorganization of tight junction structure: the role of membrane traffic. Biochim Biophys Acta. 2008 Mar;1778(3):709-16.

Zlokovic BV, Mackic JB, Djuricic B, Davson H. Kinetic analysis of leucine-enkephalin cellular uptake at the luminal side of the blood-brain barrier of an in situ perfused guinea-pig brain. J Neurochem. 1989 Nov;53(5):1333-40. 


\section{ACKNOWLEDGEMENTS}

I am grateful to my supervisors Dr. Mária Deli and Prof. Dr. Piroska Révész for their scientific guidance, encouragement and support throughout my Ph.D. studies.

I thank Prof. Pál Ormos, director general of the Biological Research Centre, Prof. László Zimányi, director of the Institute of Biophysics, and Dr. László Siklós, head of the Molecular Neurobiology Research Unit for their support.

I am thankful to Dr. Szilvia Veszelka, Dr. Lóránd Kiss, Dr. Fruzsina Walter, András Harazin, Dr. Petra Sántha, Dr. Andrea Tóth, Mária Mészáros, Ilona Gróf and Dóra Ludányi for their kind help in my experimental work.

I would like to thank Ngo Thi Khue Dung for the excellent technical assistance.

I am indebted to all our cooperating partners for their contributions, namely

Dr. Lívia Fülöp and Andrea Gyebrovszki for peptide synthesis;

Dr. Ferenc Ötvös for molecular modelling;

Dr. Ingolf Blasig and Dr. Sebastian Dabrowski for affinity measurements;

Dr. Ágnes Kittel for electron microscopical studies;

Dr. Mónika Vastag and Dr. Éva Hellinger for measurements of drugs concentrations;

Dr. Gábor Rákhely and Dr. András Tóth for real-time PCR studies;

Dr. Vilmos Tubak for providing the cell impedance instrument;

Dr. Ottó Zsíros for circular dichroism spectroscopy measurement;

Dr. Zsuzsanna Darula for mass spectometry measurements;

Dr. Zoltán Kóta for helping with spectrofluorometer analysis;

Dr. László Puskás and Lajos Nagy for Holographic phase contrast microscopy studies.

I thank the "Apáczai Csere János Scholarship for PhD students" financed by the European Union and the State of Hungary (TÁMOP 4.2.4. A/2-11-1-2012-0001). The work was supported by a research grant from Gedeon Richter Plc. (RG-IPI-2009-TP3/006).

Finally, I am especially thankful to my family for their love and untiring support during my studies. 
APPENDIX 
PUBLICATION I. 


\title{
PRELIMINARY REPORT
}

\section{Transfer of Opiorphin Through a Blood-Brain Barrier Culture Model}

\author{
Alexandra Bocsik, ${ }^{\mathrm{a}}$ Zsuzsanna Darula, ${ }^{\mathrm{b}}$ Géza Tóth, ${ }^{\mathrm{b}}$ Mária A. Deli, ${ }^{\mathrm{a}}$ and Mária Wollemann ${ }^{\mathrm{b}}$ \\ ${ }^{\mathrm{a}}$ Institute of Biophysics, ${ }^{\mathrm{b}}$ Institute of Biochemistry, Biologial Research Centre, Hungarian Academy of Sciences, Szeged, Hungary
}

Received for publication February 24, 2015; accepted June 23, 2015 (ARCMED-D-15-00127).

\begin{abstract}
Opioid peptides are potent analgesics with therapeutic potential in the treatment of acute and chronic pain. Their efficacy is limited by peptidases (enkephalinases). Opiorphin pentapeptide (QRFSR) is the first characterized human endogenous inhibitor of enkephalinases. The peptide is able to increase the binding and affinity of endogenous opiates to mu opioid receptors; thus, the mechanism of opiorphin may provide a new therapeutic approach in pain management. The analgesic effect of opiorphin was proven in several earlier published in vitro and in vivo studies. Our aim was to test the transfer of opiorphin through a blood-brain barrier model for the first time. The flux of opiorphin was tested on a blood-brain barrier culture model consisting of rat brain endothelial, glial and pericyte cells. Brain endothelial cells in this triple co-culture model form tight monolayers characterized by transendothelial electrical resistance measurement. Relative quantity of the peptide was estimated by mass spectrometry. The transfer of opiorphin through the bloodbrain barrier model was estimated to be $\sim 3 \%$, whereas the permeability coefficient was $0.53 \pm 1.36 \times 10^{-6} \mathrm{~cm} / \mathrm{s}(n=4)$. We also observed rapid conversion of N-terminal glutamine into pyroglutamic acid during the transfer experiments. Our results indicate that opiorphin crosses cultured brain endothelial cells in the absence of serum factors in a significant amount. This is in agreement with previous in vivo data showing potentiation of enkephalin-mediated antinociception. We suggest that opiorphin may have a potential as a centrally acting novel drug to treat pain. (C) 2015 IMSS. Published by Elsevier Inc.
\end{abstract}

Key Words: Opiorphin, Peptidase inhibitor, Blood-brain barrier, Brain endothelial cell, Permeability, LC-MS.

\section{Introduction}

Opioid analgesics are still one of the most effective drugs against pain; however, their clinical usefulness is limited by several side effects including physical dependence, respiratory depression, gastrointestinal effects and tolerance (1). New opioid peptides could have therapeutic potential for central nervous system (CNS) diseases, but they have a short half-life and low metabolic stability $(2,3)$. Opiorphin (QRFSR) is an endogenous peptide that inhibits Zn-dependent metallo-ecto-peptidases: neutral endopeptidase (NEP EC3.4.21.11) and aminopeptidase

Address reprint requests to: Dr. Mária Wollemann, Institute of Biochemistry, Biological Research Centre, Hungarian Academy of Sciences, Temesvari krt. 62, H-6726 Szeged, Hungary; Phone: +36 62 599425; Fax: +36 62 433506; E-mail: wolleman.maria@brc.mta.hu; or Dr. Mária A. Deli, Institute of Biophysics, Biological Research Centre, Hungarian Academy of Sciences, Temesvari krt. 62, H-6726 Szeged, Hungary; Phone: +36 62 599602; Fax: +36 62 433133; E-mail: deli.maria@brc.mta.hu
(AP-N EC3.4.11.2) (4). These enzymes metabolize opioid peptides such as enkephalins and their derivatives in vivo and in vitro (5). Opiorphin as an enkephalinase inhibitor exerts analgesic and antidepressive effects by the protection of endogenous enkephalins released after pain stimuli $(6,7)$. Opiorphin is the only natural enkephalinase-inhibitor characterized in humans and has similar pain-suppressive potency to morphine but without adverse effects $(4,6)$. The efficacy of opiorphin has been verified by in vitro methods and its analgesic activity was also shown in different in vivo pain studies $(4,6,8)$. According to our previous in vitro maximal binding and affinity measurements, opiorphin is able to increase the binding and affinity of endogenous opiates to opioid receptors (9).

In this study we were interested in the opiorphin transfer across the BBB. Opioid peptides have restricted penetration to the CNS across the BBB $(10,11)$. The transfer of opioid peptides through the BBB was studied previously with isotopically labeled peptides showing a penetration index 
$<0.01 \%$ (12-14). Specific features of the BBB, mainly interendothelial tight junctions and efflux transporters (15), as well as peptidase activity in blood, brain microvessels and brain tissue may be responsible for limiting the transfer of these potential biotherapeutics from the blood to brain.

The aim of the study was to test the transfer of unlabeled opiorphin across a well-characterized culture model of the BBB. Mass spectrometry was used to detect the passage of the peptide across the $\mathrm{BBB}$ in vitro.

\section{Materials and Methods}

\section{Materials}

All reagents used in the study were purchased from SigmaHungary Ltd. (Budapest, Hungary) unless otherwise indicated. Wistar rats were obtained from the animal facility of the BRC. All animals were treated in strict accordance with the NIH Guide for Care and Use of Laboratory Animals (NIH Publications No. 80-23) and as approved by the local authority, Csongrád County Animal Health and Food Control Station (Permit number: XVI./834/2012).

\section{Peptide Synthesis}

Opiorphin was synthesized manually using Fmoc (fluorenylmethyloxycarbonyl) solid phase synthesis on $\mathrm{N}^{\alpha}$. Fmoc-Arg(Pmc)-Wang resin. $\mathrm{N}^{\alpha}$-Fmoc-protected amino acids were used. The side chain protecting groups used to build the peptide sequence were the following: trityl (Trt) for Gln, tert-butyl (t-Bu) for Ser and 2,2,5,7,8pentamethylchroman (Pmc) for Arg. The couplings were performed by 1-hydroxybenzotriazole (HOBt) and $\mathrm{N}, \mathrm{N}^{\prime}$ diisopropylcarbodiimide (DIC). The coupling efficiencies were monitored by the Kaiser test. The Fmoc groups were removed by a solution of $20 \%$ piperidine in dimethylformamide. After assembly of the peptide sequence, a cocktail of TFA/TIS/ $\mathrm{H}_{2} \mathrm{O}$ (trifluoroacetic acid/triisopropylsilane/water, 95: 2.5: 2.5) was used to remove the side chain protecting groups and to cleave the peptide from the resin. The resin was filtered and the filtrate was cooled at $-20^{\circ} \mathrm{C}$. After precipitating with diethyl ether, the peptide was redissolved in water and lyophilized. The crude peptide was purified using a semipreparative RP-HPLC column (Altima HP $\mathrm{C}_{18}, 1$ $\mathrm{cm} \times 25 \mathrm{~cm}, 5 \mu \mathrm{m}$ particle size). The homogeneity of the final peptide was determined by analytical RP-HPLC (Altima $\mathrm{HP} \mathrm{C}_{18} 0.46 \mathrm{~cm} \times 25 \mathrm{~cm}, 5 \mu \mathrm{m}$ particle size) column, retention time: $6.5 \mathrm{~min}$. ESI-MS analysis confirmed the molecular mass of the peptide $\left(\left[\mathrm{M}+\mathrm{H}^{+}\right]_{\text {found }}\right.$ : 693.5; $\left(\left[\mathrm{M}+\mathrm{H}^{+}\right]_{\text {theoretical }}: 693.4 \mathrm{Da}\right)$.

\section{Blood-Brain Barrier Model}

Primary brain endothelial cells, astrocytes and pericytes were isolated from 1-month-old Wistar rats. Cell isolation and the preparation of the co-culture BBB model was performed as previously described (16). Brain endothelial cells and pericytes were seeded on the opposite surfaces of collagen IV and fibronectin coated Costar Transwell polycarbonate inserts (12 mm diameter, $0.4 \mu \mathrm{m}$ pore size; Corning, Corning, NY) and kept in co-culture with glial cells to reach good barrier properties for the permeability measurements (Figure 1A). The tightness of the model was checked by transendothelial electrical resistance (TEER) measurement using an EVOM resistance meter and STX-2 electrodes (World Precision Instruments, USA). TEER of coated, cell-free filters was subtracted from measured TEER values of the BBB model. TEER of rat brain endothelial cell layers was $593 \pm 47 \Omega \mathrm{cm}^{2}$ (mean $\pm \mathrm{SD}$; $n=12$ ) in agreement with our previous data (17).

\section{Permeability Assay}

To measure the transfer of opiorphin across the BBB model, cell culture inserts were transferred to 12-well plates containing $1.5 \mathrm{~mL}$ Ringer-Hepes solution (136 mM NaCl, $0.9 \mathrm{mM} \mathrm{CaCl} 2,0.5 \mathrm{mM} \mathrm{MgCl}_{2}, 2.7 \mathrm{mM} \mathrm{KCl}, 1.5 \mathrm{mM}$ $\mathrm{KH}_{2} \mathrm{PO}_{4}, 10 \mathrm{mM} \mathrm{NaH} \mathrm{PO}_{4}, 25 \mathrm{mM}$ glucose and $10 \mathrm{mM}$ Hepes, $\mathrm{pH}$ 7.4) in the lower or acceptor compartments. The peptide was dissolved in distilled water to yield a 10-mM solution, which was further diluted in RingerHepes buffer. In the upper or donor chambers, culture medium was replaced by $0.5 \mathrm{~mL}$ Ringer Hepes containing
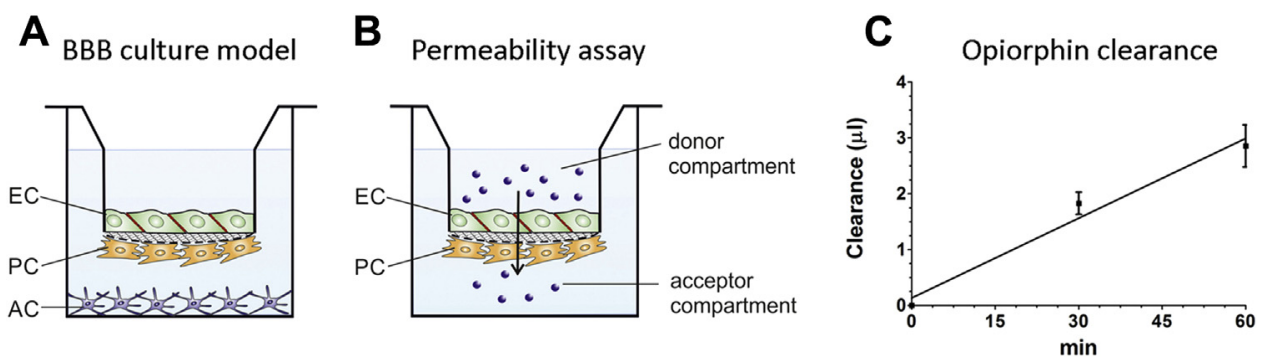

Figure 1. Culture model of the blood-brain barrier (A). The model is a co-culture of three cells types, primary rat brain endothelial cells (EC), rat pericytes (PC) and rat astrocytes (AC). In the permeability assay (B) culture inserts with EC and PC cells are used. Blue circles represent opiorphin, our test molecule. The direction of the transfer from the donor to the acceptor compartment is indicated by an arrow. Clearance of opiorphin across the culture model (C) (mean $\pm \mathrm{SD}, n=4$ ). (A color figure can be found in the online version of this article.) 
opiorphin at $10 \mu \mathrm{M}$ concentration or permeability markers fluorescein $(10 \mu \mathrm{g} / \mathrm{mL}$; molecular weight: $376 \mathrm{Da})$ or bovine serum albumin $(1 \%$, molecular weight: $65 \mathrm{kDa})$ bound to Evans blue $(165 \mu \mathrm{g} / \mathrm{mL})$ (Figure 1B). To measure peptide flux from the upper to lower compartment (blood to brain direction) the inserts were transferred at 30 and $60 \mathrm{~min}$ to new wells containing Ringer-Hepes solution. Opiorphin in samples from the donor and acceptor compartments $(n=4)$ were detected by mass spectrometry. Evans blue-albumin content of samples was measured at $584 \mathrm{~nm}$ excitation and $680 \mathrm{~nm}$ emission wavelengths (Fluostar Optima, BMG Labtechnologies, Germany). Fluorescein concentrations were determined by the same instrument using $485 \mathrm{~nm}$ excitation and $520 \mathrm{~nm}$ emission wavelengths. Clearance and the apparent permeability coefficient $\left(\mathrm{P}_{\mathrm{app}}\right)$ were calculated as described earlier (16) by the following equations:

$$
\text { Cleared volume }(\mu \mathrm{l})=\frac{C_{A} \times V_{A}}{C_{D}}
$$

where $\mathrm{C}$ is concentration of the peptide in the acceptor or donor compartments and $\mathrm{V}$ is the volume of the acceptor compartment $(1.5 \mathrm{ml})$.

$$
P_{\text {app }}(\mathrm{cm} / \mathrm{s})=\frac{\Delta[C]_{A} \times V_{A}}{A \times[C]_{D} \times \Delta t}
$$

where $\Delta[\mathrm{C}]_{\mathrm{A}}$ is the concentration difference of the peptide in the acceptor compartments after $1 \mathrm{~h}$ and $\mathrm{C}_{\mathrm{D}}$ is the concentration in the donor compartments at $0 \mathrm{~h}$, and $\mathrm{V}_{\mathrm{A}}$ is the volume of the acceptor compartment $(1.5 \mathrm{~mL})$, and $\mathrm{A}$ is the surface area available for permeability $\left(1.1 \mathrm{~cm}^{2}\right)$. The quantity of opiorphin transfer was calculated from areas under curve from the chromatograms representing the intact opiorphin peptide.

\section{Mass Spectrometry}

LC-MS experiments were performed on a nanoAcquity UPLC (Waters) on-line coupled to an Orbitrap-Elite (Thermo Scientific) hybrid tandem mass spectrometer operated in the positive ion mode. Five $\mu l$ of the samples containing the peptide was injected onto a trapping column (Waters Symmetry C18; $180 \mu \mathrm{m} \times 20 \mathrm{~mm}, 5 \mu \mathrm{m}$ particle size) and after washing with $1 \%$ solvent $\mathrm{B}$ for 5 min was transferred onto the separating column (Dionex Acclaim PepMap; $75 \mu \mathrm{m} \times 25 \mathrm{~cm}, 2 \mu \mathrm{m}$ particle size, $100 \AA$ pore size) developing a linear gradient of $1-35 \%$ solvent $\mathrm{B}$ in $10 \mathrm{~min}$ using a flow rate of $200 \mathrm{nl} / \mathrm{min}$ (solvent A: $0.1 \%$ for$\mathrm{mic}$ acid/water; solvent B: $0.1 \%$ formic acid/acetonitrile). For MS experiments, mass range of m/z: 200-600 was monitored at resolution of 60000 using internal calibration to the background polysiloxane ion (m/z: 445.120024). Relative quantity of opiorphin was estimated using the extracted ion chromatogram (XIC) of m/z: $347.1932( \pm 5$ ppm) peak intensity corresponding to the doubly charged opiorphin peptide cation.

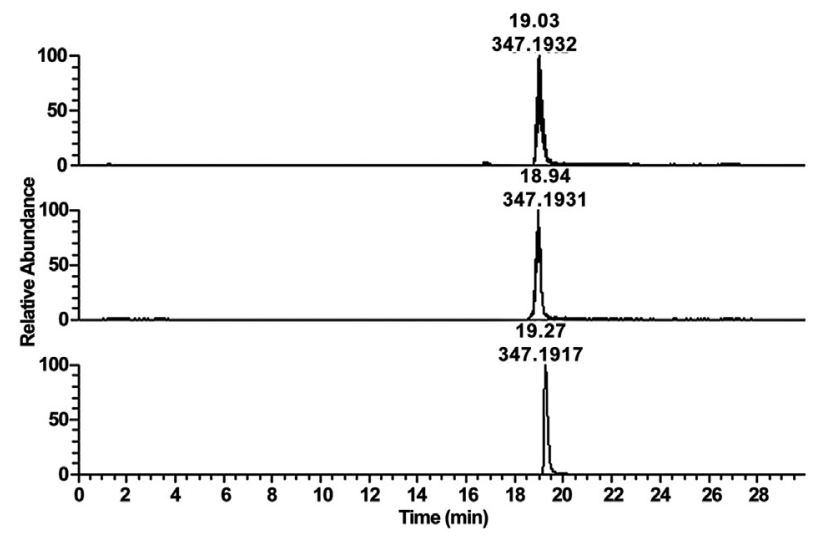

Figure 2. Extracted ion chromatograms of m/z: $347.1932 \pm 5$ ppm corresponding to the doubly charged peptide ion of opiorphin. Upper panel: sample from the receiver compartment ("brain side") after 30 min incubation, middle panel: sample from the receiver compartment after $60 \mathrm{~min}$ incubation, bottom panel: sample from the donor compartment ("blood side") after $60 \mathrm{~min}$ incubation. Peak labels denote retention time and $\mathrm{m} / \mathrm{z}$ value.

\section{Results}

MS/MS characterization of the synthetic opiorphin peptide was performed using both collision-induced dissociation and higher energy collisional activation. The observed $\mathrm{m} /$ $\mathrm{z}$ value of the protonated peptide ions and fragmentation pattern were in good agreement with those expected for the QRFSR sequence. Signal intensities in the receiver compartment samples were $1-2 \times 10^{6}$ as opposed to 1.5 $\times 10^{8}$ in the donor compartment samples (Figure 2).

The relative quantity of opiorphin that penetrated through the BBB model was calculated to be $2.91 \pm 1.13 \%$ based on the area under curve of the doubly charged opiorphin peptide ion $\mathrm{m} / \mathrm{z} 347.1932$. As a comparison, $0.41 \pm 0.03 \%$ of fluorescein and $0.03 \pm 0.01 \%$ of albumin crossed the brain endothelial cell layers in parallel inserts from the same cell isolation under identical assay conditions.

The clearance of opiorphin is shown in Figure 1C. $\mathrm{P}_{\mathrm{app}}$ of opiorphin was $0.53 \pm 1.36 \times 10^{-6} \mathrm{~cm} / \mathrm{s}(n=4)$. In parallel inserts from the same cell isolation under identical assay conditions the $\mathrm{P}_{\text {app }}$ of fluorescein was $1.03 \pm 0.09$ $\times 10^{-6} \mathrm{~cm} / \mathrm{s}(n=4)$ and that of albumin $0.07 \pm 0.04 \times$ $10^{-6} \mathrm{~cm} / \mathrm{s}(n=4)$.

We also observed rapid conversion of N-terminal glutamine into pyroglutamic acid both in $0.1 \%$ formic acid and in Ringer-Hepes buffer used for BBB penetration experiments. We monitored the pyroglutamic acid-containing peptide using its calculated molecular mass [monoisotopic MW: 675.3453 yielding a doubly charged protonated peptide ion $\mathrm{m} / \mathrm{z}: 338.6799(\mathrm{z}=2)]$.

\section{Discussion}

We measured the transfer of opiorphin across a BBB culture model for the first time. The resistance data and $\mathrm{P}_{\mathrm{app}}$ 
values for passive hydrophilic permeability markers fluorescein and albumin were in accordance with our previous data and indicated a tight barrier $(16,17)$. Instead of radiolabeling we used the native form of the peptide and a sensitive method, LC-MS, to detect opiorphin. A mass spectrometry method was already applied for the quantification of opiorphin in human saliva (18). Our data indicate that opiorphin crosses the BBB in vitro in the absence of plasma factors at a slow rate, which is lower than that of the paracellular marker fluorescein but higher than that of the passive transcellular marker albumin. At the same time the extent of penetration was significant, $\sim 3 \%$ in contrast to the low amount of the paracellular markers. As a comparison, numerous endogenous peptides or regulatory proteins have $<0.1 \% / \mathrm{g}$ uptake in brain and are still effective in the CNS after peripheral administration (12-14,19). Among the opiates, the centrally active morphine has an uptake of only $<0.02 \% / \mathrm{g}$ brain $(20)$.

The amount of opiorphin transferred across the BBB culture model indicates that a specific transport mechanism, a peptide transport system or receptor-mediated transcytosis, may be involved in its transfer. Six transport systems (PTS1-6) have been identified for peptides at the BBB, which transport enkephalins, arginine vasopressin, or pituitary adenylate cyclase-activating polypeptides, among others (11). The peptide/histidine transporter 2 (PHT2, SLC15a3) was described at the BBB carrying di- and tripeptides, whereas larger peptides or proteins like insulin or transferrin cross the BBB by receptor-mediated transcytosis (15). To reveal if carriers or transporters participate in opiorphin transfer, further experiments are needed.

We observed the conversion of N-terminal glutamine into pyroglutamic acid in the peptide samples. Peptide $\mathrm{N}$-terminal glutamines are prone to cyclization yielding pyroglutamic acid. This reaction can be catalyzed enzymatically by cyclization of L-glutamine and L-glutaminyl peptides (21), but the reaction also happens spontaneously, especially at acidic $\mathrm{pH}$ values. The presence of glutaminyl cyclase is described in brain but not known at the level of brain capillaries and there are no data on how pyroglutamate formation modifies the transport of peptides across the BBB. The tripeptide thyrotropin-releasing hormone contains a pyroglutamate and has a slow, but in vivo measurable penetration across the BBB (22).

The relative quantity of opiorphin penetration through the BBB culture model is obviously more elevated than values obtained with iv-administered labeled opioid peptides (14). A possible explanation for this difference is that in our culture system no serum factors were present during the experiments, which is a limitation of the model. Peptidases are active in blood and rapidly cleave the native opiorphin peptide, which has a metabolic half-life of 6 min in human plasma; therefore, enzyme activity limits the transfer of opiorphin to the CNS in vivo $(4,23,24)$. In vivo data suggest that even in the presence of serum peptidases opiorphin can cross the BBB in sufficient amounts to raise the concentration of endogenous opioid ligands by inhibiting enkephalinases; thus, it can be appropriate for producing central effects.

In conclusion, our results indicate that opiorphin crosses cultured brain endothelial cells. These data are in agreement with observations that opiorphin potentiates enkephalinmediated antinociception and exerts antidepressant-like effects. We suggest that opiorphin may have a potential for further development as a centrally acting novel drug for the treatment of pain or depression.

\section{Acknowledgments}

The study was supported by TAMOP-4.2.2A-11/1KONV-20120024 and OTKA 108518 grants.

\section{References}

1. Meert TF, Vermeirsch HA. A preclinical comparison between different opioids: antinociceptive versus adverse effects. Pharmacol Biochem Behav 2005;80:309-326.

2. Janecka A, Staniszewska R, Gach K, et al. Enzymatic degradation of endomorphins. Peptides 2008;29:2066-2073.

3. Tömböly C, Péter A, Tóth G. In vitro quantitative study of the degradation of endomorphins. Peptides 2002;23:1573-1580.

4. Wisner A, Dufour E, Messaoudi M, et al. Human opiorphin, a natural antinociceptive modulator of opioid-dependent pathways. Proc Natl Acad Sci U S A 2006;103:17979-17984.

5. Roques BP, Fournié-Zaluski MC, Wurm M. Inhibiting the breakdown of endogenous opioids and cannabinoids to alleviate pain. Nat Rev Drug Discov 2012;11:292-310.

6. Rougeot C, Robert F, Menz L, et al. Systematically active human opiorphin is a potent yet non-addictive analgesic without drug tolerance effects. J Physiol Pharmacol 2010;61:483-490.

7. Javelot H, Messaoudi M, Garnier S, et al. Human opiorphin is a naturally occurring antidepressant acting selectively on enkephalindependent delta-opioid pathways. J Physiol Pharmacol 2010;61: $355-362$.

8. Tian XZ, Chen J, Xiong W, et al. Effects and underlying mechanisms of human opiorphin on colonic motility and nociception in mice. Peptides 2009;30:1348-1354.

9. Tóth F, Tóth G, Benyhe S, et al. Opiorphin highly improves the specific binding and affinity of MERF and MEGY to rat brain opioid receptors. Regul Pept 2012;178:71-75.

10. Banks WA. Delivery of peptides to the brain: emphasis on therapeutic development. Biopolymers 2008;90:589-594.

11. Banks WA. Peptides and the blood-brain barrier. Peptides 2015; http://dx.doi.org/10.1016/j.peptides.2015.03.010.

12. Zlokovic BV, Mackic JB, Djuricic B, et al. Kinetic analysis of leucineenkephalin cellular uptake at the luminal side of the blood-brain barrier of an in situ perfused guinea pig brain. J Neurochem 1989;53: 1333-1340.

13. Weber SJ, Abbruscato TJ, Brownson EA, et al. Assesment of an in vitro blood-brain barrier model using several $\left[\mathrm{Met}^{5}\right]$ enkephalin opioid analogs. J Pharmacol Exp Ther 1993;266:1649-1655.

14. Banks WA, Kastin AJ. Passage of peptides across the blood-brain barrier. Pathophysiological perspectives. Life Sci 1996;59:1923-1943.

15. Campos-Bedolla P, Walter FR, Veszelka S, et al. Role of the bloodbrain barrier in the nutrition of the central nervous system. Arch Med Res 2014;45:610-638. 
16. Nakagawa S, Deli MA, Kawaguchi H, et al. A new blood-brain barrier model using primary rat brain endothelial cells, pericytes and astrocytes. Neurochem Int 2009;54:253-263.

17. Hülper P, Veszelka S, Walter FR, et al. Acute effects of short-chain alkylglycerols on blood-brain barrier properties of cultured brain endothelial cells. Br J Pharmacol 2013;169:1561-1573.

18. Brkljacic L, Sabalic M, Salaric I, et al. Development and validation of a liquid chromatography-tandem mass spectrometry method for the quantification of opiorphin in human saliva. J Chromatogr B Analyt Technol Biomed Life Sci 2011;879: 3920-3926.

19. Banks WA. The CNS as a target for peptides and peptide-based drugs. Expert Opin Drug Deliv 2006;3:707-712.
20. Advokat C, Gulati A. Spinal transection reduces both spinal antinociception and CNS concentration of systemically administered morphine in rats. Brain Res 1991;555:251-258.

21. Messer M. Enzymatic cyclization of L-glutamine and L-glutaminyl peptides. Nature 1963;197:1299.

22. Zloković BV, Lipovac MN, Begley DJ, et al. Slow penetration of thyrotropin-releasing hormone across the blood-brain barrier of an in situ perfused guinea pig brain. J Neurochem 1988;51:252-257.

23. Rosa M, Arsequell G, Rougeot C, et al. Structure-activity relationship study of opiorphin, a human dual ectopeptidase inhbitor with antinociceptive properties. J Med Chem 2012;55:1181-1188.

24. Rougeot $\mathrm{C}$, inventor; Opiorphin peptide derivatives as potent inhibitors of enkephalin degrading ectopeptidases. World patent 124948. 2009 
PUBLICATION II. 
Pharmaceutics, Drug Delivery and Pharmaceutical Technology

\title{
Reversible Opening of Intercellular Junctions of Intestinal Epithelial and Brain Endothelial Cells With Tight Junction Modulator Peptides
}

\author{
Alexandra Bocsik ${ }^{1,2}$, Fruzsina R. Walter ${ }^{1}$, Andrea Gyebrovszki ${ }^{3}$, Lívia Fülöp ${ }^{3}$, \\ Szilvia Veszelka ${ }^{1}$, Monika Vastag ${ }^{7}$, Piroska Szabó-Révész ${ }^{2}$, Mária A. Deli ${ }^{1,{ }^{*}}$ \\ ${ }^{1}$ Institute of Biophysics, Biological Research Centre, Hungarian Academy of Sciences, H-6726 Szeged, Hungary \\ ${ }^{2}$ Department of Pharmaceutical Technology, University of Szeged, H-6720 Szeged, Hungary \\ ${ }^{3}$ Department of Medical Chemistry, University of Szeged, H-6720 Szeged, Hungary \\ ${ }^{4}$ Leibniz Institut für Molekulare Pharmakologie, 13125 Berlin-Buch, Germany \\ ${ }^{5}$ Institute of Biochemistry, Biological Research Centre, Hungarian Academy of Sciences, H-6726 Szeged, Hungary \\ ${ }^{6}$ Department of Biotechnology, Faculty of Science and Informatics, University of Szeged, H-6726 Szeged, Hungary \\ ${ }^{7}$ Division of Pharmacology and Drug Safety Research, Gedeon Richter Plc., H-1103 Budapest, Hungary
} Ingolf Blasig ${ }^{4}$, Sebastian Dabrowski ${ }^{4}$, Ferenc Ötvös ${ }^{5}$, András Tóth ${ }^{6}$, Gábor Rákhely ${ }^{6}$,

\section{A R T I C L E I N F O}

\section{Article history:}

Received 4 October 2015

Revised 30 October 2015

Accepted 5 November 2015

\section{Keywords:}

blood-brain barrier

brain endothelial cells

Caco-2 cell line

intestinal barrier

peptides

permeability enhancer

tight junctions

TJ modulator

\begin{abstract}
A B S T R A C T
The intercellular junctions restrict the free passage of hydrophilic compounds through the paracellular clefts. Reversible opening of the tight junctions of biological barriers is investigated as one of the ways to increase drug delivery to the systemic circulation or the central nervous system. Six peptides, ADT-6, HAV-6, C-CPE, 7-mer (FDFWITP, PN-78), AT-1002, and PN-159, acting on different integral membrane and linker junctional proteins were tested on Caco-2 intestinal epithelial cell line and a coculture model of the blood-brain barrier. All peptides tested in nontoxic concentrations showed a reversible tight junctions modulating effect and were effective to open the paracellular pathway for the marker molecules fluorescein and albumin. The change in the structure of cell-cell junctions was verified by immunostaining for occludin, claudin-4,-5, ZO-1, $\beta$-catenin, and E-cadherin. Expression levels of occludin and claudins were measured in both models. We could demonstrate a selectivity of C-CPE, ADT-6, and HAV-6 peptides for epithelial cells and 7-mer and AT-1002 peptides for brain endothelial cells. PN-159 was the most effective modulator of junctional permeability in both models possibly acting via claudin- 1 and -5 . Our results indicate that these peptides can be effectively and selectively used as potential pharmaceutical excipients to improve drug delivery across biological barriers.
\end{abstract}

() 2016 American Pharmacists Association ${ }^{\mathbb{B}}$. Published by Elsevier Inc. All rights reserved.

\section{Introduction}

Biological barriers are crucial to protect organisms from harmful agents or pathogens and to establish and maintain the homeostasis of different organs, especially those of the central nervous system. ${ }^{1,2}$ However, the same mechanisms of epithelial and endothelial barriers that confer protection also restrict drug absorption and delivery. ${ }^{1,3}$ Active efflux transporters not only protect from the harmful effects of xenobiotics but also prevent the penetration of therapeutic

This article contains supplementary material available from the authors by request or via the Internet at http://dx.doi.org/10.1016/j.xphs.2015.11.018.

* Correspondence to: Mária A. Deli (Telephone: +36-62-599602; Fax: +36-62433133).

E-mail address: deli.maria@brc.mta.hu (M.A. Deli). drugs. ${ }^{4}$ Metabolic enzymes represent another element of the protective system of barriers. ${ }^{5}$ In addition, tight intercellular junctions (TJs) limit the free passage of molecules and cells through the intercellular clefts, also called as the paracellular pathway. ${ }^{1}$ Because the noninvasive delivery of hydrophilic drugs or biopharmaceuticals to the systemic circulation or to the central nervous system is still a challenge, several methods have been investigated to increase drug delivery across barriers. ${ }^{3}$ Absorption enhancers including clinically applied and novel excipients are effective to increase drug permeability across both epithelial and endothelial cell layers ${ }^{6}$; however, these act nonselectively on biological barriers ${ }^{7}$ and modulate both the tightness of intercellular junctions and the fluidity of the plasma membrane. ${ }^{8}$

TJs of barrier cells are complex structures composed of integral membrane proteins, linker proteins connecting membrane proteins 
to the actin cytoskeleton, and signaling molecules regulating paracellular tightness and transport. ${ }^{9}$ Among the transmembrane TJ proteins occludin and the members of the claudin family have a prominent role in forming paracellular barriers. ${ }^{10}$ Adherens junction proteins, such as E-cadherin in epithelial cells or VE-cadherin in endothelial cells, also participate in the regulation of paracellular permeability. ${ }^{11}$ Based on the amino acid sequence and/or the structure of these junctional proteins, peptides were designed as novel TJ modulators that directly and specifically interact with the extracellular loops (ECLs). ${ }^{12}$

In our study, 6 different modulator peptides were selected (Table 1 ) which act at different targets. ${ }^{1}$ Two hexameric peptides, ADT- 6 and HAV-6, were designed to act on the bulge and groove regions of the first extracellular domain (EC-1) of E-cadherin. ${ }^{13}$ These peptides interfere with the homophilic binding of E-cadherin, and time- and dose-dependently increase the paracellular permeability in different epithelial cells. ${ }^{14,19}$ Two TJ modulators used in the experiments are derived from microbial toxins. The Cterminal 16-residue long fragment of Clostridium perfringens enterotoxin (C-CPE) targets claudins. ${ }^{15} \mathrm{C}$-CPE acts specifically at the ECL2 of claudin-4 and -3 to increase intestinal permeability in vivo and in vitro. ${ }^{20,21}$ AT-1002 peptide, an active fragment of zonula occludens toxin, a Vibrio cholerae enterotoxin, increases the permeability of epithelial, especially intestinal barriers, ${ }^{16}$ similar to the full length microbial pathogenic factor. ${ }^{22}$ The last 2 peptides, 7-mer (PN-78) and PN-159, were identified on ethylene glycol tetraacetic acid (a calcium chelating reagent)-treated human bronchial epithelial cells by phage display. ${ }^{17,18}$ PN-159 effectively increases the permeability of respiratory epithelium in cultures and in animals. ${ }^{23}$ The specific targets of these peptides are unknown; they probably interact with the extracellular domain of integral membrane TJ protein(s). These 6 peptides were not investigated in a comparative way for their efficacy on the same model or for their specificity on different, epithelial versus endothelial barrier models.

For our experiments, 2 well-characterized culture models of the intestinal and the blood-brain barriers (BBBs) were used. The laboratory of Professor Borchardt introduced the Caco-2 cell line as a model system for intestinal epithelial permeability ${ }^{24}$ and brain microvessel endothelial cell monolayers as a model to estimate solute permeability through the BBB. ${ }^{25}$ Since the pioneering publication on Caco-2 cells, the application of this human intestinal epithelial cell line has become widespread in pharmaceutical research, especially in drug permeability studies. ${ }^{26}$ In the field of BBB models, in the last 20 years, monocultures were replaced by coculture models, in which astrocytes and/or pericytes induce BBB characteristics in brain endothelial cells. ${ }^{27,28}$ The primary cell-based rat BBB in vitro triple coculture model has high complexity and predictive value for drug penetration and was favorably compared with surrogate models of the BBB. ${ }^{29,30}$

TJ modulator peptides hold a great promise as drug absorption enhancers, but more data are needed on their efficacy, mode of action, reversibility, and safety before their application in clinical studies. The expression patterns of tight and adherens junction proteins are specific for different types of barriers providing an opportunity for selective modulation of paracellular permeability, but this approach remained largely unexploited so far. Because of these reasons, the aim of the present study was to compare the efficacy of 6 selected TJ modulator peptides on culture models of both the intestinal barrier and the BBB. In addition to barrier integrity measurements, cell morphology was also investigated. Because safety is a crucial parameter, cellular toxicity and reversibility was also measured. For the selective applications of peptides, the mode of action and/or the target of the TJ modulator is needed; therefore, the potential binding partners of the peptides discovered by phage display were investigated.

\section{Materials and Methods}

\section{Materials}

All reagents were purchased from Sigma-Aldrich Ltd. (Budapest, Hungary) except for those specifically mentioned.

\section{Peptide Synthesis}

The sequence of peptides is shown in Table 1. Peptides were synthesized manually on a $0.5-\mathrm{mM}$ scale with the use of standard Fmoc-chemistry on a Rink-amide resin. Couplings were performed in dimethylformamide with 3-fold excess of N, $\mathrm{N}^{\prime}$-dicyclohexylcarbodiimide, hydroxybenzotriazole, and Fmoc-amino acids for 3 $\mathrm{h}$ at ambient temperature. Fmoc deprotection was performed in $20 \%$ piperidine and dimethylformamide mixture for $20 \mathrm{~min}$. The peptides were cleaved from the resin by incubating it with the mixture of trifluoroacetic acid (TFA)/water/triisopropyl silane (48:1:1) at room temperature for $3 \mathrm{~h}$, precipitated and washed with diethyl-ether, and then, lyophilized. Crude peptides were purified using a Shimadzu semipreparative high-performance liquid chromatography system equipped with a Phenomenex Jupiter C18 column in the following solvent system: (A) $0.1 \%$ aqueous TFA and (B) $0.1 \%$ TFA in $80 \%$ aqueous acetonitrile, in a linear gradient mode. Analysis and purity control was carried out on an analytical HPLC instrument (HP Model 1100 liquid chromatograph equipped with a Phenomenex Jupiter C18 column). Quality control of the peptides was done by performing mass spectrometric measurements on a Finnigan TSQ-7000 triple quadrupole mass spectrometer in positive ion mode.

\section{Cell Cultures}

Human Caco-2 intestinal epithelial cell line (ATCC cat.no. HTB37) selected by vinblastine was used until passage 60 for the experiments. Vinblastine treatment ( $10 \mathrm{nM}$ for 6 passages) induced more homogeneous cell morphology and higher expression level of efflux pumps. ${ }^{31}$ Caco-2 cells were grown in DMEM/HAM's F-12 culture medium with stable glutamine (Biochrom $\mathrm{GmbH}$, Berlin, Germany) supplemented with $10 \%$ fetal bovine serum (Pan-Biotech $\mathrm{GmbH}$, Aidenbach, Germany) and $50-\mu \mathrm{g} / \mathrm{mL}$ gentamycin in a humidified incubator with $5 \% \mathrm{CO}_{2}$ at $37^{\circ} \mathrm{C}$. All plastic surfaces were coated with $0.05 \%$ rat tail collagen in sterile distilled water before cell seeding.

Table 1

Characteristics of the Selected Modulator Peptides

\begin{tabular}{|c|c|c|c|c|c|}
\hline Peptide & Target & Mechanism & Amino Acid Sequence & Derived From & Reference \\
\hline ADT-6 & E-cadherin & EC1 domain analogue & Ac-ADTPPV-NH2 & Designed to target EC1 domain & 13 \\
\hline HAV-6 & E-cadherin & EC1 domain analogue & Ac-SHAVSS-NH2 & Designed to target EC1 domain & 14 \\
\hline C-CPE & Claudin-3, -4 & Interact with EC1 domain & NH2-SSYSGNYPYS ILFQKF-OH & Microbial toxin fragment & 15 \\
\hline AT-1002 & $\mathrm{ZO}-1$ & Zot receptor & FCIGRL & Microbial toxin fragment & 16 \\
\hline 7-mer/PN-78 & Unknown & - & FDFWITP & Phage display & 17 \\
\hline PN-159 & Unknown & - & NH2-KLALKLALKALKLAALKLA-amide & Phage display & 18 \\
\hline
\end{tabular}


Primary cultures of brain endothelial cells, glial cells, and pericytes, and the in vitro BBB model were prepared according to the method described in our previous study. ${ }^{29}$ Brain endothelial cells were cultured in DMEM/F-12 (Gibco, Life Technologies, Carlsbad, CA), $15 \%$ plasma-derived bovine serum (First Link, Wolverhampton, UK), $100-\mu \mathrm{g} / \mathrm{mL}$ heparin, $5-\mu \mathrm{g} / \mathrm{mL}$ insulin, $5-\mu \mathrm{g} / \mathrm{mL}$ transferrin, $5-\mathrm{ng} / \mathrm{mL}$ sodium selenite, $1-\mathrm{ng} / \mathrm{mL}$ basic fibroblast growth factor (Roche, Basel, Switzerland), and $50-\mu \mathrm{g} / \mathrm{mL}$ gentamycin. During the first 3 days of culture, the medium of brain endothelial cells contained $3-\mu \mathrm{g} / \mathrm{mL}$ puromycin to eliminate P-glycoprotein negative, contaminating cell types. ${ }^{32}$ During the experiments, brain endothelial cells were always seeded on surfaces coated with $100-\mu \mathrm{g} / \mathrm{mL}$ collagen type IV and $100-\mu \mathrm{g} / \mathrm{mL}$ fibronectin in sterile distilled water. Primary rat brain pericytes were isolated by the same method, except pericytes were plated onto uncoated Petri dishes (Orange Scientific, Braine-l'Alleud, Belgium). Primary cultures of rat glial cells were prepared from one-day-old Wistar rats ${ }^{32}$ and passaged to 12-well dishes (Corning, Costar, New York, NY) coated with 100$\mu \mathrm{g} / \mathrm{mL}$ collagen type IV in sterile distilled water and cultured for 2 weeks before using the triple coculture model. Pericytes and glial cells were cultured in DMEM/HAM's F-12 supplemented with 10\% fetal bovine serum (Pan-Biotech $\mathrm{GmbH}$ ) and $50-\mu \mathrm{g} / \mathrm{mL}$ gentamycin. For the triple coculture model, pericytes (P3) were passaged to the bottom side of 12-well tissue culture inserts (Transwell 3460, polyester membrane, $0.4 \mu \mathrm{m}$ pore size; Corning Costar) at a density of $1.5 \times 10^{4}$ cells $/ \mathrm{cm}^{2}$. Endothelial cells were seeded to the upper side of the membranes $\left(8 \times 10^{4}\right.$ cells $\left./ \mathrm{cm}^{2}\right)$ and placed to 12 -well plates containing glial cells. Both compartments received endothelial culture medium, and the 3 types of cells were cultured together for 4 or 5 days. ${ }^{29,33}$ When brain endothelial cell layers became confluent, 550-nM hydrocortisone was added to tighten the junctions. ${ }^{34}$ For experiments with Caco- 2 cells, passage numbers were close to each other. For the BBB model, primary cultures were obtained from several isolations, but the barrier parameters were very similar in the assays.

\section{Peptide Treatment}

The stock solutions (10 mM) were prepared freshly, ADT-6, HAV6, C-CPE, and AT-1002 peptides were dissolved in sterile distilled water, whereas 7-mer PN-78 and PN-159 peptides were dissolved in sterile DMSO. Treatment solutions were further diluted in RingerHepes (150-mM NaCl, 6-mM $\mathrm{NaHCO}_{3}, 5.2-\mathrm{mM} \mathrm{KCl,} \mathrm{2.2-} \mathrm{mM} \mathrm{CaCl}_{2}$, 0.2-mM $\mathrm{MgCl}_{2}$, 2.8-mM D-glucose, 5-mM Hepes; $\mathrm{pH} 7.4$ ) or cell culture medium. Peptide concentrations were selected based on references shown in Table 1 . In a previous study, both E-cadherin peptides were used at $1-\mathrm{mM}$ concentration. ${ }^{13}$ In our tests, $1-\mathrm{mM}$ concentration of ADT- 6 or HAV-6 did not increase the permeability of Caco-2 cell layers for fluorescein; therefore, 2-mM was used, which enhanced the permeability but showed no toxicity (Supplementary Figs. S1 and S2). C-CPE peptide was effective in 1 -mM concentration without negative influence on the cell viability (Supplementary Figs. S1 and S2). Caco-2 cells were treated with AT-1002 peptide in higher $(5 \mathrm{mM})$ concentrations in another work, ${ }^{16}$ but brain endothelial cells were sensitive even for $2 \mathrm{mM}$ for longer treatments (Supplementary Fig. S3); therefore, $2 \mathrm{mM}$ was selected as a safe concentration for $1 \mathrm{~h}$ on both models (Supplementary Figs. S1 and S2). In the case of 7-mer PN-78, we applied 100- $\mu \mathrm{M}$ concentration, which was also used in bronchial epithelial cells. ${ }^{17}$ PN-159 was used at $10-\mu \mathrm{M}$ concentration, which was effective on epithelial cells. ${ }^{18}$ Higher concentrations were toxic on both models (Supplementary Figs. S1 and S2). Final concentrations of the peptides in treatment solutions were as follows: 2 mM for ADT-6, HAV-6, and AT-1002 peptides; $1 \mathrm{mM}$ for C-CPE peptide; $100 \mu \mathrm{M}$ for 7-mer peptide; and $10 \mu \mathrm{M}$ for $\mathrm{PN}-159$ peptide.

\section{Cell Viability Assays}

For the cell viability assays, Caco-2 epithelial cells and rat brain endothelial cells were seeded to 96 -well plates at the density of $6 \times 10^{3}$ cells/well (Orange Scientific) and cultured for 3-5 days. Confluent cultures were treated with peptides in phenol red free DMEM (Life Technologies, Gibco) for $1 \mathrm{~h}$. To determine the 100\% toxicity, cells were incubated with $1 \mathrm{mg} / \mathrm{mL}$ Triton X-100 detergent. After treatment, the medium was changed and $0.5-\mathrm{mg} / \mathrm{mL} 3-(4,5-$ dimethyltiazol-2-yl)-2,5-diphenyltetrazolium bromide (MTT) solution was added to the cells for $3 \mathrm{~h}$ in a $\mathrm{CO}_{2}$ incubator. The metabolic activity of cells is reflected by the conversion of the yellow MTT dye to purple formazan. Formazan crystals were dissolved in DMSO, and the amount of converted dye was determined by measuring the absorbance at $595 \mathrm{~nm}$ wavelength with a microplate reader (Fluostar Optima; BMG Labtechnologies, Ortenberg, Germany). Cell viability and/or metabolic activity was calculated as the percentage of dye conversion by nontreated cells.

Kinetics of epithelial and endothelial cell reaction to peptide treatment were monitored by impedance measurement at $10 \mathrm{kHz}$ (RTCA-SP instrument; ACEA Biosciences, San Diego, CA). Impedance measurement is label-free, real time, noninvasive, and correlates linearly with adherence, growth, number, and viability of cells. ${ }^{6,35}$ For background measurements, $50-\mu$ L cell culture medium was added to the wells, then cells were seeded at a density of $6 \times$ $10^{3}$ cells/well to coated 96-well plates with integrated gold electrodes (E-plate 96, ACEA Biosciences). Cells were cultured for 5-7 days in $\mathrm{CO}_{2}$ incubator at $37^{\circ} \mathrm{C}$ and monitored every $10 \mathrm{~min}$ until the end of experiments. At the beginning of plateau phase of growth, cells were treated with peptide solutions, and the effects were followed for $24 \mathrm{~h}$. Triton X-100 detergent $(1 \mathrm{mg} / \mathrm{mL})$ was used as a reference compound inducing cell toxicity. Cell index was defined as $\mathrm{Rn}-\mathrm{Rb}$ at each time point of measurement, where $\mathrm{Rn}$ is the cellelectrode impedance of the well when it contains cells and $\mathrm{Rb}$ is the background impedance of the well with the medium alone.

\section{Measurement of the Integrity of the Paracellular Barrier}

Transepithelial or transendothelial electrical resistance (TEER) reflects the tightness of the intercellular junctions. ${ }^{36}$ TEER was measured by an EVOM volt-ohmmeter (World Precision Instruments, Sarasota, FL) combined with STX-2 electrodes and was expressed relative to the surface area of the monolayers, $\Omega \times \mathrm{cm}^{2}$. Resistance of cell-free inserts $\left(130 \Omega \times \mathrm{cm}^{2}\right)$ was subtracted from the measured values.

For permeability tests, Caco- 2 cells were seeded onto Transwell inserts and cultured for 3 weeks. ${ }^{8,30}$ The BBB model was used after 4-5 days of coculture. For both models, culture medium was changed and resistance was checked every second day. For the experiment, inserts were transferred to 12 -well plates containing 1.5-mL Ringer-Hepes buffer in the lower (basal and/or abluminal) compartments. In the upper (apical and/or luminal) compartments, culture medium was replaced by $0.5-\mathrm{mL}$ buffer containing peptide solutions for $1 \mathrm{~h}$. Permeability marker molecules albumin $(1 \mathrm{mg} /$ $\mathrm{mL}$; molecular weight: $65 \mathrm{kDa}$ ) labeled with Evans blue (167.5 $\mu \mathrm{g}$ / $\mathrm{mL})$ and fluorescein $(10 \mu \mathrm{g} / \mathrm{mL}$; molecular weight: $376 \mathrm{Da})$ were added 30 min later. The incubation with permeability markers in the presence of peptides lasted for $30 \mathrm{~min}$. Samples were collected from both compartments, and the concentrations of the marker molecules were determined by a fluorescence multi-well plate reader (Fluostar Optima; excitation wavelength: $485 \mathrm{~nm}$, emission wavelength: $535 \mathrm{~nm}$ in the case of fluorescein and excitation wavelength: $584 \mathrm{~nm}$, emission wavelength: $680 \mathrm{~nm}$ in the case of Evans blue-labeled albumin). To test the reversibility of the peptide effect, inserts with the cells were placed back to the culture 
plates containing medium after the permeability tests. Treatment solutions from the upper compartments were removed and after a gentle wash were changed for culture medium. Cells were kept in a $\mathrm{CO}_{2}$ incubator at $37^{\circ} \mathrm{C}$ for $24 \mathrm{~h}$; then, after the measurement of TEER, the permeability experiments were repeated.

The apparent permeability coefficients $\left(\mathrm{P}_{\mathrm{app}}\right)$ were calculated as described previously. ${ }^{8,35}$ Briefly, cleared volume was calculated from the concentration difference of the tracer in the lower and/or basal compartment $\left(\Delta[C]_{B}\right)$ after $30 \mathrm{~min}$ and upper and/or apical compartments at $0 \mathrm{~h}\left([\mathrm{C}]_{A}\right)$, the volume of the lower and/or basal compartment $\left(\mathrm{V}_{\mathrm{B}} ; 1.5 \mathrm{~mL}\right)$, and the surface area available for permeability $\left(A ; 1.1 \mathrm{~cm}^{2}\right)$.

\section{Immunohistochemistry}

Morphologic changes in epithelial and endothelial barrier integrity were followed by immunostaining for integral membrane tight junction proteins occludin and claudin-5, adherens junction protein E-cadherin, and cytoplasmic linker proteins $\beta$-catenin and zonula occludens protein-1 (ZO-1). After permeability tests, inserts were washed with phosphate-buffered saline (PBS). In the case of $\mathrm{BBB}$, model pericytes were removed from the bottom of the membranes, then brain endothelial or epithelial cells were fixed with 1:1 mixture of ice cold acetone and methanol for $10 \mathrm{~min}$ at room temperature. Cells were blocked with $3 \%$ bovine serum albumin in PBS and incubated with primary antibodies rabbit antioccludin, mouse anti-claudin-5, mouse anti-E-cadherin, rabbit anti-ZO-1, and rabbit anti- $\beta$-catenin (Life Technologies) overnight. Incubation with secondary antibodies Alexa Fluor-488-labeled anti-mouse (Life Technologies, Invitrogen) and Cy3-labeled antirabbit lasted for $1 \mathrm{~h}$. Hoechst dye 33342 was used to stain cell nuclei. After mounting the samples (Fluoromount-G; Southern Biotech, Birmingham), staining was visualized by a Leica TCS SP5 confocal laser scanning microscope (Leica Microsystems $\mathrm{GmbH}$, Wetzlar, Germany).

\section{Quantitative Real-Time Polymerase Chain Reaction (RT-PCR)}

Gene expression analysis was performed as described recently by our group. ${ }^{33,37}$ Confluent cultures were washed, scraped, and collected, and cell pellets were used for total RNA isolation using RNAqueous-4PCR Kit (Life Technologies, Ambion, Austin, TX). cDNA synthesis was performed by High Capacity cDNA Reverse Transcription Kit (Life Technologies). The expression of occludin and the selected claudin genes were analyzed by quantitative PCR using TaqMan Low Density Array 384-well microfluidic cards preloaded with inventoried TaqMan Gene Expression Assays (Supplementary Table S1; Life Technologies, Applied Biosystems, Austin, TX). Expression of all genes was normalized to the $18 \mathrm{~S}$ ribosomal RNA as endogenous control, highly expressed in eukaryotic cells. Expression values of studied genes were determined by the correlation of normalized expression of genes calculated by $2^{-\Delta \mathrm{Ct}}$ formula to the lowest expression level which can be safely detected by this RT-PCR method.

\section{Microscale thermophoresis}

Association between peptide and claudins was measured with microscale thermophoresis. ${ }^{38}$ The claudins carried yellow fluorescence protein, ${ }^{39}$ and the peptide was added in defined amounts as titration series (in PBS, 15 dilutions). After incubation $\left(1 \mathrm{~h}, 22^{\circ} \mathrm{C}\right)$, samples were loaded into standard treated capillaries, and fluorescence was measured with Monolith ${ }^{\mathrm{TM}}$ NT.115 (light-emitting diode power $50 \%$, infrared laser power $80 \%$, laser-on time $35 \mathrm{~s}$ ). Evaluation was performed with NT Analysis software 1.2.229
(NanoTemper, Munich, Germany). Binding was characterized by dissociation constant $\left(\mathrm{K}_{\mathrm{d}}\right)$. Determination was achieved using saturation-binding curves obtained at equilibrium. ${ }^{40}$

\section{Molecular Modeling}

Protein structures were obtained by homology modeling using the MODELLER program package. ${ }^{41}$ First, the structure of mouse claudin-15 was completed by homology modelling because its $\mathrm{X}$-ray structure file is lacking the fragment of residues from 34 to $41 .^{42}$ Human claudins 1,3 , and 5 were homology modeled using the completed mouse claudin-15 as a template. The protein homology models were further relaxed by a short (400 ns) molecular dynamics simulation in which the proteins were embedded in a 95 by $95 \AA$ POPC bilayer-water system containing $150-\mathrm{mM}$ $\mathrm{NaCl}$. Molecular dynamics simulations were performed by the program NAMD, ${ }^{43}$ using the CHARMM27 molecular force field with CMAP correction. The results were visualized by VMD, v1.9.1. ${ }^{44}$ The docking studies were performed by the CABS docking server, ${ }^{45}$ and the resulted C-alpha traces were reconstructed by MODELLER using the python script supplied by the server homepage.

\section{Statistical Analysis}

For statistical analysis, GraphPad Prism 5.0 software (GraphPad Software Inc., San Diego, CA) was used. All data presented are means \pm SD. Values were compared using ANOVA followed by Dunnett's test and $t$ test. Changes were considered statistically significant at $p<0.05$. All measurements were repeated 3 times, and the number of parallel samples in the experiments (n) was 3-6, which depended on the type of assays.

\section{Results}

\section{Effect of Tight Junction Modulator Peptides on Cell Viability}

Based on the colorimetric end point, dye conversion MTT assay treatments with peptides ADT-6, HAV-6, and AT-1002 in $2 \mathrm{mM}$; $\mathrm{C}-\mathrm{CPE}$ in $1 \mathrm{mM}$; 7-mer in $100 \mu \mathrm{M}$; and PN-159 in $10 \mu \mathrm{M}$ concentrations for $1 \mathrm{~h}$ did not cause significant change in the metabolic activity of Caco-2 epithelial (Fig. 1a) or brain endothelial cells (Fig. 1b). Impedance measurement, a sensitive method to detect cellular effects, revealed no decrease for a 1-h treatment in Caco-2 cells (Fig. 1c). Brain endothelial cells were more sensitive; ADT-6, HAV-6, and AT-1002 peptides caused 15\%-20\% decrease in cell layer impedance after 1 -h treatment. As a comparison, Triton X-100 caused $100 \%$ toxicity in both assays (Fig. 1 ).

Long-term effect of peptides on epithelial and endothelial barriers was also determined (Supplementary Fig. S3). In Caco-2 layers, no change was seen in impedance except for a temporary increase after PN-159 peptide treatment. In brain endothelial cells, only AT1002 and C-CPE peptides decreased significantly the cell index after $24 \mathrm{~h}$. The effects of peptides with scrambled sequences were tested on epithelial cells, and no change in cell index was seen until $24 \mathrm{~h}$ (Supplementary Fig. S4).

\section{Effect of Tight Junction Modulator Peptides on Barrier Integrity}

All 6 peptides significantly decreased the TEER of Caco-2 layers after 1-h treatment (Fig. 2a). Treatments with ADT-6, C$\mathrm{CPE}$, and PN-159 reduced the resistance of cell layers by more than $50 \%$, whereas 7-mer, HAV-6, and AT-1002 caused a 30\%-45\% drop as compared with control $\left(1309 \pm 97 \Omega \times \mathrm{cm}^{2}\right)$. The resistance of brain endothelial monolayers was also decreased by the 
a

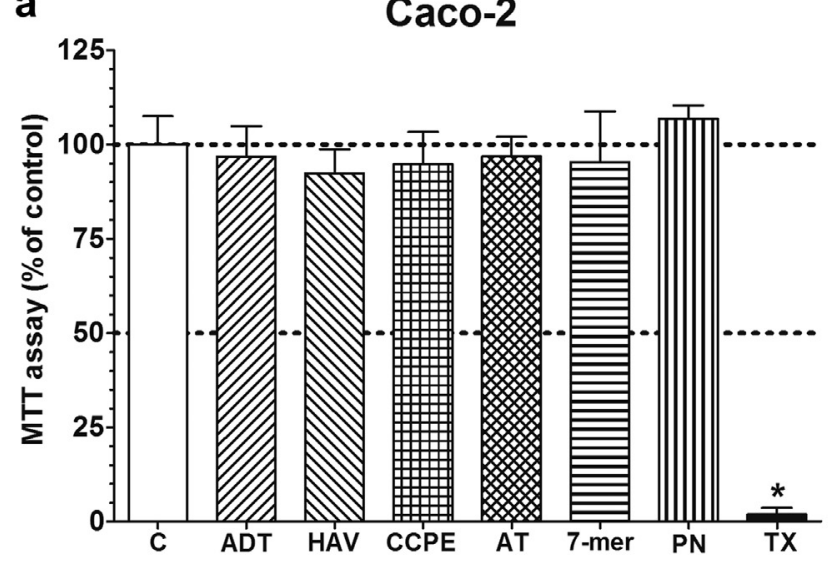

C

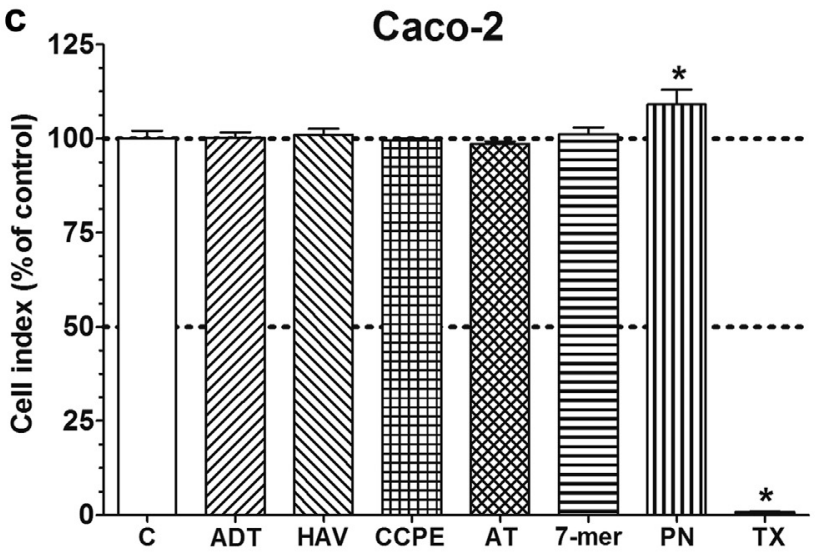

b
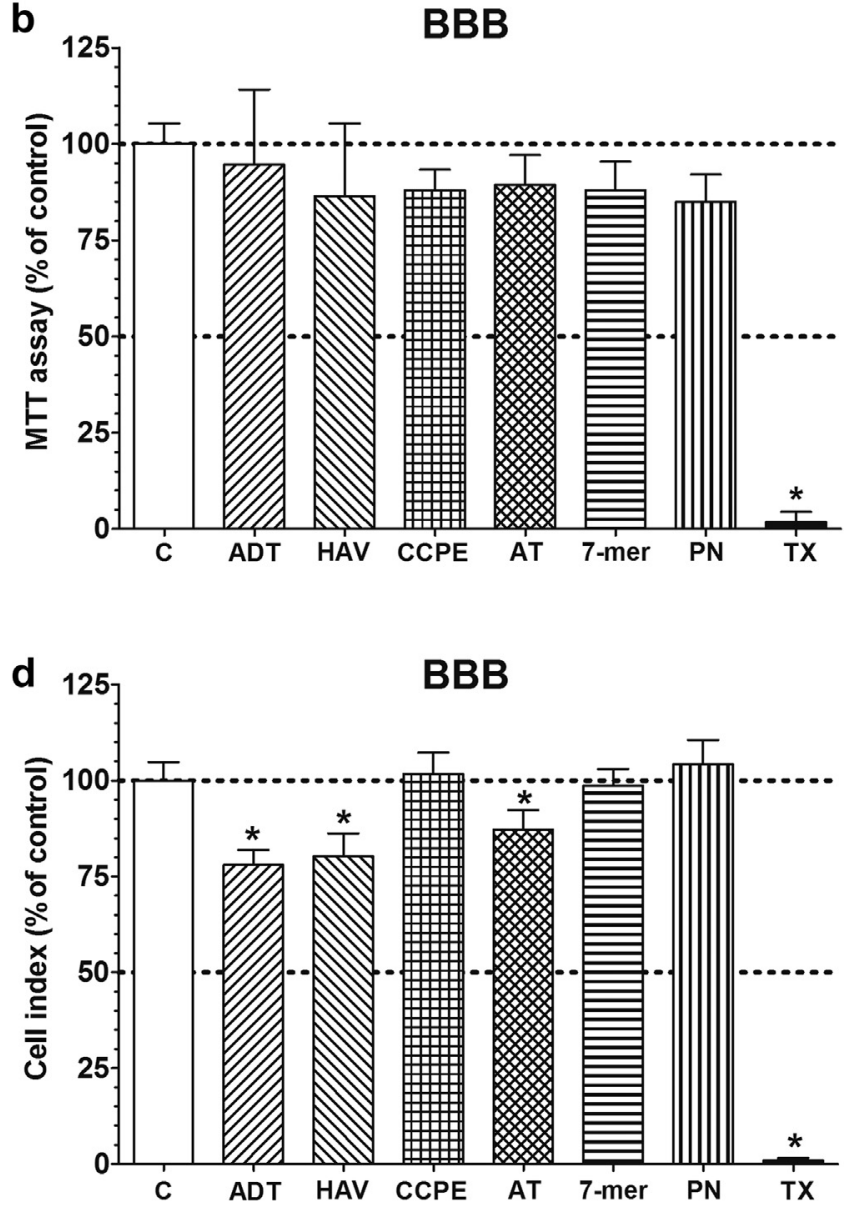

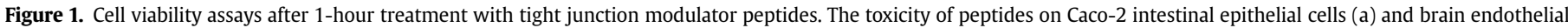

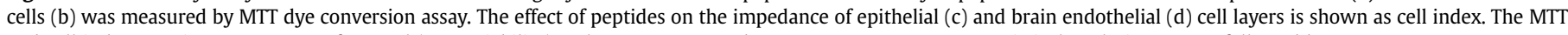

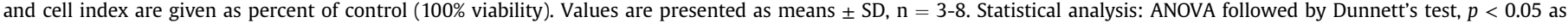
compared with the control groups.

peptides, except C-CPE peptide, which had no significant effect (Fig. 2b). The TJ modulator peptides caused less than $50 \%$ reduction of TEER compared with control $\left(314 \pm 48 \Omega \times \mathrm{cm}^{2}\right)$. PN-159 peptide was the most effective on both models (Fig. 2). Barrier integrity was recovered in both models in all treatment groups after $24 \mathrm{~h}$.

The modulator peptides increased the permeability of Caco-2 layers for fluorescein and albumin markers (Figs. 3a and 3b). ADT-6, HAV-6, and especially PN-159 peptides were the most effective. PN-159 peptide increased the epithelial permeability for fluorescein more than 200-fold and for albumin around 30fold. The 7-mer peptide had no effect on fluorescein flux, but increased the permeability of albumin. Scrambled peptides had no influence on intestinal barrier integrity. Neither fluorescein nor albumin permeability changed after 1 -h treatment (Supplementary Fig. S5).

On the BBB model, AT-1002, 7-mer, and PN-159 peptides significantly enhanced the permeability of both markers (Figs. 3c and 3d). AT-1002 and 7-mer peptides increased the flux of markers 3.5 to 6 -fold, whereas $\mathrm{PN}-159$ peptide showed the highest effect with about 10-fold increase. In the BBB model, E-cadherin peptides had a small effect on fluorescein, but not on albumin penetration, whereas C-CPE had no effect (Figs. 3c and 3d).

Permeability assays were repeated after 24-h recovery, and the TJ modulating effect of the peptides were reversible on both Caco-2 and BBB models (Fig. 3).
Effect of Modulator Peptides on the Morphology of Intercellular Junctions

In both culture models, the cells were tightly apposed and all junctional proteins were localized at the intercellular connections forming pericellular belts in control groups (Figs. 4 and 5). The E-cadherin peptides had robust effects on junctions of Caco- 2 cells, fragmentation of $\beta$-catenin and E-cadherin stainings at the cell border and redistribution of the immunostaining to the cytoplasm were observed (Fig. 4). Microbial toxin C-CPE peptide caused visible changes in ZO-1, $\beta$-catenin, and occludin immunostaining, labeling at the cell borders markedly decreased. AT-1002 and 7-mer peptides had slight effect on these junctional proteins. ZO-1 immunolabeling was less changed for peptide treatments, except PN-159. Epithelial junctional morphology was drastically changed by PN-159, ZO-1, and $\beta$-catenin proteins partially disappeared from cell borders. Occludin immunostaining in several cells became absent in cell contacts, enriched in the cytoplasm, and showed spotty staining pattern (Fig. 4).

All peptides, except C-CPE, influenced junctional morphology at the BBB model (Fig. 5). E-cadherin peptides, AT-1002, and 7-mer peptides had similar effects on immunostaining of ZO-1, $\beta$-catenin, and claudin-5 proteins, labeling was less sharp on cell borders, and gaps and holes appeared between the cells. PN-159 peptide caused the biggest change in immunostainings for all 3 proteins in brain endothelial cell junctions (Fig. 5). A strong decrease of the staining at 
a

\section{Caco-2}
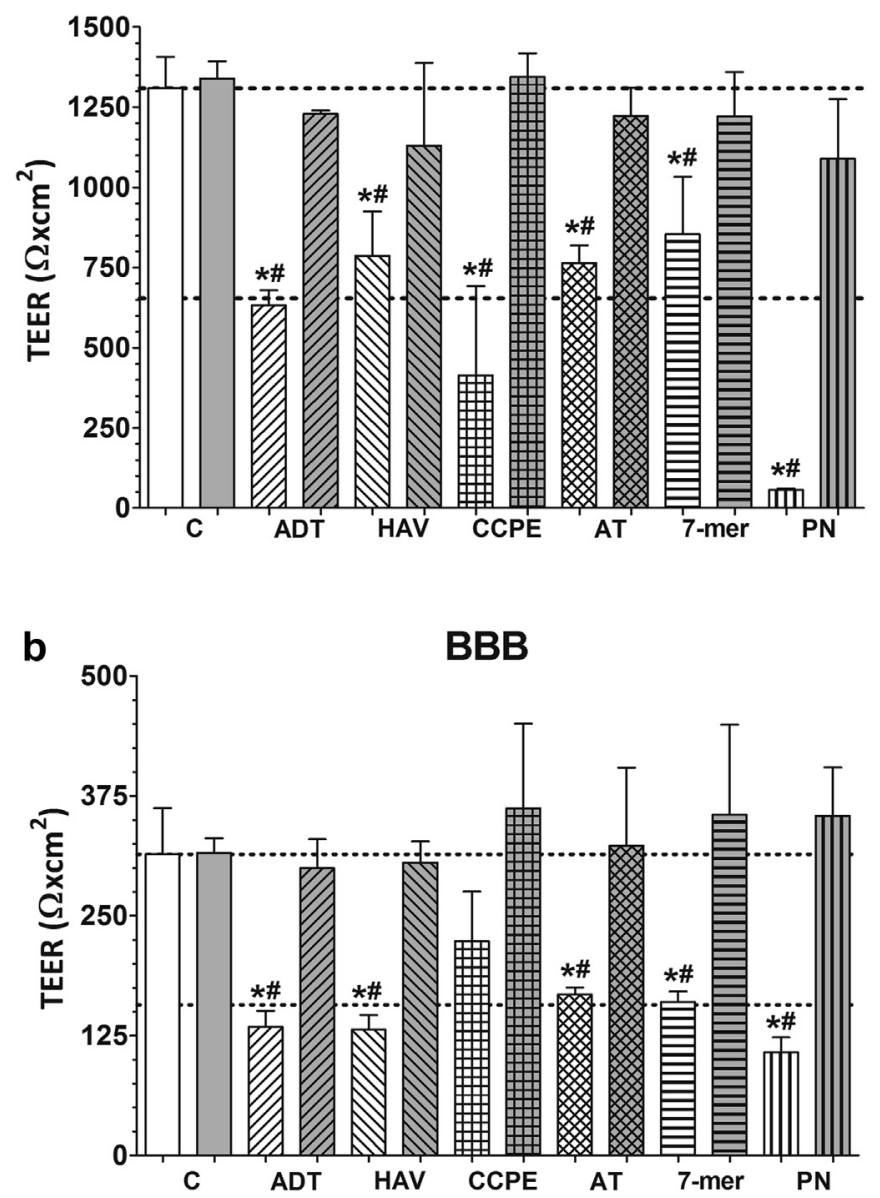

Figure 2. Effects of modulator peptides on the resistance of Caco-2 epithelial (a) and brain endothelial (b) cell layers. White columns represent the effect of 1-h peptide treatment and gray columns show resistance after 24-h recovery. Data are presented as means $\pm \mathrm{SD}, \mathrm{n}=3-6$. Statistical analysis: ANOVA followed by Dunnett's test. Statistically significant differences are: ${ }^{*} p<0.05$, compared to control group (Caco-2: $1309 \pm 97 \Omega \times \mathrm{cm}^{2}$; BBB: $314 \pm 48 \Omega \times \mathrm{cm}^{2}$ ); \#p < 0.05 compared to control group value 24-h later (Caco-2: $1338 \pm 53 \Omega \times \mathrm{cm}^{2}$; BBB: $350 \pm 60 \Omega \times \mathrm{cm}^{2}$ ).

the cell border was accompanied by an increase in staining over cell bodies. The morphologic changes caused by the peptides were reversible after 24 -h recovery in both models.

\section{Gene Expression of Occludin and Claudins}

Occludin mRNA was highly expressed in both models (Fig. 6). In vinblastine-selected Caco- 2 cells, the expression of claudin-1, $-3,-4$, and -7 genes were the highest, whereas claudin- $5,-11$, and -19 were not expressed. In contrast, in brain endothelial cells, claudin-5 mRNA was the most abundant, similar to isolated brain capillary data. ${ }^{46,47}$ High levels of claudin-11 and -15 and lower levels of claudin-1 and -3 mRNA were measured in our culture BBB model. Claudin-11 and -15 mRNA expression was also detected in mouse brain capillary endothelial cells. ${ }^{46}$ In freshly isolated mouse brain endothelial cells, low levels of claudin $-1^{46}$ and claudin $-3^{47}$ mRNA were described. No expression of genes of claudin- $7,-8,-14$, and -16 was measured in the BBB model. Claudin-18 was not found in the cultures.

\section{Affinity Measurements of Peptides to Claudin Proteins}

High-affinity binding of $\mathrm{PN}-159$ was detected by microscale thermophoresis to claudin-5-YFP $\left(K_{d}: 327 \mathrm{nM}\right)$ and claudin-1-YFP
$\left(\mathrm{K}_{\mathrm{d}}: 820 \mathrm{nM}\right)$. Unspecific binding $\left(\mathrm{K}_{\mathrm{d}}>4000 \mathrm{nM}\right)$ was measured for claudin-3-YFP and YFP (negative control; Figs. 7a and 7b).

\section{Molecular Modeling of Claudin-1, -3 and -5 and Docking PN-159 Peptide to the Extracellular Portion}

Docking of PN-159 peptide to full length homology-modeled human claudin monomers 1,3 , and 5 was performed on the CABS server. Favorable docking poses were seeked by both energetic and geometric considerations. Docking poses located around ECLs and the short extracellular helix of the proteins were analyzed in all docking trajectories. Docking energies ("total energy") were decomposed to "ligand energy," "interaction energy," and "receptor energy" parts (Supplementary Table S2). Correct docking poses were expected to have low values not only for the total energies but also as low as possible for all energy components simultaneously. Thus, the "ligand energy," "interaction energy," and "total energy" values were investigated. For comparison, total energies were normalized in the sense that, for each claudin, the total energy was decreased by the maximum value of the total energy. Based on the modeling, energetically highly favorable interactions were found between PN-159 and the ECL1 of claudin-5 and claudin-1 but not for claudin-3 (Supplementary Table S2). The energy values from modeling correlate well with the rank order of the binding of PN159 to the tested claudins (Figs. 7a). Docked poses of PN-159 with ECL1 of claudin-1 and -5 are shown on Figures $7 c$ and $7 d$. In case of human claudin-1, the following residues participate in major interactions with PN-159 peptide: K65 with L19 (polar) and D68 with K20 (ionic). In addition, N39, I40, and Q44 form a hydrophobic pocket accomodating $\mathrm{L} 5$ of the peptide (Fig. 7c). This later interaction may contribute to the disappearance of $\beta$-strands 1 and 5 . Two major interactions were observed between claudin-5 ECL1 and PN159 peptide: Q63 with K12 (polar) and a stronger ionic interaction between D68 and K1 (Fig. 7d). Binding of PN-159 to claudin-5 disrupted all $\beta$-strands in ECLs. Supplementary Fig. S6 shows a docking pose of PN-159 to claudin-5 with a weaker, but still more favorable, total energy as compared to claudin- 1 and -3 (Supplementary Table S2). In this case, 2 polar interactions were found between N39 and K9 and Q57 and K17 leaving all $\beta$-strands intact.

\section{Discussion}

This study compared for the first time the effects of 6 modulator peptides acting on different targets on 2 culture models of different barriers, namely the intestinal and the BBBs. All peptides induced reversible opening of junctions, but selectivity and differences in efficacy were observed. Potential targets of the most effective peptide PN-159 were identified as claudin- 5 and -1 by affinity measurement and molecular modeling.

\section{Peptides Acting on E-cadherin}

Peptides HAV-6 designed for the bulge and ADT- 6 designed for the groove regions of the EC1 domain of E-cadherin ${ }^{13}$ increased the permeability for marker molecules and decreased the TEER on Caco-2 intestinal cell layers (Figs. 2 and 3). Our results are similar to those described on $\mathrm{MDCK}^{13}$ and Caco-2 epithelial cells. ${ }^{14}$ We verified that the TJ modulator effect is reversible for both peptides. Full recovery of the barrier properties was also proved by immunostaining (Fig. 4). Both peptides decreased TEER and induced reversible changes in immunostaining on the BBB model, but only ADT-6 induced an increase in paracellular permeability for the small marker. In contrast to epithelial cells, ADT-6 did not change the flux of albumin, and HAV-6 had no effect on the permeability of markers in cultured endothelial cells. A possible explanation for the 

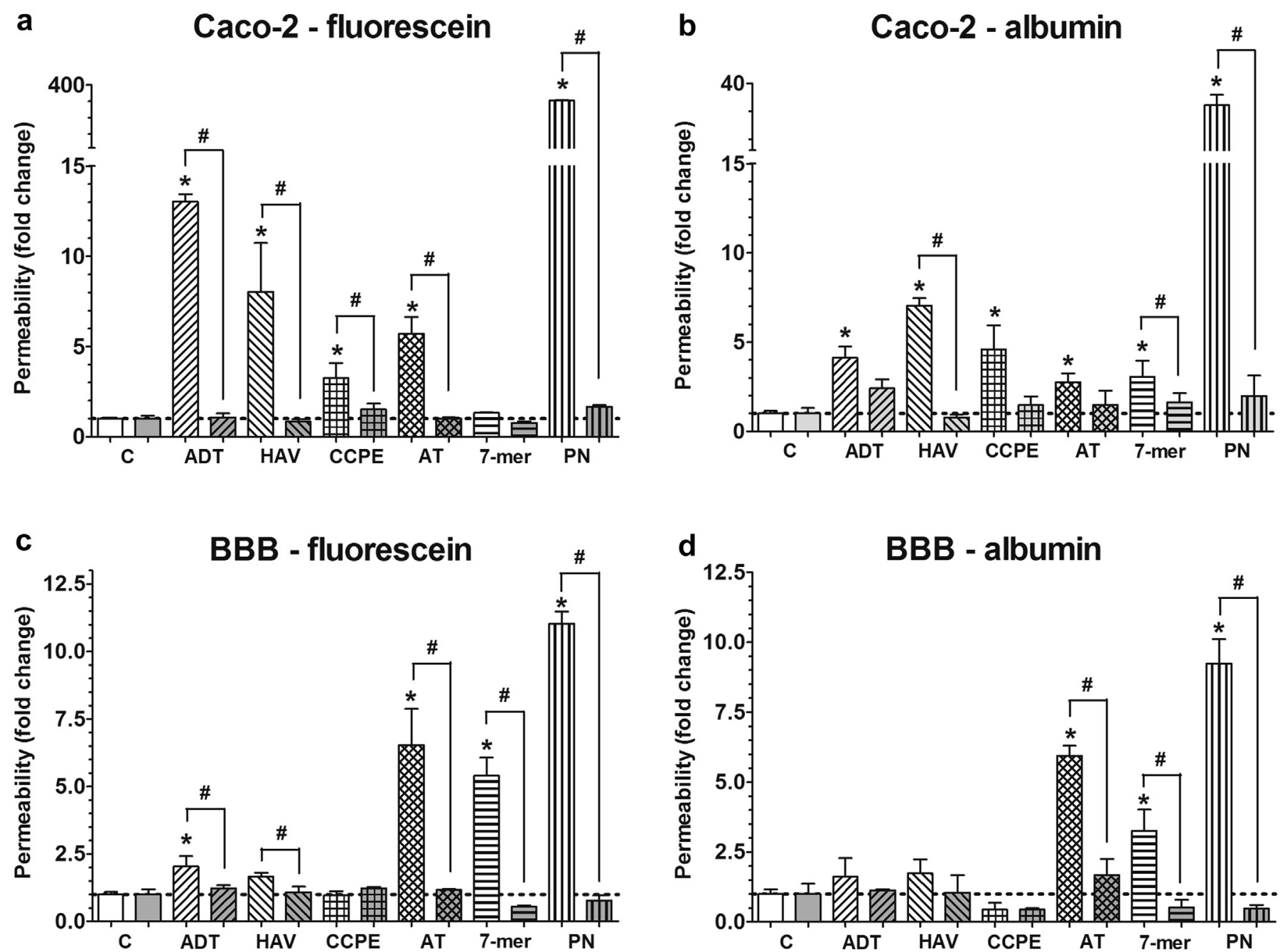

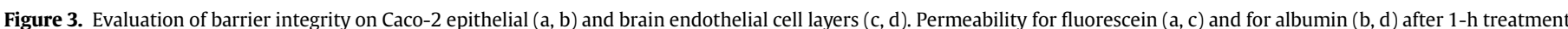

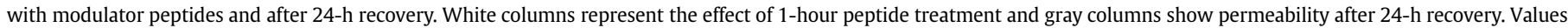

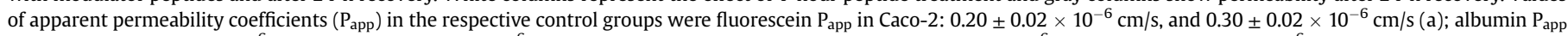

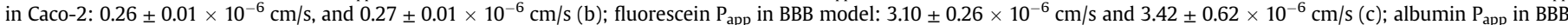

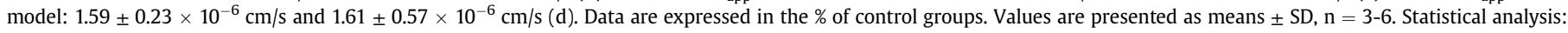

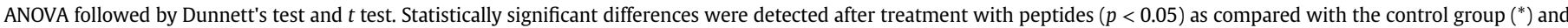
compared with each peptide (\#) after recovery.

different action of the peptides on the 2 culture models could be that E-cadherin, specific for epithelial cells, contains the HAV motif, a classical cadherin-binding motif in the EC1 domains of type I subfamily members, but vascular endothelial VE-cadherin expressed in brain endothelial cells, ${ }^{48}$ a member of the classical type II subfamily, lacks this motif. ${ }^{49}$

\section{Peptides Mimicking Microbial Toxins}

AT-1002 peptide acting on ZO-1 cytoplasmic TJ linker protein decreased resistance on both models and increased the permeability particularly in the case of BBB, which is a new observation (Figs. 2 and 3). Our results are in agreement with previous studies showing that this peptide increases the permeability of epithelial barriers. ${ }^{16,50}$ In the present work, AT-1002 was examined in lower concentration and with shorter incubation time than in previous studies ${ }^{16,51}$ because brain endothelial cells seemed to be more sensitive to the peptide effect than epithelial cells based on the impedance measurements (Fig. 1 and Supplementary Fig. S3). AT-1002 peptide treatment caused visible but not remarkable changes in immunostaining for all the junctional proteins examined including ZO-1 in both models indicating a marked effect on paracellular junctions (Figs. 4 and 5). Importantly, these changes were reversible on both cell types.

We observed that C-CPE peptide significantly decreased the transepithelial resistance and increased the permeability of Caco-2 cell layers for marker molecules in agreement with literature data. ${ }^{52}$ The effects on Caco- 2 cells were reversible, similar to data obtained on MDCK kidney epithelial cells. ${ }^{15}$ In contrast to Caco-2 cells, C-CPE, which was tested on the BBB model for the first time, did not act on brain endothelial cells. This clostridium toxin peptide fragment increases intestinal permeability mainly through claudin-3 and -4 , but it cannot bind to claudin- 1 and -5 because of its structure. ${ }^{53,54}$ Expression level of claudin- 3 and -4 is high in epithelial, but low in brain endothelial cells, explaining our results (Fig. 6).

\section{Peptides Selected by Phage Display}

The 7-mer peptide decreased the transepithelial resistance without changing fluorescein penetration on Caco-2 cell layers in concordance with data on 4 different epithelial cell lines including 


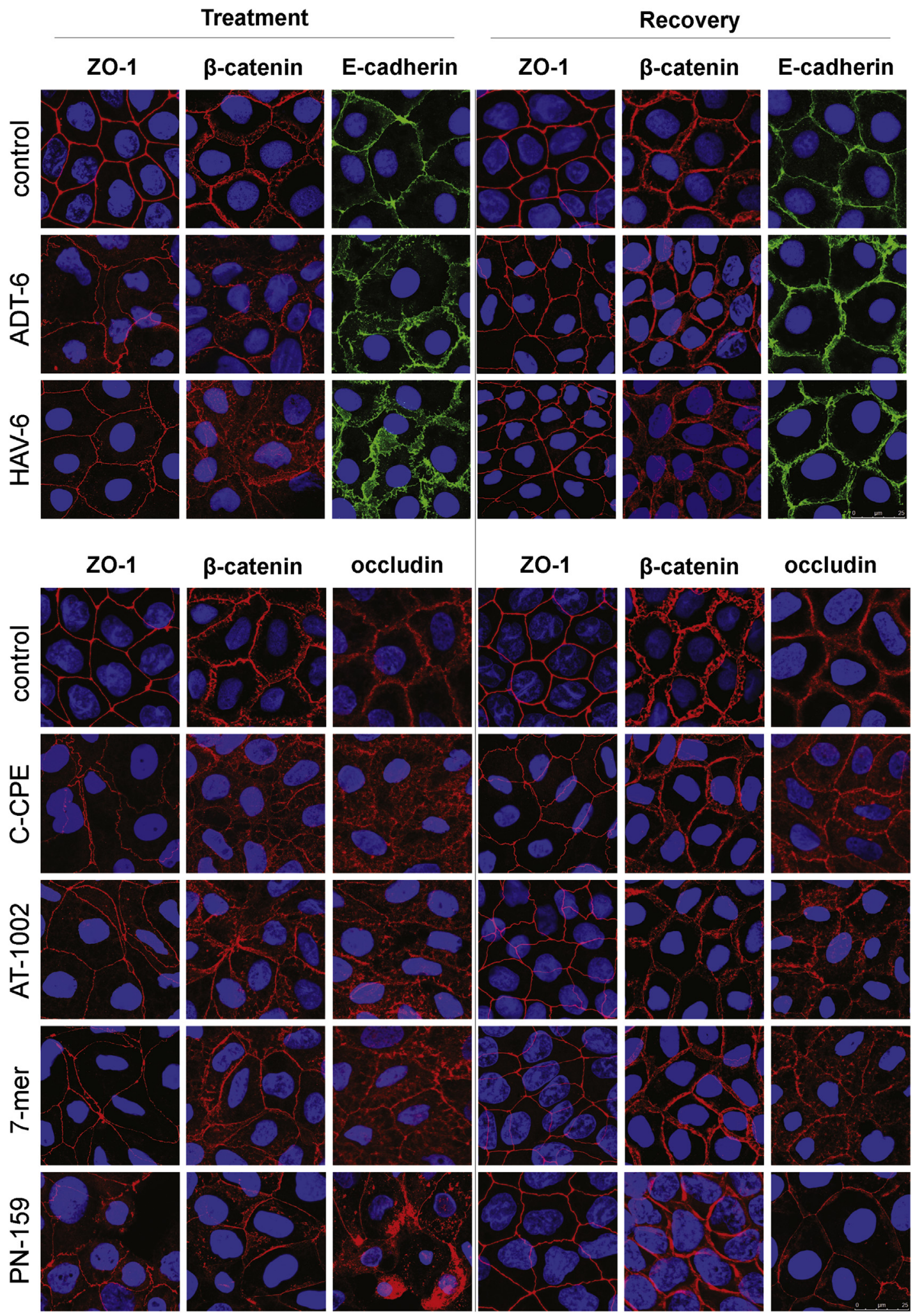

Figure 4. Effects of modulator peptides on junctional morphology of Caco-2 cells. Immunostaining for occludin and zonula occludens-1 (ZO-1) tight junction proteins, and $\beta$ catenin and E-cadherin adherens junction proteins after 1-h peptide treatment and 24-h recovery. Red color: immunostaining for ZO-1, $\beta$-catenin, and occludin. Green color: immunostaining for E-cadherin. Blue color: staining of cell nuclei. Bar $=25 \mu \mathrm{m}$.

Caco-2 cells. ${ }^{17}$ Interestingly, albumin flux was increased after peptide treatment, indicating a mechanism other than the paracellular transport route, which is also supported by the visibly intact intercellular junctions. This peptide, with unidentified target, was not studied on endothelial cells previously; therefore, our study is the first to show that the 7-mer peptide increases the permeability for small and large marker molecules on a coculture BBB model. Our results revealed that endothelial cell junctions are 


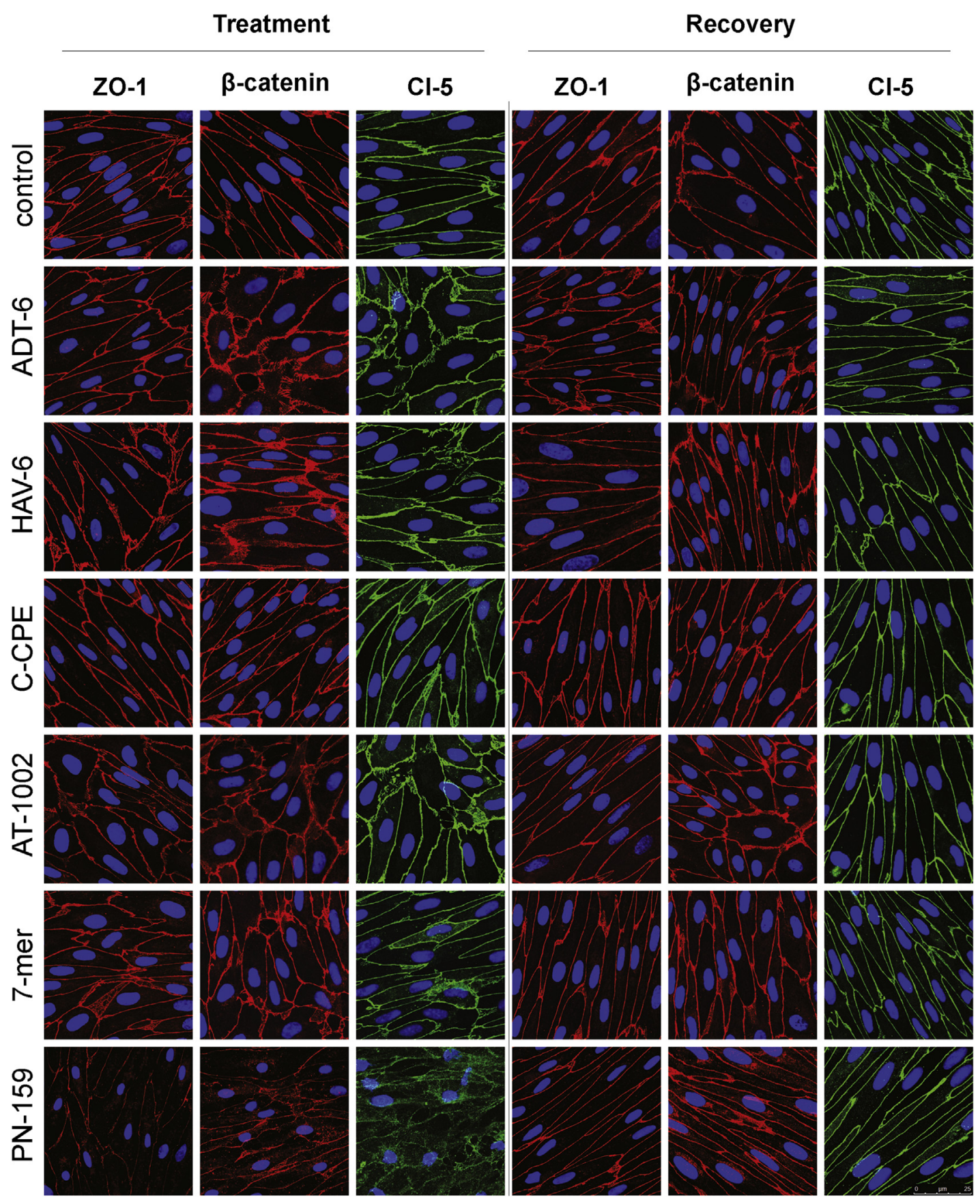

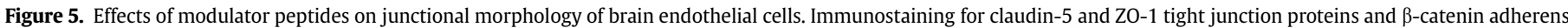

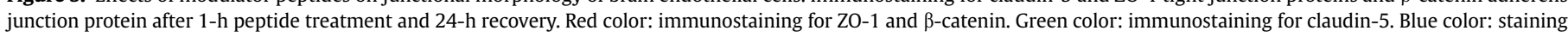
of cell nuclei. Bar $=25 \mu \mathrm{m}$.

more responsive to 7-mer peptide than Caco- 2 cell junctions (Figs. 2-5).

The other peptide selected by phage display, PN-159, was the most effective modulator of junctional permeability in both models (Figs. 2-5). This peptide was characterized as an effective modulator of airway epithelial TJs in vitro and in vivo. ${ }^{18,23}$ The effect of PN-159 in the same concentration as in our study was more similar on bronchial epithelial cells than on Caco- 2 cells. ${ }^{18}$ However, until the present work there were no data on its effect on the BBB. This stable peptide with a low cytotoxicity profile and fully reversible action on different cell types has a potential for therapeutic application. Because PN-159 peptide was originally discovered by phage technology on bronchial epithelial cell layers in which TJ proteins were made accessible by removal of calcium, its binding partner remained unknown so far. Our affinity measurements (Fig. 7a and 7b) revealed that claudin- 5 and claudin-1, but not claudin-3, can be among the potential targets of PN-159. Similar affinity values as well as epithelial and endothelial barrier opening activity have been observed for the claudin peptidomimetic $\mathrm{C} 1 \mathrm{C} 2,{ }^{55}$ further supporting the potential of our approach. Based on the affinitybinding measurement of PN-159 to full length human claudin-1, -3 , and -5 , we wanted to reveal the binding mode of the peptide by docking to claudin monomers (Fig. 7c and 7d). PN-159 has a unique structure composed of only positively charged and 


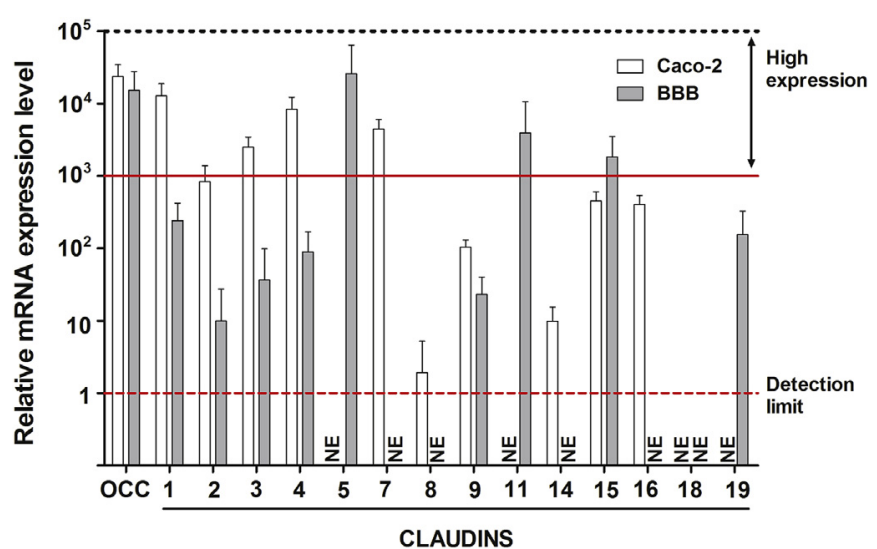

Figure 6. Gene expression level of occludin and selected claudins in Caco-2 epithelial and brain endothelial cells. NE, not expressed; OCC, occludin. hydrophobic residues. The ionic interaction between lysins of the peptide and D68 of claudin- 1 and -5 may be crucial in the biological effects of the peptide (Supplementary Table S2), because (1) this interaction was not observed in the docking of PN-159 to claudin-5 with weaker total energy and (2) in claudin-3, where residue 68 is a serine instead of aspartate in the ECL1, no binding affinity was measured and highly unfavorable docking energy was found. Furthermore, the ability of PN-159 to disrupt the $\beta$-strands in ECLs may contribute to the biological effect because the highest binding and lowest total energy were observed for claudin-5, where $\beta$ strands disappeared. Lower energy and/or binding was evident when $\beta$-strands were fully or partially visible after peptide binding in our modeling.

\section{Comparison of the Efficacy and Barrier Selectivity of the Peptides}

Comparing the efficacy of the 6 peptides, the following rank order can be established on Caco-2 cells: 7-mer $<$ C-CPE $<$ AT-1002 $<$ HAV-6 < ADT-6 < PN-159. This order is different on endothelial barrier: C-CPE $<$ HAV-6 $<$ ADT-6 $<7-$ mer $<$ AT-1002 $<<$ PN-159. The

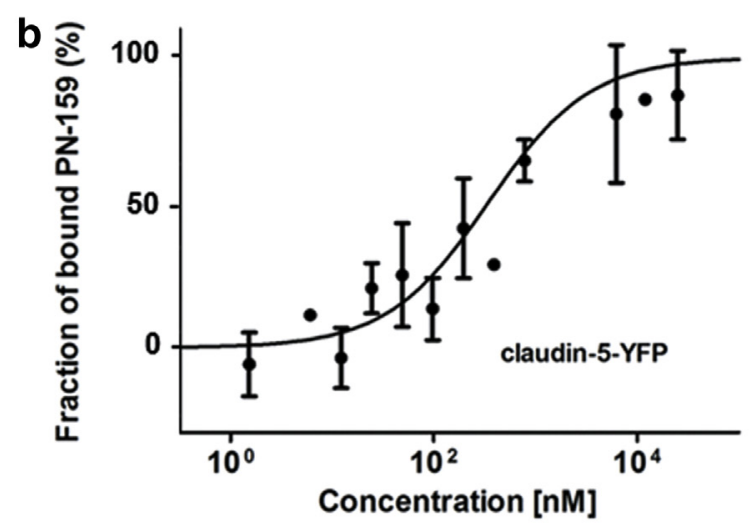

claudin-5

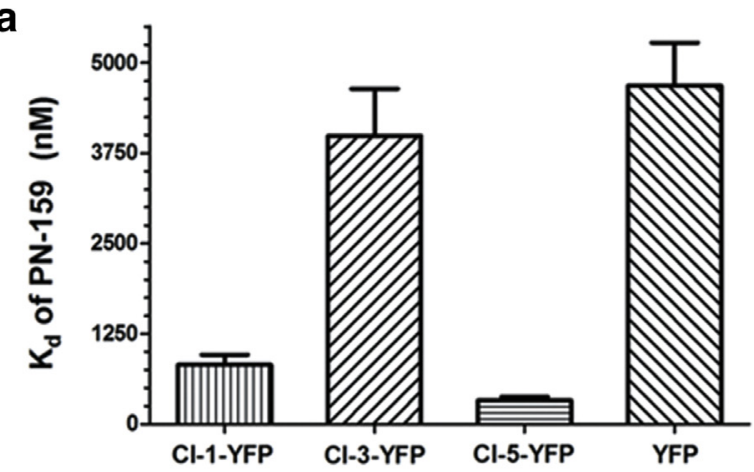

claudin-1
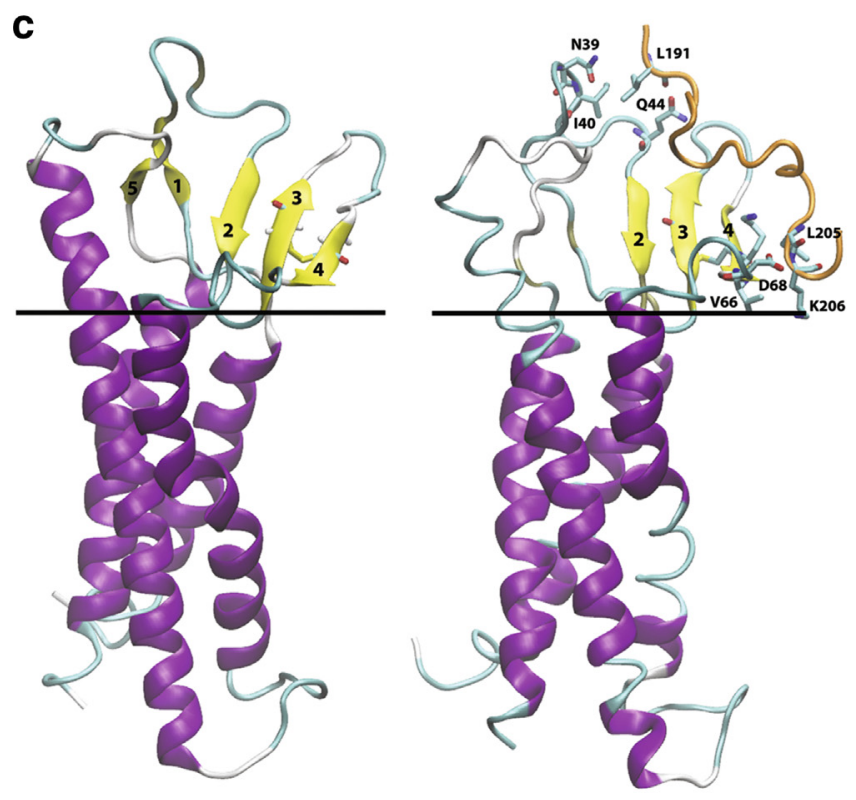
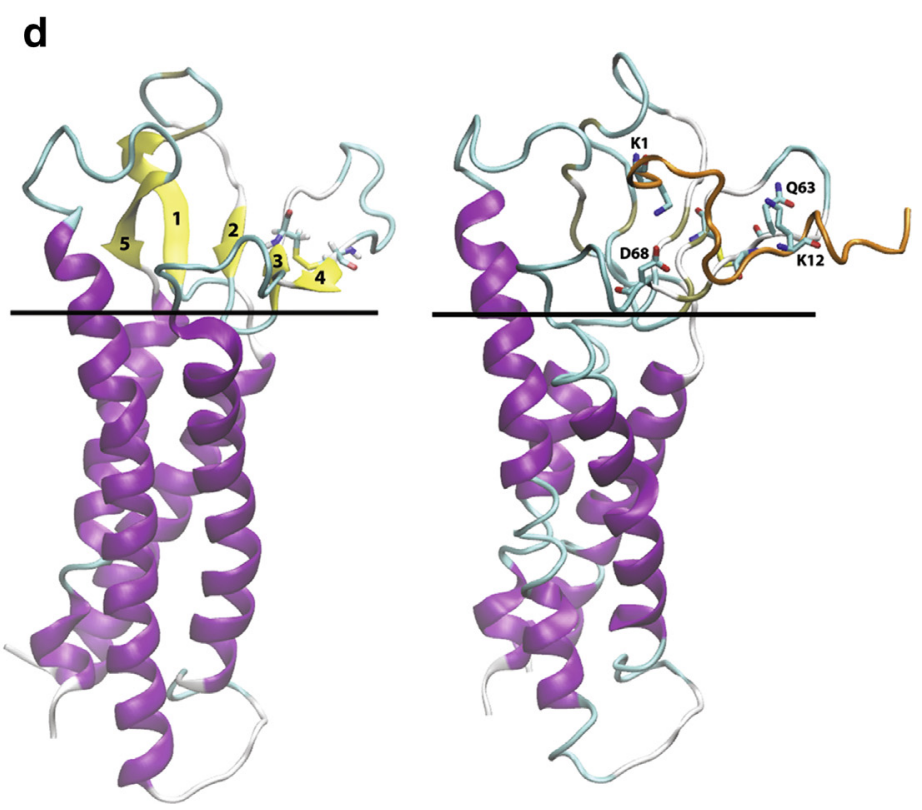

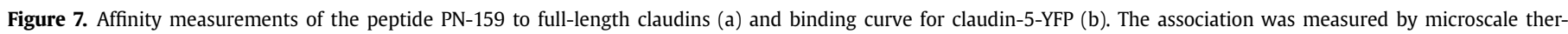

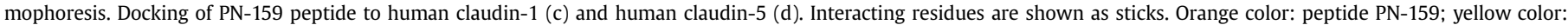
$\beta$-strands; purple color: $\alpha$-helices of claudins. Membrane surface is marked by a solid black line. $\mathrm{K}_{\mathrm{d}}$, dissociation constant; YFP, yellow fluorescent protein. 
TJ modulator effects of C-CPE, ADT-6, and HAV-6 were selective on epithelial cells, which can be explained by the different claudin and cadherin pattern between the epithelial and brain endothelial models. In our previous study, major differences were demonstrated between the BBB coculture and the Caco- 2 models in their cytoarchitecture, TJ structure, and claudin immunostaining. ${ }^{30}$ Caco-2 cells gave strong staining for claudins- 1 and -4 , whereas the principal claudin in brain endothelial cells was claudin-5. These results were strengthened by the present gene array data. The higher efficacy of 7-mer and AT-1002 peptides on endothelial cells are new observations, and further studies would be needed to reveal the molecular background.

For the in vivo application of $\mathrm{TJ}$ opening peptides, additional interactions which may modulate their efficacy must also be considered, namely with the mucus layer of intestinal epithelium ${ }^{56}$ and the luminal glycocalyx of brain endothelium. ${ }^{57}$ In addition, opening of paracellular junctions for drugs by peptides might also result in enhanced transport of other molecules, xenobiotics, or pathogens across the protective gastrointestinal barrier and BBB. In case of the BBB, extravasation of serum proteins, like albumin, can cause brain edema, which is a side effect of clinical BBB disruption by hyperosmotic mannitol for the treatment of brain tumors. ${ }^{58}$ Size-selective opening of the BBB which would allow the passage of small molecules but not that of serum proteins would be preferable for potential clinical use. Because of these reasons, safety assessment of TJ modulators must include testing for adverse reactions including edema formation and for potentially increased microbial infections.

\section{Conclusion}

All peptides tested showed a reversible TJ modulating effect and were effective to open the paracellular pathway for the marker molecules. We could demonstrate a selectivity of C-CPE, ADT-6, and HAV-6 peptides for epithelial cells and 7-mer and AT-1002 peptides for brain endothelial barrier. PN-159 was the most effective modulator of junctional permeability in both models possibly acting via claudin- 1 and -5 . Our results indicate that these peptides can be effectively and selectively used as potential pharmaceutical excipients to improve drug delivery across biological barriers.

\section{Acknowledgment}

This work was supported by the European Union and the State of Hungary (TÁMOP 4.2.4. A/2-11-1-2012-0001) and Gedeon Richter (RG-IPI-2009-TP3/006). Therbiogen Ltd. is gratefully thanked for providing the RTCA-SP instrument for the experiments.

\section{References}

1. Deli MA. Potential use of tight junction modulators to reversibly open membranous barriers and improve drug delivery. Biochim Biophys Acta. 2009;1788: 892-910.

2. Abbott NJ, Patabendige AA, Dolman DE, Yusof SR, Begley DJ. Structure and function of the blood-brain barrier. Neurobiol Dis. 2010;37:13-25.

3. Laksitorini M, Prasasty VD, Kiptoo PK, Siahaan TJ. Pathways and progress in improving drug delivery through the intestinal mucosa and blood-brain barriers. Ther Deliv. 2014;5:1143-1163.

4. Miller DS. Regulation of ABC transporters blood-brain barrier: the good, the bad, and the ugly. Adv Cancer Res. 2015;125:43-70.

5. Shawahna R, Decleves X, Scherrmann JM. Hurdles with using in vitro models to predict human blood-brain barrier drug permeability: a special focus on transporters and metabolizing enzymes. Curr Drug Metab. 2013;14:120-136.

6. Kiss L, Walter FR, Bocsik A, et al. Kinetic analysis of the toxicity of pharmaceutical excipients Cremophor EL and RH40 on endothelial and epithelial cells. J Pharm Sci. 2013;102:1173-1181.

7. Tscheik C, Blasig IE, Winkler L. Trends in drug delivery through tissue barriers containing tight junctions. Tissue Barriers. 2013;1:e24565.
8. Kiss L, Hellinger É, Pilbat AM, et al. Sucrose esters increase drug penetration, but do not inhibit p-glycoprotein in Caco-2 intestinal epithelial cells. J Pharm Sci. 2014;103:3107-3119.

9. Van Itallie CM, Anderson JM. Architecture of tight junctions and principles of molecular composition. Semin Cell Dev Biol. 2014;36:157-165.

10. Krause G, Winkler L, Mueller SL, Haseloff RF, Piontek J, Blasig IE. Structure and function of claudins. Biochim Biophys Acta. 2008;1778:631-645.

11. Baum B, Georgiou M. Dynamics of adherens junctions in epithelial establishment, maintenance, and remodeling. J Cell Biol. 2011;192:907-917.

12. Takahashi A, Kondoh M, Kodaka M, Yagi K. Peptides as tight junction modulators. Curr Pharm Des. 2011;17:2699-2703.

13. Sinaga E, Jois SD, Avery M, et al. Increasing paracellular porosity by E-cadherin peptides: discovery of bulge and groove regions in the EC1-domain of E-cadherin. Pharm Res. 2002;19:1170-1179.

14. Kiptoo P, Sinaga E, Calcagno AM, et al. Enhancement of drug absorption through the blood-brain barrier and inhibition of intercellular tight junction resealing by E-cadherin peptides. Mol Pharm. 2011;8:239-249.

15. Sonoda N, Furuse M, Sasaki H, et al. Clostridium perfringens enterotoxin fragment removes specific claudins from tight junction strands: evidence for direct involvement of claudins in tight junction barrier. J Cell Biol. 1999;147:195-204.

16. Song KH, Fasano A, Eddington ND. Effect of the six-mer synthetic peptide (AT1002) fragment of zonula occludens toxin on the intestinal absorption of cyclosporin A. Int J Pharm. 2008;351:8-14.

17. Herman RE, Makienko EG, Prieve MG, Fuller M, Houston Jr ME, Johnson PH. Phage display screening of epithelial cell monolayers treated with EGTA: identification of peptide FDFWITP that modulates tight junction activity. J Biomol Screen. 2007;12:1092-1101.

18. Johnson PH, Quay SC. Advances in nasal drug delivery through tight junction technology. Expert Opin Drug Deliv. 2005;2:281-298.

19. Makagiansar IT, Avery M, Hu Y, Audus KL, Siahaan TJ. Improving the selectivity of HAV-peptides in modulating E-cadherin-E-cadherin interactions in the intercellular junction of MDCK cell monolayers. Pharm Res. 2001;18:446-453.

20. Kondoh M, Takahashi A, Fujii M, Yagi K, Watanabe Y. A novel strategy for a drug delivery system using a claudin modulator. Biol Pharm Bull. 2006;29:1783-1789.

21. Li X, Saeki R, Watari A, Yagi K, Kondoh M. Tissue distribution and safety evaluation of a claudin-targeting molecule, the C-terminal fragment of Clostridium perfringens enterotoxin. Eur J Pharm Sci. 2014;52:132-137.

22. Fasano A, Uzzau S. Modulation of intestinal tight junctions by Zonula occludens toxin permits enteral administration of insulin and other macromolecules in an animal model. J Clin Invest. 1997;99:1158-1164.

23. Chen SC, Eiting K, Cui K, et al. Therapeutic utility of a novel tight junction modulating peptide for enhancing intranasal drug delivery. J Pharm Sci. 2006;95:1364-1371.

24. Hidalgo IJ, Raub TJ, Borchardt RT. Characterization of the human colon carcinoma cell line (Caco-2) as a model system for intestinal epithelial permeability. Gastroenterology. 1989;96:736-749.

25. Shah MV, Audus KL, Borchardt RT. The application of bovine brain microvessel endothelial-cell monolayers grown onto polycarbonate membranes in vitro to estimate the potential permeability of solutes through the blood-brain barrier. Pharm Res. 1989;6:624-627.

26. Volpe DA. Drug-permeability and transporter assays in Caco-2 and MDCK cell lines. Future Med Chem. 2011;3:2063-2077.

27. Veszelka S, Kittel Á, Deli MA. Tools for modelling blood-brain barrier penetrability. In: Tihanyi K, Vastag M, eds. Solubility, Delivery and ADME Problems of Drugs and Drug Candidates. Washington: Bentham Science Publishers Ltd; 2011:166-188.

28. Avdeef A, Deli MA, Neuhaus W. In vitro assays for assessing BBB permeability: artificial membrane and cell culture models. In: Di L, Kerns EH, eds. Blood-Brain Barrier in Drug Discovery: Optimizing Brain Exposure of CNS Drugs and Minimizing Brain Side Effects for Peripheral Drugs. Hoboken, NJ: John Wiley and Sons, Inc.; 2015:188-237.

29. Nakagawa S, Deli MA, Kawaguchi H, et al. A new blood-brain barrier model using primary rat brain endothelial cells, pericytes and astrocytes. Neurochem Int. 2009;54:253-263.

30. Hellinger E, Veszelka S, Tóth AE, et al. Comparison of brain capillary endothelial cell-based and epithelial (MDCK-MDR1, Caco-2, and VB-Caco-2) cell-based surrogate blood-brain barrier penetration models. Eur J Pharm Biopharm. 2012;82:340-351.

31. Hellinger E, Bakk ML, Pócza P, Tihanyi K, Vastag M. Drug penetration model of vinblastine-treated Caco-2 cultures. Eur J Pharm Sci. 2010;41:96-106.

32. Perrière N, Demeuse P, Garcia E, et al. Puromycin-based purification of rat brain capillary endothelial cell cultures. Effect on the expression of blood-brain barrier-specific properties. J Neurochem. 2005;93:279-289.

33. Walter FR, Veszelka S, Pásztói M, et al. Tesmilifene modifies brain endothelial functions and opens the blood-brain/blood-glioma barrier. J Neurochem. 2015;134(6):1040-1054.

34. Deli MA, Ábrahám CS, Kataoka Y, Niwa M. Permeability studies on in vitro blood-brain barrier models: physiology, pathology, and pharmacology. Cell Mol Neurobiol. 2005;25:59-127.

35. Kürti L, Veszelka S, Bocsik A, et al. The effect of sucrose esters on a culture model of the nasal barrier. Toxicol In Vitro. 2012;26:445-454.

36. Benson K, Cramer S, Galla HJ. Impedance-based cell monitoring: barrier properties and beyond. Fluids and Barriers of the CNS. 2013;10:5.

37. Tóth AE, Tóth A, Walter FR, et al. Compounds blocking methylglyoxal-induced protein modification and brain endothelial injury. Arch Med Res. 2014;45:753-764. 
38. Jerabek-Willemsen M, Wienken CJ, Braun D, Baaske P, Duhr S. Molecular interaction studies using microscale thermophoresis. Assay Drug Dev Technol. 2011;9:342-353.

39. Piontek J, Fritzsche S, Cording J, et al. Elucidating the principles of the molecular organization of heteropolymeric tight junction strands. Cell Mol Life Sci. 2011;68:3903-3918

40. Dabrowski S, Staat C, Zwanziger D, et al. Structure and function of the first extracellular loop of the cell-cell contact protein claudin-1 - lessons from peptide to animal. Antioxid Redox Signal. 2015;22:1-14.

41. Sali A, Blundell TL. Comparative protein modelling by satisfaction of spatial restraints. J Mol Biol. 1993;234:779-815.

42. Suzuki H, Nishizawa T, Tani K, et al. Crystal structure of a claudin provides insight into the architecture of tight junctions. Science. 2014;344:304-307.

43. Phillips JC, Braun R, Wang W, et al. Scalable molecular dynamics with NAMD. J Comput Chem. 2005;26:1781-1802.

44. Humphrey W, Dalke A, Schulten K. VMD: visual molecular dynamics. J Mol Graph. 1996;14:33-38.

45. Kurcinski M, Jamroz M, Blaszczyk M, Kolinski A, Kmiecik S. CABS-dock web server for the flexible docking of peptides to proteins without prior knowledge of the binding site. Nucleic Acids Res. 2015;43:419-424.

46. Ohtsuki S, Yamaguchi H, Katsukura Y, Asashima T, Terasaki T. mRNA expression levels of tight junction protein genes in mouse brain capillary endothelial cells highly purified by magnetic cell sorting. J Neurochem. 2008; 104:147-154.

47. Urich E, Lazic SE, Molnos J, Wells I, Freskgård PO. Transcriptional profiling of human brain endothelial cells reveals key properties crucial for predictive in vitro blood-brain barrier models. PLoS One. 2012;7:e38149.

48. Bazzoni G, Dejana E. Endothelial cell-to-cell junctions: molecular organization and role in vascular homeostasis. Physiol Rev. 2004;84:869-901.
49. Vestweber D. VE-cadherin: the major endothelial adhesion molecule controlling cellular junctions and blood vessel formation. Arterioscler Thromb Vasc Biol. 2008;28:223-232.

50. Rittirsch D, Flierl MA, Nadeau BA, et al. Zonulin as prehaptoglobin2 regulates lung permeability and activates the complement system. Am J Physiol Lung Cell Mol Physiol. 2013;304:L863-872.

51. Gopalakrishnan S, Pandey N, Tamiz AP, et al. Mechanism of action of ZOTderived peptide AT-1002, a tight junction regulator and absorption enhancer. Int J Pharm. 2009;365:121-130.

52. Winkler L, Gehring C, Wenzel A, et al. Molecular determinants of the interaction between Clostridium perfringens enterotoxin fragments and claudin-3. J Biol Chem. 2009;284:18863-18872.

53. Saitoh Y, Suzuki H, Tani K, et al. Tight junctions. Structural insight into tight junction disassembly by Clostridium perfringens enterotoxin. Science. 2015;347:775-778.

54. Protze J, Eichner M, Piontek A, et al. Directed structural modification of Clostridium perfringens enterotoxin to enhance binding to claudin-5. Cell Mol Life Sci. 2015;72:1417-1432.

55. Staat C, Coisne C, Dabrowski S, et al. Mode of action of claudin peptidomimetics in the transient opening of cellular tight junction barriers. Biomaterials. 2015;54:9-24.

56. Maher S, Brayden DJ, Feighery L, McClean S. Cracking the junction: update on the progress of gastrointestinal absorption enhancement in the delivery of poorly absorbed drugs. Crit Rev Ther Drug Carrier Syst. 2008;25:117-168.

57. Li G, Fu BM. An electrodiffusion model for the blood-brain barrier permeability to charged molecules. J Biomech Eng. 2011;133:021002.

58. Siegal T, Rubinstein R, Bokstein F, et al. In vivo assessment of the window of barrier opening after osmotic blood-brain barrier disruption in humans. J Neurosurg. 2000;92:599-605. 
Bocsik et al. Reversible opening of intercellular junctions of intestinal epithelial and brain endothelial cells with tight junction modulator peptides

\section{Supplementary Material}


Bocsik et al. Reversible opening of intercellular junctions of intestinal epithelial and brain endothelial cells with tight junction modulator peptides

Table S1. The list of the studied genes.

\begin{tabular}{|l|l|l|l|}
\hline & & \multicolumn{1}{|c|}{ Caco-2 } & \multicolumn{1}{c|}{ BBB } \\
\hline occludin & OCLN & Hs00170162_m1 & Rn00580064_m1 \\
\hline claudin-1 & CLDN1 & Hs01076359_m1 & Rn00581740_m1 \\
\hline claudin-2 & CLDN2 & Hs00252666_s1 & Rn02063575_s1 \\
\hline claudin-3 & CLDN3 & Hs00265816_s1 & Rn00581751_s1 \\
\hline claudin-4 & CLDN4 & Hs00533616_s1 & Rn01196224_s1 \\
\hline claudin-5 & CLDN5 & Hs01561351_m1 & Rn01753146_s1 \\
\hline claudin-7 & CLDN7 & Hs00600772_m1 & Rn01496517_g1 \\
\hline claudin-8 & CLDN8 & Hs00273282_s1 & Rn01767199_s1 \\
\hline claudin-9 & CLDN9 & Hs00253134_s1 & Rn01460292_s1 \\
\hline claudin-11 & CLDN11 & Hs00912957_m1 & Rn01293260_m1 \\
\hline claudin-14 & CLDN14 & Hs00273267_s1 & Rn01407193_m1 \\
\hline claudin-15 & CLDN15 & Hs00204982_m1 & Rn02108734_s1 \\
\hline claudin-16 & CLDN16 & Hs00198134_m1 & Rn00590884_m1 \\
\hline claudin-18 & CLDN18 & Hs00212584_m1 & Rn01447445_m1 \\
\hline claudin-19 & CLDN19 & Hs00381204_m1 & Rn01416539_m1 \\
\hline
\end{tabular}


Bocsik et al. Reversible opening of intercellular junctions of intestinal epithelial and brain endothelial cells with tight junction modulator peptides

\section{Supplementary Fig. S1}
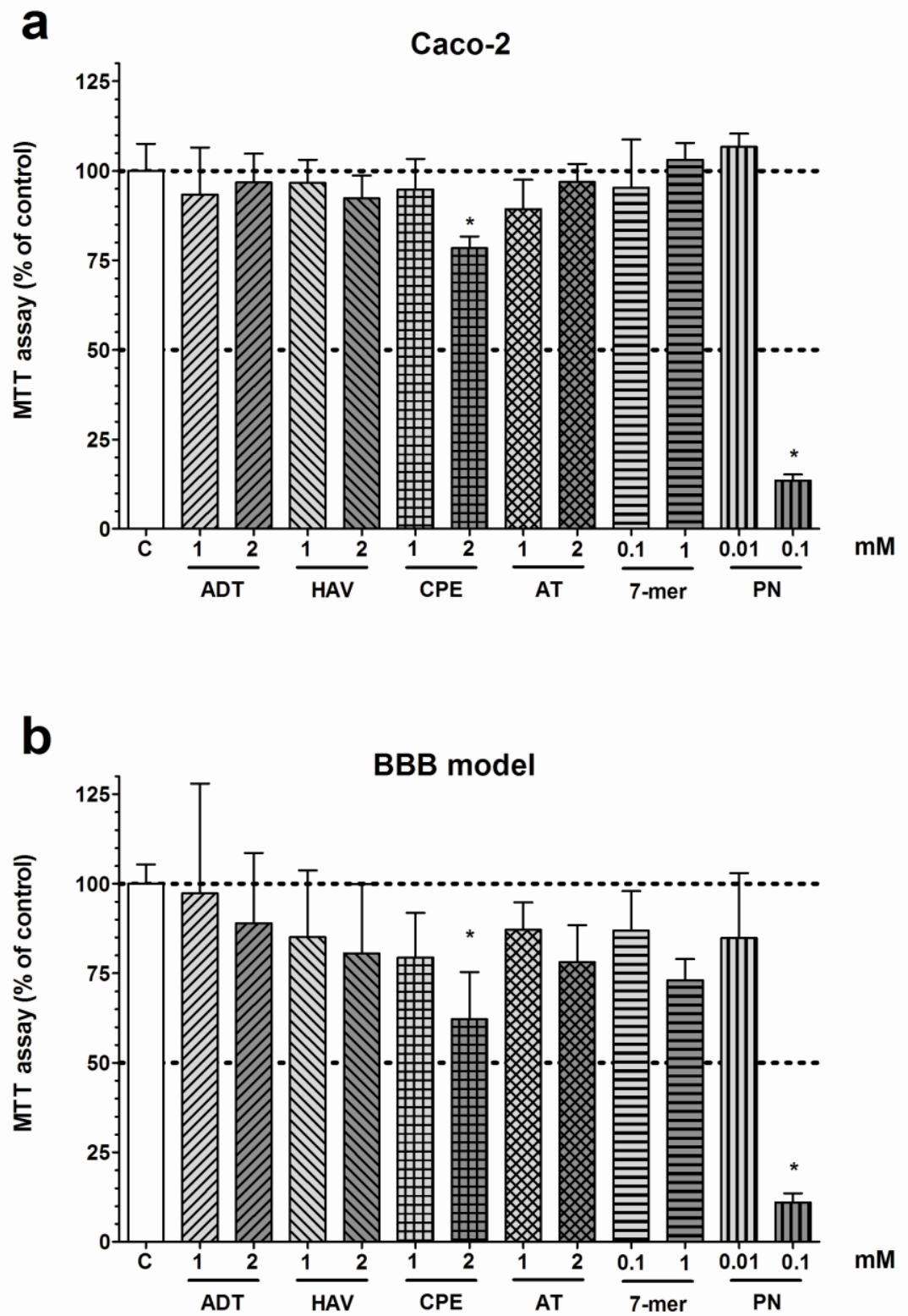

Cell viability assays after 1-hour treatment with tight junction modulator peptides at two concentrations. The toxicity of peptides on Caco-2 intestinal epithelial cells (a) and brain endothelial cells (b) was measured by MTT dye conversion assay and shown as percent of control (100\% viability). Values are presented as means $\pm \mathrm{SD}, \mathrm{n}=3-8$. Statistical analysis: ANOVA followed by Dunnett's test, $p<0.05$ as compared with the control groups. 
Bocsik et al. Reversible opening of intercellular junctions of intestinal epithelial and brain endothelial cells with tight junction modulator peptides

\section{Supplementary Fig. S2}

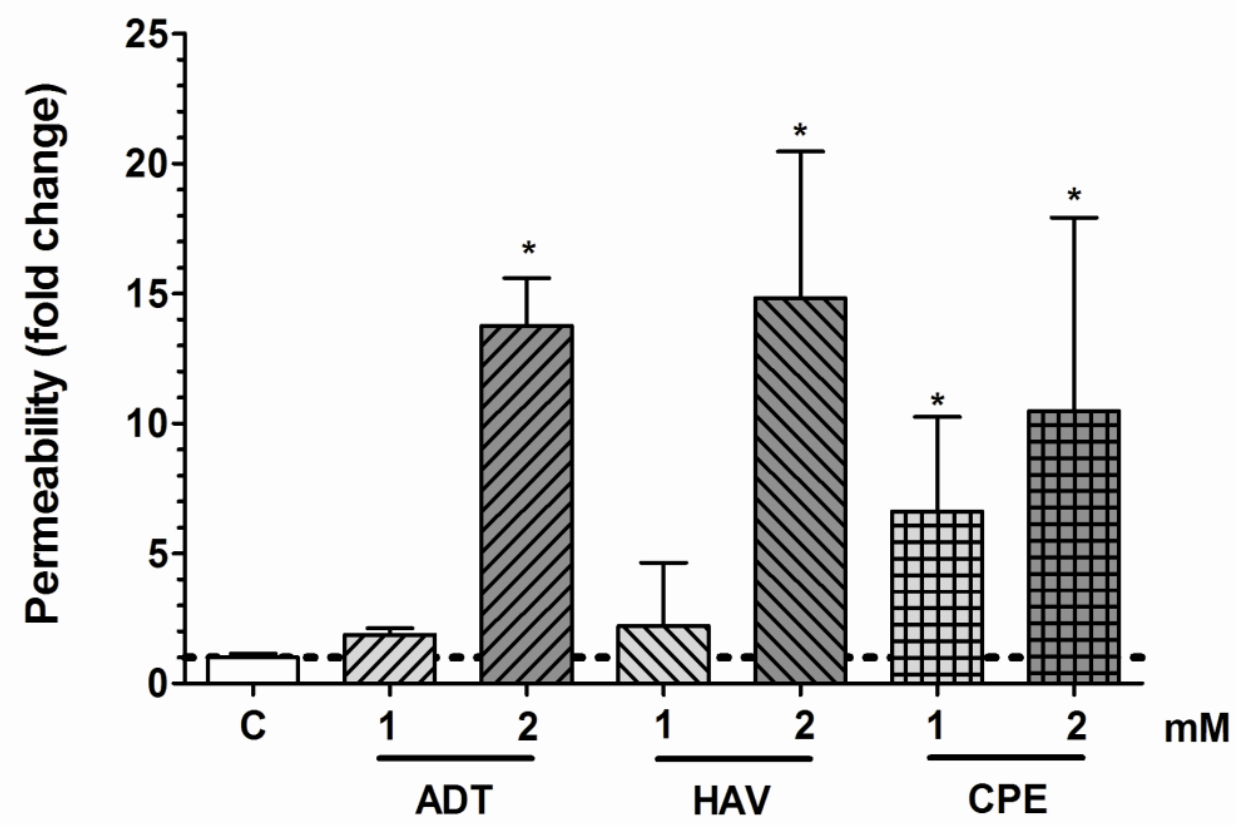

Permeability of fluorescein across Caco-2 epithelial cell layers after 1-hour treatment with ADT-6, HAV-6 and C-CPE modulator peptides at concentrations of 1 and $2 \mathrm{mM}$. The apparent permeability coefficient $\left(\mathrm{P}_{\mathrm{app}}\right)$ for fluorescein in the control groups was $0.28 \pm$ $0.04 \times 10^{-6} \mathrm{~cm} / \mathrm{s}$. Values are expressed in the $\%$ of control group and presented as means $\pm \mathrm{SD}, \mathrm{n}=3-8$. Statistical analysis: ANOVA followed by Dunnett's test, $p<0.05$ as compared with the control groups. 
Bocsik et al. Reversible opening of intercellular junctions of intestinal epithelial and brain endothelial cells with tight junction modulator peptides

\section{Supplementary Fig. S3}
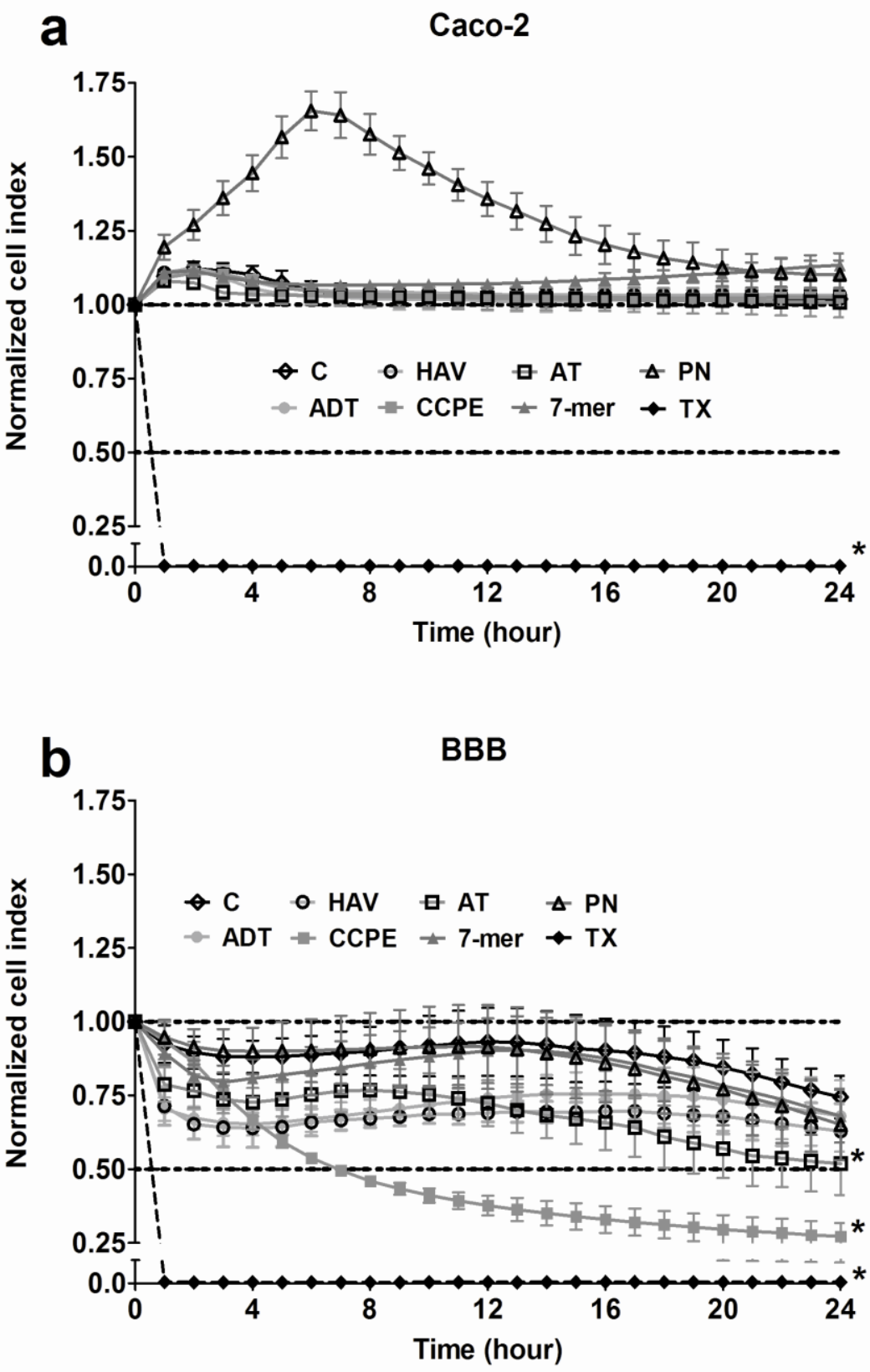

Kinetics of peptide effects on the impedance of epithelial (a) and brain endothelial (b) cell layers. Values are presented as mean $\pm \mathrm{SD}, \mathrm{n}=3-8$. Statistical analysis: ANOVA followed by Dunnett's test; $p<0.05$, significant differences in peptide-treated groups at 24 hour as compared with control groups. 
Bocsik et al. Reversible opening of intercellular junctions of intestinal epithelial and brain endothelial cells with tight junction modulator peptides

\section{Supplementary Fig. S4}

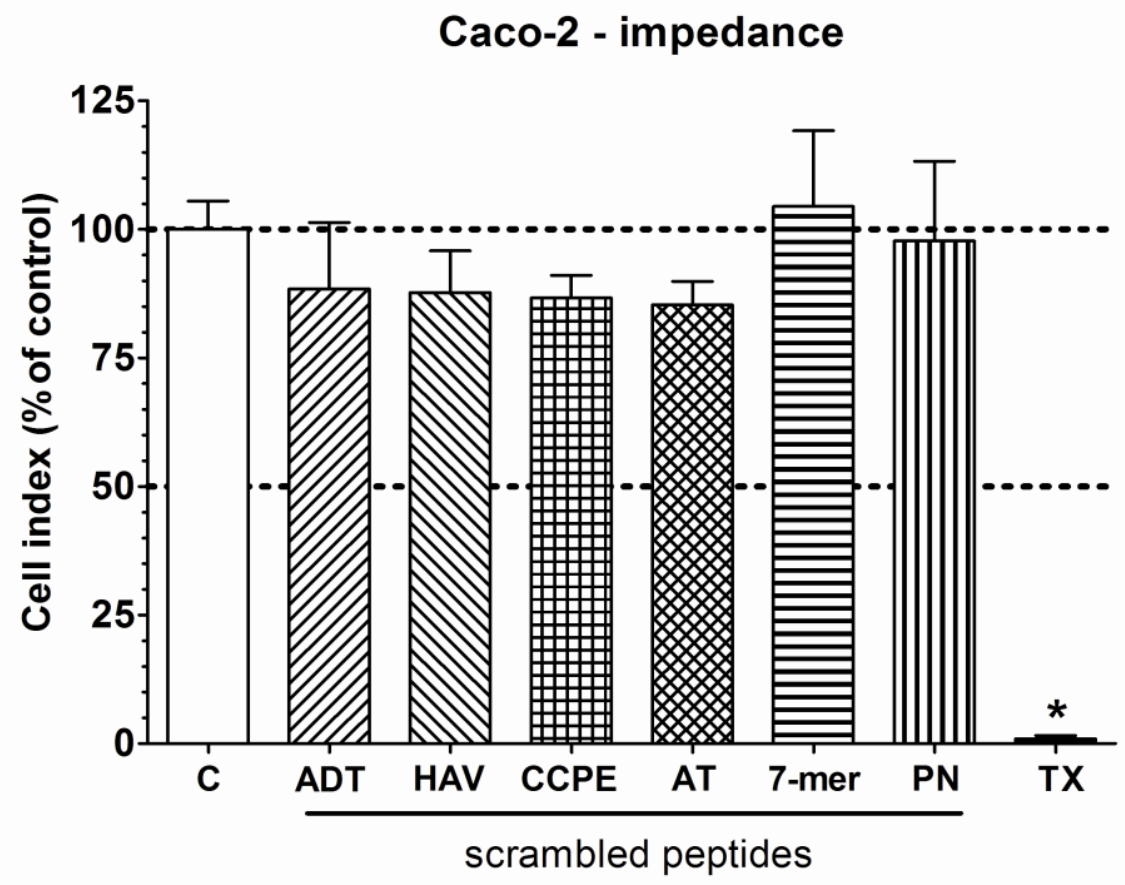

Effects of 24-hour treatment with scrambled peptides on Caco-2 epithelial cell viability. Data are shown as cell index in percentage of control group. Data are presented as means $\pm \mathrm{SD}, \mathrm{n}=3-6$. Statistical analysis: ANOVA followed by Dunett's test. Statistically significant differences are $p<0.05$, compared to control group. 
Bocsik et al. Reversible opening of intercellular junctions of intestinal epithelial and brain endothelial cells with tight junction modulator peptides

\section{Supplementary Fig. S5}
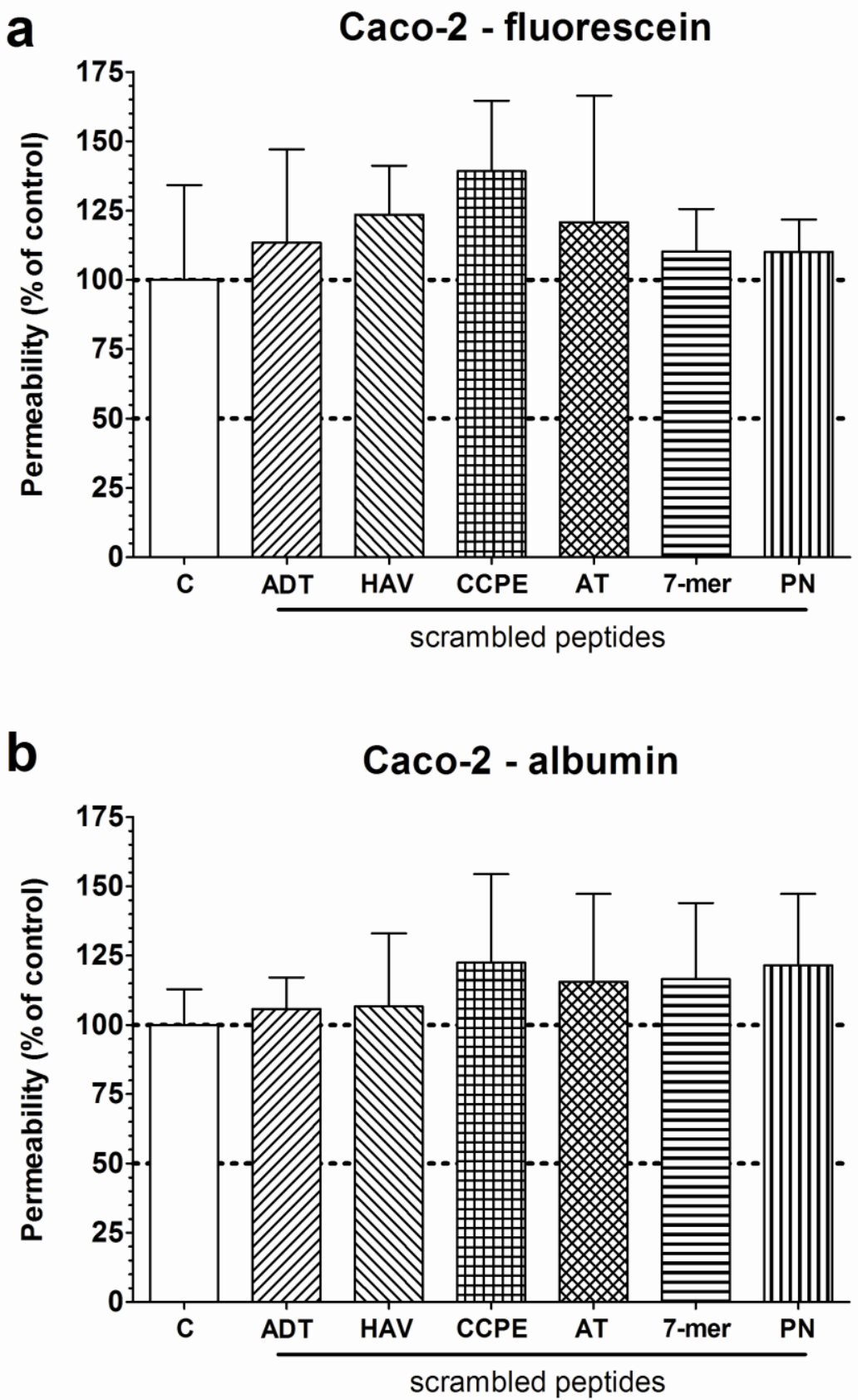

Permeability of Caco-2 cell layers for fluorescein (a) and albumin (b) after 1-hour treatment with scrambled peptides. Values of apparent permeability coefficients $\left(\mathrm{P}_{\text {app }}\right)$ in the control groups were for fluorescein: $0.27 \pm 0.06 \times 10^{-6} \mathrm{~cm} / \mathrm{s}$; for albumin: $0.17 \pm$ $0.02 \times 10^{-6} \mathrm{~cm} / \mathrm{s}$. 
Bocsik et al. Reversible opening of intercellular junctions of intestinal epithelial and brain endothelial cells with tight junction modulator peptides

\section{Supplementary Fig. S6}

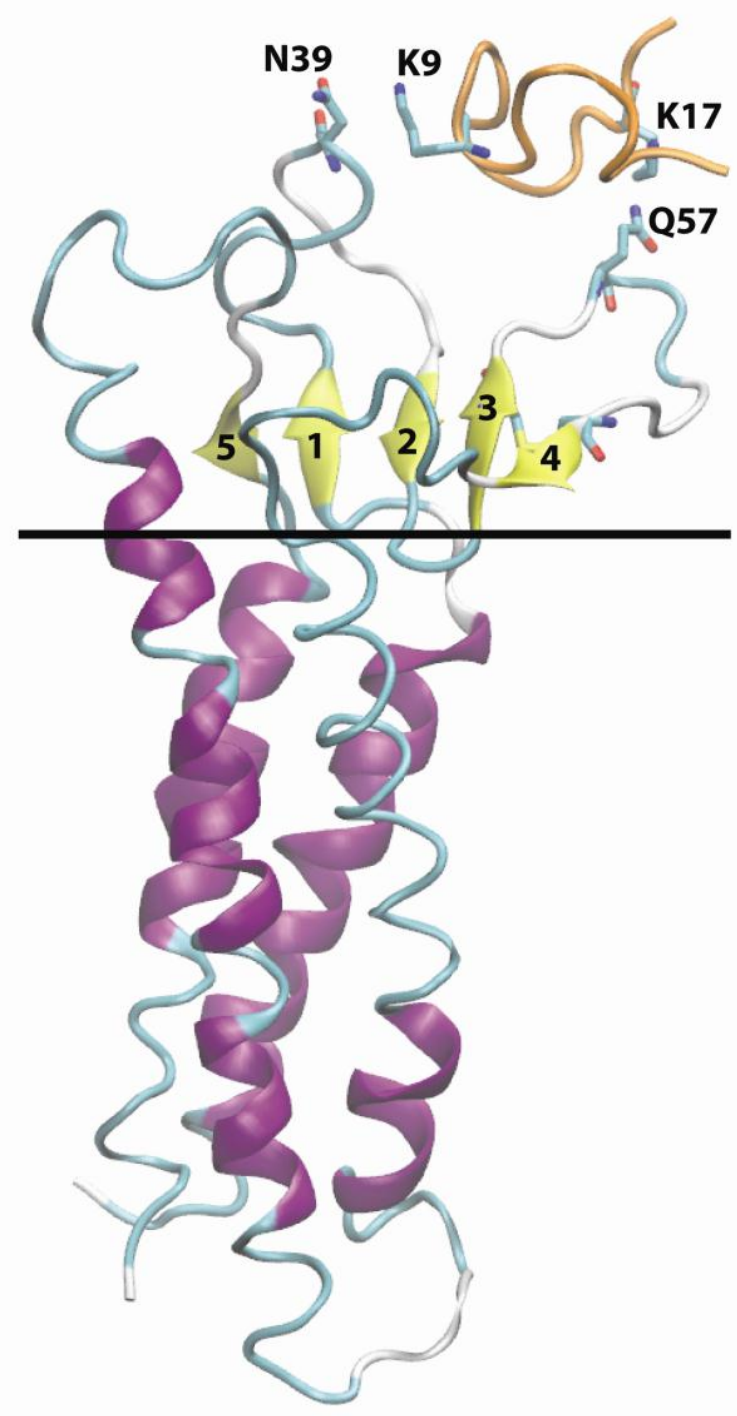

Docking of PN-159 peptide to human claudin-5 with weaker total energy as shown in Supplementary Table S2. Interacting residues are shown as sticks. Orange color: peptide PN-159; Yellow color: $\beta$-strands; purple color: $\alpha$-helices of claudin-5. Membrane surface is marked by a solid black line. 
Bocsik et al. Reversible opening of intercellular junctions of intestinal epithelial and brain endothelial cells with tight junction modulator peptides

Table S2. Table Docking energy components of $\mathrm{PN}-159$ peptide to claudin monomers

\begin{tabular}{|l|c|c|c|c|}
\hline \multirow{2}{*}{ Claudin-1 } & \multirow{2}{*}{ Claudin-3 } & \multicolumn{2}{|c|}{ Claudin-5 } \\
\cline { 4 - 5 } & & & weaker & stronger \\
\hline $\mathbf{E}_{\text {lig }}$ & -19.6 & -9.86 & -19.7 & -13.58 \\
\hline $\mathbf{E}_{\text {int }}$ & -34.8 & -66.8 & -29.6 & -35.6 \\
\hline $\mathbf{E}_{\text {tot }}$ & -980.69 & -881.54 & -1014.16 & -1076.53 \\
\hline
\end{tabular}

Abbreviations: $\mathrm{E}_{\text {tot }}$ : total energy; $\mathrm{E}_{\text {lig }}$ : ligand energy; $\mathrm{E}_{\text {int }}$ : interaction energy 